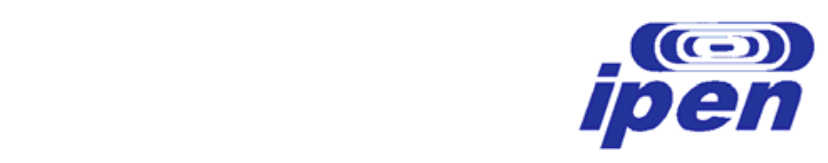

INSTITUTO DE PESQUISAS ENERGÉTICAS E NUCLEARES

Autarquia associada à Universidade de São Paulo

\title{
ESTUDO DO MÉTODO RADIOMÉTRICO PARA AVALIAÇÃO DA MIGRAÇÃO DE ELEMENTOS DE EMBALAGENS PLÁSTICAS \\ PARA O SEU CONTEÚDO
}

\section{EUFEMIA PAEZ SOARES}

\begin{abstract}
Tese apresentada como parte dos requisitos para obtenção do grau de Doutor em Ciências na Área de Tecnologia Nuclear - Aplicações.
\end{abstract}

Orientadora:

Dra. Mitiko Saiki

São Paulo 
INSTITUTO DE PESQUISAS ENERGÉTICAS E NUCLEARES

Autarquia associada à Universidade de São Paulo

\section{ESTUDO DO MÉTODO RADIOMÉTRICO PARA AVALIAÇÃO DA MIGRAÇÃO DE ELEMENTOS DE EMBALAGENS PLÁSTICAS PARA O SEU CONTEÚDO}

\section{EUFEMIA PAEZ SOARES}

Tese apresentada como parte dos
requisitos para obtenção do grau de
Doutor em Ciências na Área de
Tecnologia Nuclear - Aplicações.

Orientadora:

Dra. Mitiko Saiki

São Paulo 
Aos meus amores Vicente, Gabriel e Julio.

Aos meus pais, Francisco e Iracema, exemplos para todos os meus passos.

À minha avó Benedicta (in memorian) que sempre me incentivou. 


\section{AGRADECIMENTOS}

À Dra. Mitikgo Saiki, pela dedicação, paciência e profissionalismo na orientação e condução desta tese. Agradeço por seu exemplo de dedicação e empenho profissional, que me motivaram no desenvolvimento deste trabalho.

Ao Diretor da Escola SENAI Fundação Zerrenner, Prof. José Carlos Dalfré, pela oportunidade concedida para desenvolver este trabalho, permitindo meu crescimento profissional.

À amiga e Diretora da Escola SENAI Mario Amato, Profa. Sílvia Helena Carabolante, à amiga Marilene e a todos os amigos que lá trabalham, principalmente, Cátia Guzela, Baltus, Andréa, Newton, Emy, Ana Clélia, Cássia, Gleisa, e Carlos, pelo apoio nas análises dos polímeros e das soluções.

Aos amigos da Escola SENAI Fundação Zerrenner, em especial Nilton, Solange, Leandro, Kátia e Priscilla que, como profissionais, trouxeram informações importantes ao desenvolvimento desta tese e Karina, Danilo, Leury, Alessandra, Vera, Jorge, Gerson e Martha pela ajuda nos trabalhos e nos trâmites 6urocráticos.

Ao Laboratório de Análise por Ativação Neutrônica (LAN) do $I P E \mathcal{N}-C \mathcal{N} E \mathcal{N} / S P$, pela oportunidade concedida para realizar o trabalho experimental.

Ao Dr. Leonardo Gondim de Andrade e Silva do Centro de Tecnologia de Radiações (CTR) do IPES-CNEN/SP pela colaboração e ricas sugestões incorporadas nesta tese.

À Sra. Maria Rosa da Silva de Alcântara, do Instituto Adolfo Lutz, pelas valiosas explicações sobre o método convencional. 
Às Doutoras Marina, Ana Maria, Déborah, Maria José, Rosemeire e Vera do $\mathcal{L} \mathcal{A N}$, pelo apoio e estímulo durante a realização deste trabalho.

Aos amigos do IPEN, Andreza, Edson Alves, Edson Moreira, Guilherme, Luciana, Marília, Regina, Ricardo, Selma e Osman, pela amizade, convivência e auxílio na condução deste trabalho.

Às amigas Maria Luiza, Édina e Arlete Fiorotto por toda a cooperação e apoio.

Aos familiares, pela ajuda inestimável nos momentos de necessidade.

A todos que direta ou indiretamente cooperaram na realização deste trabalho.

A Deus por me ifuminar em todos os meus passos. 
"O aprendizado é um tesouro que acompanha seu dono em todos os lugares" Luigi Pirandello

"O limite do homem é o limite de seus sonhos" John Fitzgerald Kennedy 


\title{
ESTUDO DO MÉTODO RADIOMÉTRICO PARA AVALIAÇÃO DA MIGRAÇÃO DE ELEMENTOS DE EMBALAGENS PLÁSTICAS PARA O SEU CONTEÚDO
}

\author{
Eufemia Paez Soares
}

\section{RESUMO}

Nos últimos anos, problemas relacionados à contaminação de alimentos por substâncias ou elementos que podem ser um risco a saúde humana são uma preocupação não somente das autoridades governamentais, mas também da própria população. Dentro deste contexto, as embalagens plásticas podem constituir uma fonte de contaminação de alimentos uma vez que o processo de produção de plásticos envolve o uso de catalisadores e dos mais variados tipos de aditivos os quais podem conter elementos tóxicos. Quando os alimentos entram em contato com estas embalagens, seus componentes podem migrar para o alimento. No Brasil, para o controle dos materiais a serem utilizados para embalagens de alimentos, a Agência Nacional de Vigilância Sanitária (ANVISA) estabeleceu valores limites de substâncias migrantes e procedimentos para determinação da migração de elementos e substâncias das embalagens plásticas para os alimentos. No presente estudo, o método radiométrico foi avaliado para determinação da migração de elementos das embalagens plásticas para simulantes de alimentos ou para o próprio alimento. Este método radiométrico consistiu na irradiação das amostras de embalagens plásticas com um fluxo de nêutrons térmicos do reator de pesquisa IEA-R1 para produzir os radioisótopos dos elementos presentes nessas embalagens. A seguir, o plástico irradiado foi exposto à migração do elemento para o simulante ou para o alimento. A migração foi determinada pela medição da radioatividade no simulante ou no alimento pela espectrometria de raios gama. Os tipos de simulantes de alimentos e as condições experimentais foram estabelecidos de 
acordo com o regulamento da ANVISA. A migração de elementos foi estudada para embalagens plásticas de refrigerantes, água, leite, derivados de leite, sucos e alimentos gordurosos. $\mathrm{Na}$ análise por ativação com nêutrons destas embalagens foi verificada a presença de elementos como As, Cd, Cr, Co e Sb. Os resultados da migração obtidos pelo método radiométrico indicaram que $\mathrm{Cd}$, $\mathrm{Co}, \mathrm{Cr}$ e $\mathrm{Sb}$ presentes nos plásticos migram tanto para o simulante como para o alimento. Nem todas as embalagens apresentaram migração destes elementos e nestes casos foram determinados os valores limites de detecção. Os resultados das análises das embalagens plásticas irradiadas com nêutrons por calorimetria exploratória diferencial e por espectroscopia no infravermelho por transformada de Fourier mostraram que na embalagem de polietileno de alta densidade pode ocorrer a degradação oxidativa. Entre as principais vantagens do método radiométrico na avaliação da migração estão a sua simplicidade, a não necessidade da análise do branco e a possibilidade de determinar a migração no próprio alimento. Os resultados obtidos indicaram a potencialidade do uso deste método na avaliação da migração de elementos das embalagens plásticas para o seu conteúdo. 


\title{
A STUDY ON THE RADIOMETRIC METHOD FOR EVALUATING ELEMENT MIGRATION FROM PLASTIC PACKAGINGS TO ITS CONTENTS
}

\author{
Eufemia Paez Soares
}

\begin{abstract}
Over the past few years, problems related to food contamination by substances or elements that can be a risk to human health have became a concern, not only to government authorities, but to the general population as well. Within this context, plastic packaging can constitute a source of food contamination since plastic manufacturing processes involve the use of catalysts and different types of additives that may contain toxic elements. When food comes into contact with this packaging, components of the package may migrate to the food. In order to control the material used as food packaging, the National Health Surveillance Agency (ANVISA) in Brazil, has established boundary values of migrant substances and procedures to determine migration from plastic packagings to food. In this study the radiometric method was evaluated for element migration determination from plastic packaging to food simulating or to the food itself. This radiometric method consisted in irradiating plastic packaging samples with a thermal neutron flux from the IEA-R1 nuclear research reactor in order to produce radionuclides of elements present in the packagings. The irradiated plastic was then exposed to food simulants or food for element migration. Gamma ray spectrometry was used to measure radioactivity in the simulants or food in order to quantify the migration. The food simulating types and experimental conditions were established according to the ANVISA regulations. Element migration was studied for plastic packaging used for soft drinks, drinking water, milk, dairy products, juices and fatty foods. In the instrumental neutron activation analysis of these packagings the presence of $\mathrm{As}, \mathrm{Cd}, \mathrm{Cr}$, Co and $\mathrm{Sb}$
\end{abstract}


was verified. Results obtained from the migration experiments by the radiometric method indicated that $\mathrm{Cd}, \mathrm{Co}, \mathrm{Cr}$ and $\mathrm{Sb}$ present in these plastics migrated to the simulants or to the food. In some packagings, the migration of only some of these elements was observed. In these cases the migration detection limits were determined. Results from the analyses of the neutron irradiated plastic packagings by differential scanning calorimetry and Fourier transform infrared spectroscopy showed that in high density polyethylene packagings oxidative degradation can occur. Among the main advantages of the radiometric method application for element migration evaluation are its simplicity, no need of blank analysis and the possibility to obtain element migration to the food itself. The results obtained indicated the potentiality of using this method in the element migration evaluation from the plastic packagings to their contents. 


\section{SUMÁRIO}

\section{Página}

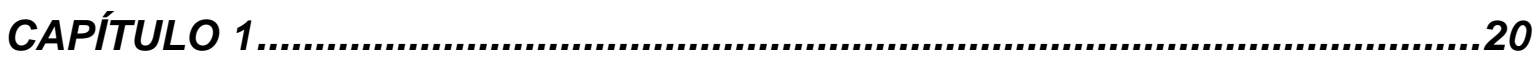

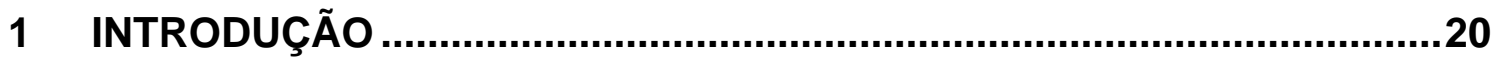

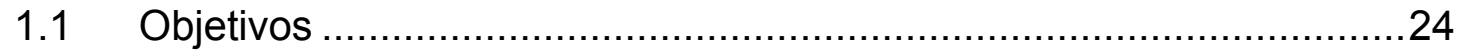

CAPÍTULO 2

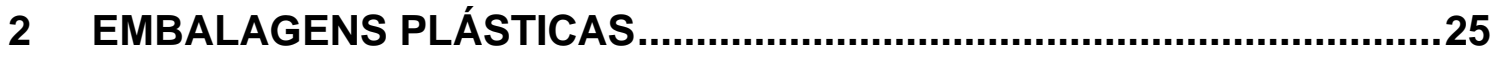

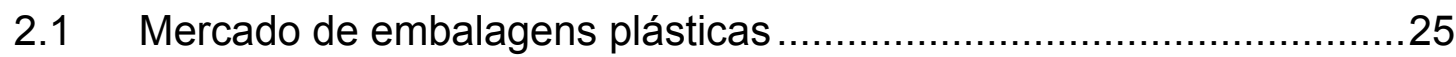

2.2 Tipos de plásticos utilizados em embalagens ................................27

2.3 Presença de elementos químicos no plástico ...................................28

CAPÍTULO 3

3 CONSIDERAÇÕES GERAIS SOBRE A MIGRAÇÃO DE SUBSTÂNCIAS DO MATERIAL POLIMÉRICO ...............................................................

3.1 Migração de espécies químicas de materiais poliméricos para o seu conteúdo

3.2 Legislação aplicada a embalagens plásticas para alimentos ...............36

3.3 Efeitos da irradiação dos materiais poliméricos com nêutrons do reator nuclear.

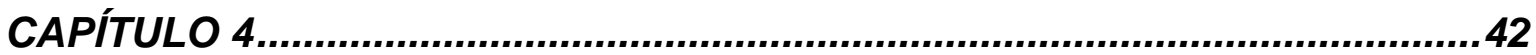

4 CONSIDERAÇÕES SOBRE O ENSAIO DE MIGRAÇÃO.........................42

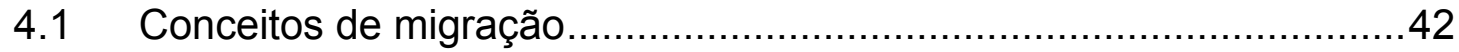

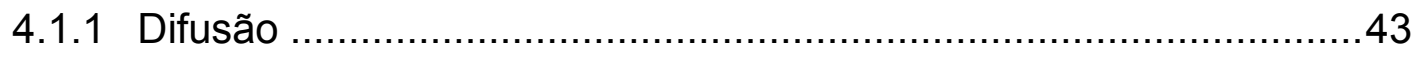

4.2 Seleção dos simulantes de alimentos para avaliação da migração ....46 


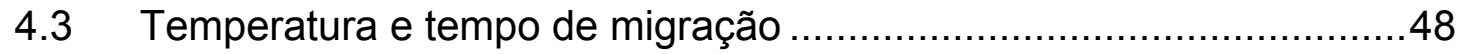

4.4 Volume de amostra e massa de simulante ........................................49

4.5 Cálculos de migração de elementos e limites máximos permitidos

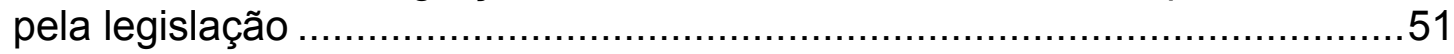

CAPÍTULO 5

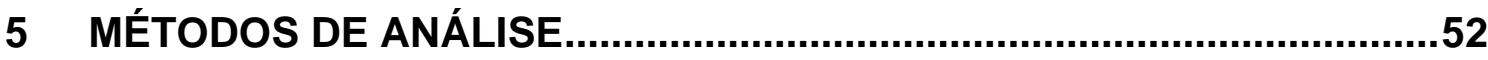

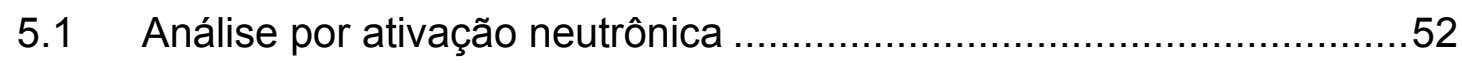

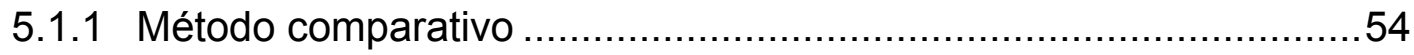

5.2 Espectroscopia de absorção atômica................................................56

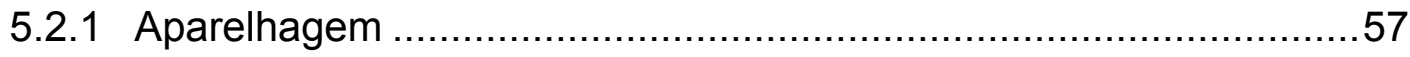

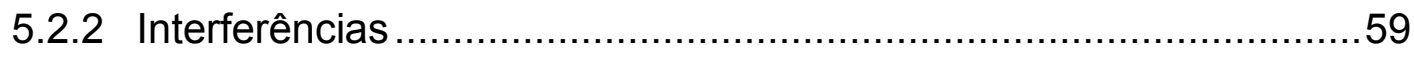

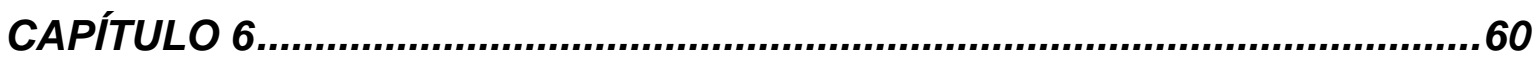

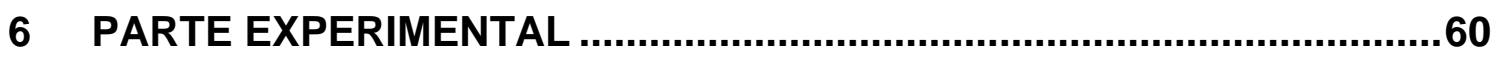

6.1 Aquisição de amostras de embalagens para estudo...........................60

6.2 Limpeza e preparação das amostras de embalagens plásticas ..........61

6.3 Procedimento experimental para determinação de elementos presentes nas embalagens pelo método de análise por ativação com nêutrons

6.3.1 Preparação de padrões sintéticos a serem utilizados na análise

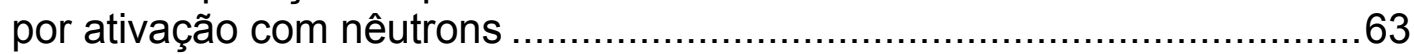

6.3.2 Procedimento da análise por ativação com nêutrons .......................64

6.3.3 Análise de materiais de referência certificados ..............................68

6.4 Procedimento radiométrico para avaliação da migração dos elementos do plástico para o seu conteúdo ou para os simulantes de alimentos.

6.5 Determinação de limite de detecção da migração pelo método radiométrico

6.6 Procedimento para a determinação da migração pelo método convencional

6.6.1 Procedimento utilizado para determinação da migração de elementos em material de referência certificado de polietileno 
6.7 Procedimento utilizado na avaliação dos efeitos da irradiação com nêutrons nas embalagens plásticas

CAPÍTULO 7

7 RESULTADOS E DISCUSSÃO.

7.1 Análise elementar de embalagens plásticas pelo método de análise por ativação com nêutrons.

7.1.1 Análise dos materiais de referência certificados 79

7.1.2 Análise das amostras de embalagem

7.2 Migração de elementos das embalagens plásticas para simulantes de alimentos ou para o próprio alimento, obtidas pelo método radiométrico 85

7.2.1 Migração para simulantes de alimentos .85

7.2.2 Migração dos elementos para alimentos .90

7.2.3 Avaliação da repetitividade na determinação da migração pelo método radiométrico

7.2.4 Valores limites de detecção da migração dos elementos

7.3 Migração de elementos das embalagens plásticas para simulantes de alimentos obtida pelo método convencional

7.3.1 Migração para simulante de alimento

7.3.2 Migração de elementos de um material de referência de polietileno para simulante de alimento

7.3.3 Comparação entre os métodos radiométrico e convencional para avaliação da migração.

7.4 Análises por calorimetria exploratória diferencial e espectroscopia no infravermelho por transformada de Fourier

CAPÍTULO 8

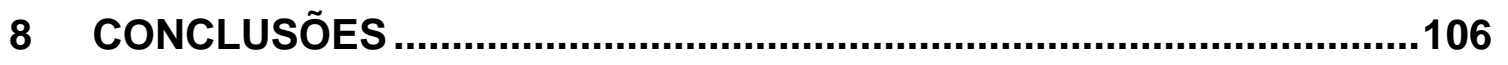




\section{LISTA DE TABELAS}

\section{Página}

Tabela 2.1. Porcentagem em volume consumido dos materiais mais utilizados na confecção de embalagens para uso geral. .................................................26

Tabela 4.1. Simulantes utilizados em ensaios de migração............................47

Tabela 4.2. Tipos de alimentos e simulantes utilizados no ensaio de migração. ..48

Tabela 4.3. Condições para os ensaios de migração estabelecidas pela ANVISA (1999).

Tabela 6.1. Dados das embalagens nacionais adquiridas para o presente trabalho e seus respectivos códigos, conteúdo, quantidade de embalagens e tipo de polímero.

Tabela 6.2. Amostras de embalagens de alimentos adquiridas do exterior e seus respectivos códigos, conteúdo, quantidade de embalagens, país de origem e tipo de polímero.

Tabela 6.3. Soluções padrão de elementos da Spex Certiprep utilizadas no trabalho.

Tabela 6.4. Soluções padrão preparadas a partir das soluções padrão certificadas da Spex Certiprep

Tabela 6.5. Radioisótopos medidos com suas respectivas energias de raios gama e meias-vidas (IAEA, 1990). 66

Tabela 6.6. Valores certificados de concentração de elementos no material de referência BCR-681 (IRMM, 2000). 
Tabela 7.1. Concentrações de elementos obtidos nos materiais de referência Polyethylene IMEP-10 e BCR-681, Marine Sediment MESS-2 e Mixed Polish Herbs MPH-2 (IRMM, 1993 e 2000; NRCC, 1997; INCT, 2002).

Tabela 7.2. Concentrações de elementos nas embalagens plásticas de refrigerantes e águas, em $\mu \mathrm{g} \mathrm{g}^{-1}$, obtidos por NAA

Tabela 7.3. Concentrações de elementos nas embalagens plásticas de sucos, leite e derivados de leite, produtos gordurosos e produtos aquosos contendo óleo ou gordura, em $\mu \mathrm{g} \mathrm{g}^{-1}$, obtidos por NAA.

Tabela 7.4. Migração de elementos das embalagens de refrigerantes, obtida pelo método radiométrico, em $\mu \mathrm{g} \mathrm{dm}^{-2} \mathrm{~kg}^{-1}$. Condições experimentais: Simulante = ácido acético $3 \%$, Tempo de exposição $=10$ dias, Temperatura $=40^{\circ} \mathrm{C}$

Tabela 7.5. Migração de elementos das embalagens de suco, obtida pelo método radiométrico, em $\mu \mathrm{g} \mathrm{dm}^{-2} \mathrm{~kg}^{-1}$. Condições experimentais: Simulante = ácido acético $3 \%$, Tempo de exposição $=10$ dias, Temperatura $=40^{\circ} \mathrm{C}$.

Tabela 7.6. Migração de elementos das embalagens de derivados de leite, obtida pelo método radiométrico, em $\mu \mathrm{g} \mathrm{dm}^{-2} \mathrm{~kg}^{-1}$. Condições experimentais: Simulante $=$ ácido acético $3 \%$, Tempo de exposição $=10$ dias, Temperatura $=40^{\circ} \mathrm{C}$. .88

Tabela 7.7. Migração de elementos das embalagens de alimentos aquosos contendo óleo ou gordura e $\mathrm{pH}$ ácido, em $\mu \mathrm{g} \mathrm{dm}^{-2} \mathrm{~kg}^{-1}$. Condições experimentais: Simulante $=$ ácido acético $3 \%$, Tempo de exposição $=10$ dias, Temperatura $=40^{\circ} \mathrm{C}$.

Tabela 7.8. Migração de elementos das embalagens de água e leite, obtida pelo método radiométrico, em $\mu \mathrm{g} \mathrm{dm}^{-2} \mathrm{~kg}^{-1}$. Condições experimentais: Simulante $=$ água, Tempo de exposição $=10$ dias, Temperatura $=40^{\circ} \mathrm{C}$. 89

Tabela 7.9. Migração de elementos das embalagens de produtos gordurosos e aquosos contendo óleo, obtida pelo método radiométrico, em $\mu \mathrm{g} \mathrm{dm}^{-2} \mathrm{~kg}^{-1}$. Condições experimentais Simulante $=\mathrm{n}$-heptano, Tempo de exposição $=30$ minutos, Temperatura $=20^{\circ} \mathrm{C}$ 
Tabela 7.10. Migração de elementos das embalagens, obtida pelo método radiométrico, em $\mu \mathrm{g} \mathrm{dm}^{-2} \mathrm{~kg}^{-1}$, para alimento. Condições experimentais: Tempo de exposição $=10$ dias, Temperatura $=40^{\circ} \mathrm{C}$

Tabela 7.11. Valores individuais da migração de Co e Sb de uma embalagem de refrigerante para o simulante ácido acético $3 \%$ e para o alimento. .93

Tabela 7.12. Parâmetros obtidos na aplicação dos testes $Q$ de Dixon e Grubbs aos resultados da Tabela 7.11

Tabela 7.13. Comparação entre os resultados da migração de elementos $\mathrm{Cd}, \mathrm{Cr}$ e Sb obtidos e os valores Limites Máximos de Tolerância (LMT) (ANVISA, 1965)

Tabela 7.14. Valores limites de deteç̧ão da migração de elementos em $\mu \mathrm{g} \mathrm{dm} \mathrm{mg}^{-1}$

Tabela 7.15. Migração dos elementos em $\mathrm{ng} \mathrm{dm}^{-2} \mathrm{~kg}^{-1}$, obtida pelo método convencional seguido de AAS e NAA. Condições experimentais: Tempo de exposição $=10$ dias, Temperatura $=40^{\circ} \mathrm{C}$.

Tabela 7.16. Migração dos elementos do material de referência BCR-681 obtida pelo método convencional seguido de AAS e pelo método radiométrico 100

Tabela 7.17. Comparação entre os métodos de migração radiométrico e convencional.

Tabela 7.18. Propriedades térmicas das amostras de embalagens, em função do tempo de irradiação com nêutrons, obtidas por DSC 


\section{LISTA DE FIGURAS}

Página

Figura 2.1. Porcentagem em volume de comercialização de vários tipos de plásticos no setor de embalagens (Datamark, 2004a).................................28

Figura 5.1. Esquema da captura radioativa. 53

Figura 5.2. Esquema básico de um equipamento de AAS. 57

Figura 6.1. Amostras de embalagens de alimentos analisadas.

Figura 6.2. Amostra embalada em invólucro de polietileno (1) e montada na prancheta (2). (Diâmetro das pranchetas $=3 \mathrm{~cm}$ )

Figura 6.3. Esquema geral do procedimento da NAA. 67

Figura 6.4. Foto do padrão e corpo-de-prova (amostra). 69

Figura 6.5. Foto da amostra de embalagem irradiada a ser imersa no simulante de alimento.

Figura 6.6. Esquema do procedimento para determinação da migração pelo método radiométrico.

Figura 6.7. Esquema do procedimento para determinação da migração pelo método convencional seguido de AAS e NAA.

Figura 7.1. Espectros de FTIR de uma embalagem HDPE, de suco, não irradiada e irradiada com nêutrons por diferentes tempos. 104

Figura 7.2. Espectros de FTIR de uma embalagem PET, de refrigerante, não irradiada e irradiada com nêutrons. 


\section{LISTA DE ABREVIATURAS}

AAS Atomic Absorption Spectroscopy (Espectroscopia de absorção atômica)

ABNT Associação Brasileira de Normas Técnicas

ABRE Associação Brasileira de Embalagem

ANVISA Agência Nacional de Vigilância Sanitária

BG Background (radiação de fundo)

CEC Commission of the European Communities (Comissão da comunidade européia)

DMA Dynamical Mechanical Analysis (Análise dinâmico- mecânica)

DSC Differential Scanning Calorimetry (Calorimetria exploratória diferencial)

DTA Differential Thermal Analysis (Análise térmica diferencial)

EC European Community (Comunidade européia)

EEC European Economic Community (Comunidade econômica européia)

FDA Food and Drugs Administration (Administração de alimentos e drogas)

FTIR Fourier Transform Infrared Spectroscopy (Espectroscopia no infravermelho com transformada de Fourier)

GC-MS Gas Chromatography - Mass Spectroscopy (Cromatografia gasosa acoplada a espectroscopia de massa)

GMC Grupo mercado comum

HDPE High Density Polyethylene (Polietileno de alta densidade)

HPLC High Performance Liquid Chromatography (Cromatografia líquida de alta eficiência) 


\begin{tabular}{|c|c|}
\hline IAL & Instituto Adolfo Lutz \\
\hline ICP-IDMS & $\begin{array}{l}\text { Inductively Coupled Plasma Isotope Dilution Mass Spectroscopy } \\
\text { (Espectroscopia de massa de diluição isotópica com fonte de } \\
\text { plasma acoplado indutivamente) }\end{array}$ \\
\hline ICP-MS & $\begin{array}{l}\text { Inductively Coupled Plasma - Mass Spectroscopy (Espectroscopia } \\
\text { de massa com fonte de plasma acoplado indutivamente) }\end{array}$ \\
\hline ICP-OES & $\begin{array}{l}\text { Inductively Coupled Plasma- Optical Emission Spectroscopy } \\
\text { (Espectroscopia de emissão óptica com fonte de plasma acoplado } \\
\text { indutivamente) }\end{array}$ \\
\hline INAA & $\begin{array}{l}\text { Instrumental Neutron Activation Analysis (Análise instrumental por } \\
\text { ativação com nêutrons) }\end{array}$ \\
\hline INCT & Institute of Nuclear Chemistry and Technology \\
\hline IPEN & Instituto de Pesquisas Energéticas e Nucleares \\
\hline IRMM & Institute for Reference Materials and Measurements. \\
\hline IUPAC & $\begin{array}{l}\text { International Union of Pure and Applied Chemistry (União } \\
\text { internacional de química pura e aplicada) }\end{array}$ \\
\hline LC & Limite de composição \\
\hline LD & Limite de detecção \\
\hline LDPE & Low Density Polyethylene (Polietileno de baixa densidade) \\
\hline LME & Limite de Migração Específica \\
\hline LMT & Limite Máximo de Tolerância \\
\hline MERCOSUL & Mercado Comum do Sul \\
\hline NAA & Neutron Activation Analysis (Análise por ativação com nêutrons) \\
\hline NRCC & National Research Council Canada \\
\hline PA6 & Polyamide 6 (Poliamida 6) \\
\hline PCR - PET & $\begin{array}{l}\text { Post-Consumer Recycled Polyethylene therephtalate (Poli } \\
\text { (tereftalato de etileno) reciclado pós-consumo) }\end{array}$ \\
\hline PE & Polyethylene (Polietileno) \\
\hline PET & Polyethylene therephtalate (Poli (tereftalato de etileno)) \\
\hline
\end{tabular}


PGA Prompt Gamma Analysis (Análise por ativação por gama pronto)

PP Polypropylene (Polipropileno)

PS Polystyrene (Poliestireno)

PVAL Polyvinyl alcohol (Poli (álcool vinílico))

PVC Polyvinyl chloride (Poli (cloreto de vinila))

RE Resolução

$\mathrm{T}_{\mathrm{g}} \quad$ Temperatura de transição vítrea

TGA Análise termogravimétrica

TI-IDMS Thermal Ionization Isotope Dilution Mass Spectroscopy

(Espectroscopia de massa de diluição isotópica com ionização térmica)

$\mathrm{T}_{\mathrm{m}} \quad$ Temperatura de fusão cristalina

USEPA United State Environmental Protection Agency (Agência de proteção ambiental dos Estados Unidos)

WHO Word Health Organization (Organização mundial de saúde)

XRF X-ray fluorescence spectroscopy (Espectroscopia de fluorescência de raios $X)$ 


\section{CAPÍTULO 1}

\section{INTRODUÇÃO}

$\mathrm{Na}$ comercialização de alimentos, uma das principais exigências do consumidor é que o alimento possua sabor e odor agradável. A alteração destas características pode advir da deterioração do próprio alimento ou da migração de substâncias das embalagens para o produto alimentício (Sarantópoulos et al., 2002).

Os alimentos são hoje comercializados em embalagens confeccionadas de diversos tipos de materiais, como: papel, papelão, vidro, metal, plástico entre outros. Entre estes, o plástico é o material que vem sendo cada vez mais utilizado na fabricação de embalagens, principalmente devido à sua versatilidade, atendendo às exigências do mercado consumidor (Hayasaki, 2006).

Esta versatilidade é proveniente, principalmente, das propriedades dos diferentes tipos de polímeros, das quais destacam-se a resistência à oxidação, ao calor e à radiação ultravioleta, resistência à água, ácidos, bases e solventes, transparência à luz, estabilidade dimensional e a permeabilidade a gases e vapores (Mano, 1991; Crosby, 1981). Desta forma, é possível escolher o plástico cujas propriedades sejam adequadas para embalar materiais sólidos, líquidos ou gasosos e, no caso de embalagens alimentícias, esta escolha tem como foco a manutenção das características do alimento por tempo adequado para estocagem e consumo, como, por exemplo, para as bebidas carbonatadas não-alcoólicas.

Em relação à segurança alimentar, é importante destacar que o plástico utilizado na confecção das embalagens pode conter constituintes inorgânicos provenientes do resíduo catalítico de seu processo de fabricação, das tintas de impressão ou ainda dos aditivos utilizados no processo, os quais podem migrar para o conteúdo das embalagens (Thompson et al., 1996; Crompton, 1979). 
A contaminação de alimentos por espécies químicas das embalagens é um problema bastante sério, uma vez que elementos ou compostos tóxicos nelas presentes podem migrar durante o período de estocagem.

Para garantir que os materiais utilizados nas embalagens sejam seguros, órgãos reguladores dos Estados Unidos, da Comunidade Européia, do Brasil, entre outros, têm procurado estabelecer por meio de seus regulamentos, valores limites de migrantes bem como metodologias de análise da migração de elementos e substâncias das embalagens plásticas para os alimentos. $O$ estabelecimento destes regulamentos tem como objetivo o controle da contaminação química dos produtos alimentícios, com limites cada vez mais exigentes para atender aos critérios de segurança alimentar, bem como, às características organolépticas exigidas pelo consumidor. No Brasil, este órgão regulador é a Agência Nacional de Vigilância Sanitária (ANVISA), cuja missão é promover a proteção da saúde da população por intermédio do controle sanitário da produção e da comercialização de produtos e serviços submetidos à vigilância sanitária.

Com a crescente utilização de materiais poliméricos e o seu baixo grau de degradabilidade, a solução de descartá-los em aterros sanitários tem se tornado cada vez mais inadequada. Entretanto, a reciclagem de materiais poliméricos indica ser uma alternativa bastante adequada em função da grande quantidade de plástico descartado. Além disso, devido ao aumento globalizado do número de legislações e projetos de lei que incentivam a recuperação e a reciclagem de materiais para a diminuição do seu volume nos aterros, vem crescendo o interesse pela utilização de material polimérico pós-consumo na confecção de novas embalagens destinadas para alimentos (Nunes et al., 2003). Até a década de 90 , a reciclagem de plásticos para a sua reutilização em embalagens alimentícias era mundialmente proibida. Nos Estados Unidos, o poli (tereftalato de etileno) reciclado pós-consumo (PCR-PET) foi introduzido para aplicações em embalagens para contato direto com alimentos a partir de 1991, porém, o uso destes reciclados está restrito a materiais que tenham sido analisados e aprovados para este fim, de acordo com várias regulamentações estabelecidas (Santos et al., 2004; Bayer, 2002). 
No Brasil, a ANVISA, colocou recentemente à consulta pública, um regulamento para a utilização do PCR-PET grau alimentício em embalagens para uso em contato direto com alimentos (ANVISA, 2007). A aprovação deste regulamento permitirá a reciclagem de poli (tereftalato de etileno) (PET) para produção de embalagens alimentícias, principalmente de garrafas para bebidas. Como conseqüência, a identificação da possível migração de contaminantes orgânicos e inorgânicos para alimentos se torna cada vez mais necessária e crítica na seleção do material para a confecção da embalagem.

Com relação às metodologias existentes para avaliação da migração de contaminantes tem sido utilizado, tradicionalmente, o método convencional que é realizado deixando o corpo-de-prova imerso em um simulante de alimento no qual é feita a medição de migrante. Antes dessa medição, muitas vezes é requerida uma etapa de pré-concentração desse simulante exposto à migração, com a finalidade de aumentar a sensibilidade do método analítico (ANVISA, 1999; IAL, 2005). A medição dos contaminantes elementares que passaram para os simulantes é, em geral, realizada por espectroscopia de absorção atômica (AAS), espectroscopia de massa com fonte de plasma acoplado indutivamente (ICP-MS), espectroscopia de emissão óptica com fonte de plasma acoplado indutivamente (ICP-OES) e métodos colorimétricos. Esses métodos analíticos, além de morosos, apresentam grandes riscos de contaminação e requerem a análise do branco dos reagentes utilizados como simulantes. Além disso, as técnicas utilizadas para medir os elementos não são apropriadas para a análise de simulantes à base de óleo que requerem tratamento de digestão para as medições.

Face ao exposto, julgou-se viável fazer um estudo e a aplicação do método radiométrico para a determinação de migração de elementos das embalagens para simulantes de alimentos ou para o próprio alimento. O estudo da aplicação de um método radiométrico é de grande interesse por se tratar de uma técnica nuclear que apresenta alta capacidade de detecção de elementos. Devido ao fato do método radiométrico não requerer a análise do branco, ele poderá ser aplicado no estudo de migração para amostras reais de alimento, cuja determinação não possa ser feita pelo método convencional. 
No presente projeto de pesquisa foi realizado um estudo sobre a metodologia radiométrica a ser aplicada à determinação de elementos que migram das embalagens plásticas para o seu conteúdo. Neste método de avaliação da migração, as amostras de embalagens irradiadas com nêutrons de um reator nuclear e tornadas radioativas são submetidas ao teste de migração para posterior medição direta da radioatividade gama transferida para o simulante.

O desenvolvimento deste trabalho apresenta aspectos importantes do ponto de vista da definição de parâmetros experimentais da metodologia radiométrica para posterior aplicação no controle de materiais poliméricos utilizados no Brasil em embalagens para alimentos e medicamentos. Uma dessas aplicações poderá ser a análise de material reciclável grau alimentício tendo em vista a possível aprovação do regulamento que autoriza a reutilização de PCR-PET para fabricação de embalagens para contato direto com alimentos (ANVISA, 2007).

Os resultados de migração constituem também uma contribuição original, tendo em vista que não há praticamente dados de migração, assim como da composição elementar dos plásticos utilizados como embalagens no Brasil. Os dados das determinações de elementos presentes nos plásticos poderão, também, fornecer informações de interesse para profissionais das áreas de plásticos, do meio ambiente e da saúde.

Além disso, as análises de materiais poliméricos são de grande interesse se considerarmos que brinquedos fabricados com materiais poliméricos são, comumente, colocados na boca por crianças. A presença de elementos tóxicos pode causar danos à saúde e a legislação deixa evidente que a presença de contaminantes deve ser controlada para evitar a exposição da população.

Atualmente, na cidade de São Paulo, lixos sólidos municipais contêm uma quantidade relativamente grande de plásticos que são depositados nos aterros, entretanto, dependendo de políticas adotadas pelo país, parte deste material polimérico descartado poderá ser destinado à incineração para produção de energia. Porém, o processo de incineração do material polimérico pode constituir uma fonte de contaminação de elementos tóxicos ao meio ambiente. Desta 
forma, a análise de elementos tóxicos presentes nesses materiais poderá fornecer dados para a seleção e o descarte adequado desses materiais.

\subsection{Objetivos}

O presente trabalho teve como objetivo realizar o estudo de um método radiométrico para a determinação da migração de elementos de embalagens plásticas de alimentos para o seu conteúdo ou para simulantes.

Em vista da grande variedade e do crescente uso de embalagens plásticas, julgou-se interessante verificar a possibilidade de utilização de um método radiométrico na avaliação da migração dos elementos em complemento aos métodos convencionais existentes. Sendo assim, neste trabalho, foram avaliados os valores de limites de detecção dos elementos na migração e, para algumas amostras, a migração também foi determinada aplicando-se o método convencional seguido de AAS.

Antes do estudo da migração dos elementos, foram realizadas as determinações de elementos presentes nas embalagens por NAA a serem utilizadas no trabalho. Essas análises facilitaram a seleção dos elementos a serem investigados nos experimentos de migração.

Depois de verificar a possibilidade de aplicar o método radiométrico segundo as normas da ANVISA, foram realizadas as determinações de migração das embalagens de alimentos, tais como de refrigerantes e águas de diferentes procedências, sucos, produtos gordurosos, leite e derivados.

As principais dificuldades a serem enfrentadas na aplicação do método radiométrico na determinação da migração dos elementos seriam os danos que a irradiação com nêutrons poderia causar ao material polimérico, impossibilitando seu uso para avaliação da migração. Para avaliar o efeito da irradiação com nêutrons nas amostras plásticas das embalagens, foram realizadas análises de calorimetria exploratória diferencial (DSC) e espectroscopia no infravermelho por transformada de Fourier (FTIR). 


\section{CAPÍTULO 2}

\section{EMBALAGENS PLÁSTICAS}

\subsection{Mercado de embalagens plásticas}

Proteção, conservação e transporte de mercadorias foram algumas das razões para a criação das primeiras embalagens. Desta forma, houve um avanço no desenvolvimento das comunidades proveniente das facilidades introduzidas pela comercialização dos produtos em embalagens. Com o advento da indústria, as embalagens passaram a ter também as funções de manter as características originais dos produtos e a de torná-los desejados pelo cliente. Hoje, o mercado consumidor exige embalagens que atendam às suas expectativas quanto à proteção e conservação do produto, à facilidade para o consumo, às informações sobre composição ou conservação, entre outras características (Mestriner, 2002; Arvanitoyannis e Bosnea, 2001).

As indústrias de embalagens no Brasil estão atentas ao mercado e têm pesquisado novos materiais e soluções para atender às demandas do mercado interno e também do externo. No Brasil, atualmente, a receita líquida de vendas de embalagens passa da ordem dos 30 bilhões de reais e a de exportações dos 300 milhões de dólares (Cavalcanti e Chagas, 2006). As principais indústrias usuárias de embalagens são as de alimentos, bebidas, fumo, farmacêutica, perfumaria e produtos de limpeza (ABRE, 2007).

Vários materiais como papel, papel ondulado e papel cartão, madeira, metal, vidro, plástico entre outros podem ser utilizados na confecção de embalagens. Destes materiais, o plástico vem se destacando cada vez mais na fabricação de embalagens para alimentos. Observa-se que a produção de 
plásticos para o setor de alimentos e bebidas cresceu 5,18\%, mesmo tendo ocorrido uma retração na produção de plásticos para o setor de embalagens do ano de 2005 para o de 2006, devido principalmente à diminuição da produção de sacos e sacolas (ABRE, 2007).

A matéria-prima mais utilizada para embalagens, até o início da década de 60, era o celofane por possuir superfície lisa e brilhante e permitir boa impressão. Com o desenvolvimento dos plásticos, o celofane foi substituído pelo polietileno (PE), polipropileno (PP), poli (cloreto de vinila) (PVC), poli (tereftalato de etileno) (PET) entre outros e, atualmente, o uso de celofane praticamente está extinto (Cavalcanti e Chagas, 2006).

A indústria de embalagens plásticas tem investido em tecnologias para atender ao público consumidor e, desta forma, vem se sobressaindo no mercado de embalagens para alimentos, como, por exemplo, pela facilidade de transporte e de consumo, possibilidade de abertura e fechamento da embalagem, condição para processamento como autoclavagem entre outras (Hayasaki, 2006).

Segundo dados da Datamark (2004b), a indústria brasileira de embalagem foi avaliada com uma produção de 6,5 milhões de toneladas no total no ano de 2004, sendo distribuídos em vários tipos de materiais conforme apresentado na Tabela 2.1 .

Tabela 2.1. Porcentagem em volume consumido dos materiais mais utilizados na confecção de embalagens para uso geral.

\begin{tabular}{lc}
\hline Material & Volume, $\%$ \\
\hline Corrugados & 32,6 \\
Duplex/triplex & 6,3 \\
Flexível & 6,9 \\
Metal & 15,8 \\
Papel & 4,2 \\
Plástico & 19,4 \\
Vidro & 14,8 \\
\hline
\end{tabular}


Do material polimérico utilizado para a confecção de embalagens, 63,9\% são utilizados diretamente para alimentos (Datamark, 2004c).

É importante destacar que com o crescimento das indústrias de embalagens, cresceu também o impacto causado por esses materiais ao meio ambiente, decorrente do aumento da quantidade de embalagens descartadas após o consumo de seu conteúdo. Assim, na criação de novas embalagens são considerados os aspectos de segurança alimentar, redução de perdas, aumento de vida útil do produto, conservação do conteúdo, facilidade de consumo e destinação final da embalagem (Prado Filho, 2006).

\subsection{Tipos de plásticos utilizados em embalagens}

As embalagens plásticas para alimentos foram introduzidas após a Segunda Guerra Mundial e um dos primeiros produtos fabricados, em 1946, foram copos de polietileno produzidos pela Tupperware Co. fundada por Earl S. Tupper. O plástico chegou ao Brasil na década de 1950 (Cavalcanti e Chagas, 2006, Wiebeck e Harada, 2005).

No mercado, são encontradas embalagens plásticas na forma de filmes, sacos, tubos, engradados, caixas, frascos entre outras. Esta versatilidade é possível, pois o material polimérico é leve e pode ser moldado com facilidade no formato desejado para atender às especificações do produto ou do cliente (Prado Filho, 2006).

Entre os plásticos mais utilizados na confecção de embalagens, destaca-se o PET, cujo volume comercializado em 2004 foi de 32,7\% (Datamark, 2004a). Este tipo de plástico é utilizado, principalmente, na confecção de garrafas para refrigerantes, águas minerais e sucos concentrados. $O$ polietileno de baixa densidade (LDPE) é utilizado na forma de filmes mono e multicamadas para a confecção de sacos flexíveis co-laminados e o polietileno de alta densidade (HDPE) em frascos de laticínios, água mineral e sucos de frutas (Billmeyer, 1984; Mano, 1991; Wiebeck e Harada, 2005; Prado Filho, 2006). 
Na Figura 2.1 são mostradas as porcentagens em volume de comercialização de diversos tipos de plásticos utilizados no setor de embalagens.

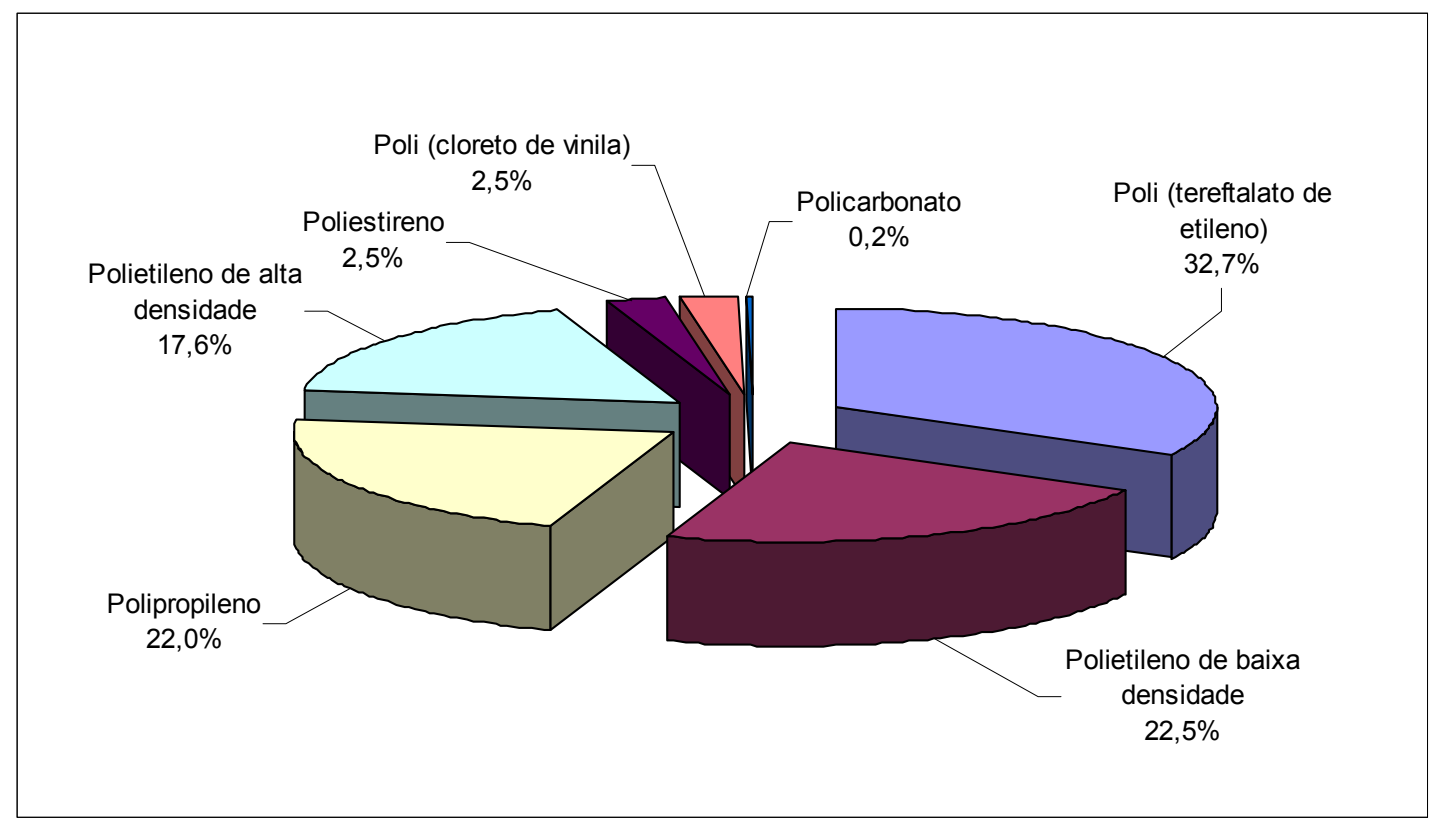

Figura 2.1. Porcentagem em volume de comercialização de vários tipos de plásticos no setor de embalagens (Datamark, 2004a).

\subsection{Presença de elementos químicos no plástico}

Antes de apresentar os diversos trabalhos publicados referentes à presença de elementos químicos no plástico, serão apresentados, a seguir, os conceitos sobre polímeros e plásticos bem como sobre a origem dos elementos nestes materiais.

De acordo com a União Internacional de Química Pura e Aplicada, IUPAC (1974, 2002), polímero é definido como:

"Substância constituída de moléculas caracterizadas pela repetição múltipla de uma ou mais espécies de átomos ou grupos funcionais (unidades constitucionais) ligados uns aos outros em quantidades suficientes para fornecer um conjunto de propriedades que não variam acentuadamente com a adição ou a remoção de uma ou de algumas unidades constitucionais." 
Já, os plásticos são materiais que contêm como componente básico um polímero orgânico sintético, são sólidos à temperatura ambiente e se caracterizam pela capacidade de se tornarem fluidos podendo, desta forma, ser moldados, por ação do calor e pressão (Lucas et al, 2001).

Na produção de polímeros, são utilizados dois métodos de preparação, a saber, a polimerização por condensação e a por adição (Canevarolo Júnior, 2002). Estes métodos de polimerização podem deixar resíduos que incluem monômeros, oligômeros, catalisadores, solventes, contaminações diversas dos equipamentos entre outras (Crompton, 1979; Crosby,1981).

Também os plásticos são preparados a partir de formulações que podem conter, além do polímero, os materiais plastificantes que melhoram a processabilidade, resistência e flexibilidade do plástico; corantes e pigmentos para colorir; estabilizantes térmicos para evitar a degradação térmica no processamento; cargas de enchimento para diminuir o custo do produto final e agentes antiestáticos entre outros componentes (Crompton, 1979; Crosby 1981; Shreve e Brink Junior, 1997; Rabello, 2000).

Conseqüentemente, o material polimérico utilizado na confecção da embalagem alimentícia pode conter resíduos de elementos químicos provenientes dos materiais que o compõem e esses resíduos podem migrar para o alimento.

Relativamente à análise elementar de materiais poliméricos no Brasil convém salientar que há poucos trabalhos devido ao recente crescimento da indústria de plásticos e a dificuldade de trabalhar com esse tipo de material aplicando métodos convencionais de análise.

Dentre os trabalhos sobre análise de plásticos realizados no Brasil, destacam-se os desenvolvidos no Laboratório de Análise por Ativação Neutrônica do Instituto de Pesquisas Energéticas e Nucleares (IPEN). Foram analisados os materiais poliméricos não metalizados e metalizados em diversos tipos de embalagens e produtos (Nomura et al., 2000; Soares et al., 2002 e 2005) e os resultados obtidos indicaram a presença de diversos constituintes inorgânicos tóxicos, como $\mathrm{Cd}, \mathrm{Cr}$, Ni e $\mathrm{Sb}$.

No Laboratório do Instituto Adolfo Lutz (IAL), Zenebon et al. (2004) determinando metais presentes em corantes e pigmentos utilizados em 
embalagens para alimentos, encontraram, em algumas amostras, altos teores de $\mathrm{Pb}, \mathrm{Cd}$ e $\mathrm{Zn}$. Estes pesquisadores salientaram a necessidade de um controle contínuo desses elementos uma vez que eles podem migrar para o alimento.

Bichino et al. (2005) analisaram por espectroscopia de fluorescência de raios $X(X R F)$, polietilenos comerciais produzidos pelas tecnologias Ziegler-Natta, Philips e metalocênica. Estes pesquisadores mostraram que a XRF permite a determinação direta de metais em matrizes poliméricas presentes em níveis de $\mathrm{mg} \mathrm{kg}^{-1}$ para elementos apresentando número atômico maiores ou iguais que o do $\mathrm{Ti}(Z \geq 22)$, ou seja, a técnica mostrou ser adequada para a determinação de Ti, V, Cr, Al e Zr em polietilenos.

Diemer e Heumann (2000), na Alemanha, desenvolveram o método de espectroscopia de massa de diluição isotópica com fonte de plasma acoplado indutivamente (ICP-IDMS) para a determinação dos metais tóxicos $\mathrm{Pb}, \mathrm{Cd}, \mathrm{Cr}$ e $\mathrm{Hg}$ em poliolefinas e compararam seus resultados com aqueles obtidos por espectroscopia de massa de diluição isotópica com ionização térmica (TI-IDMS). Esses pesquisadores verificaram que há uma boa concordância entre os resultados obtidos pelos dois métodos e a precisão foi demonstrada por meio da análise de um material certificado de referência e participação na comparação interlaboratorial de resultados. 


\section{CAPÍTULO 3}

\section{CONSIDERAÇÕES GERAIS SOBRE A MIGRAÇÃO DE SUBSTÂNCIAS DO MATERIAL POLIMÉRICO}

\subsection{Migração de espécies químicas de materiais poliméricos para o seu conteúdo}

Vários fatores devem ser considerados na escolha de um material polimérico para a confecção de uma embalagem alimentícia, entre eles, destacase a possibilidade das substâncias que compõem o plástico migrarem para os alimentos conferindo gosto, odor ou ainda a ocorrência da transferência de substâncias tóxicas quando estes alimentos são estocados nas embalagens (Crompton, 1979; Crosby 1981).

Fazendo uma revisão bibliográfica sobre a migração de elementos do plástico para simulantes de alimentos, verifica-se que em periódicos indexados, o número de trabalhos publicados é bastante reduzido, principalmente no caso da migração de elementos químicos.

Dentre esses trabalhos sobre migração de elementos das embalagens, destaca-se o de Weisel et al. (1991) que utilizando a AAS identificaram a presença de $\mathrm{Pb}$ em rótulos pintados sobre embalagens plásticas de pão sendo que 17 das 18 embalagens analisadas apresentavam $\mathrm{Pb}$ no seu exterior. Estes pesquisadores questionaram 106 famílias, das quais 16\% daquelas que responderam o questionário disseram que invertem as embalagens e as reutilizam para acondicionar alimentos. Dessa maneira, na reutilização da 
embalagem o alimento fica em contato direto com a tinta de impressão. Weisel et al. (1991), também estimaram que, após um contato de 10 minutos com uma solução de ácido fraco ou vinagre, pode ocorrer a extração de $100 \mu \mathrm{g}$ de Pb da tinta de impressão para o alimento indicando que a utilização desse tipo de tinta em embalagens torna-se um risco à saúde pública.

Thompson et al. (1997) tentaram validar o método radiométrico de migração de elementos traço de embalagens de alimento para quatro tipos de simulantes de alimentos, fazendo comparação dos resultados do método radiométrico com os do método convencional. Foi encontrada dificuldade em estimar a migração de Sb do PET, pois obtiveram resultados abaixo dos limites de detecção em ambos os métodos. Também estes pesquisadores não detectaram a migração de $\mathrm{Co}, \mathrm{Cr}, \mathrm{Zn}$, Ba de LDPE, pelo método radiométrico e os resultados obtidos pelo método convencional não foram estatisticamente significativos quando são consideradas as incertezas dos resultados. Foi concluído que o método radiométrico fornece menores valores de limite de detecção que o método convencional. Além disso, esses pesquisadores afirmaram que o comportamento da migração parece não ter sido afetado pela irradiação do plástico com nêutrons quando ocorre baixa migração dos elementos para o simulante.

Lau e Wong (2000), numa revisão de trabalhos sobre contaminação dos alimentos originária das embalagens plásticas, verificaram que vários métodos analíticos têm sido desenvolvidos para avaliar migrantes ou contaminantes nos alimentos, entretanto estas determinações são demoradas e custosas devido à complexidade da matriz de alimentos e à baixa concentração dos migrantes. Para sanar estas dificuldades, estes autores sugerem, para avaliação da migração, o uso de novos procedimentos baseados em modelos teóricos para estimar a extensão da migração. O trabalho apresenta, também, uma revisão sobre os regulamentos de controle, métodos analíticos, fatores que afetam a migração e avaliação da migração.

Al-Malack (2001), na Arábia Saudita, por meio da técnica de espectroscopia com fonte de plasma acoplado indutivamente (ICP) estudou a migração de $\mathrm{Pb}, \mathrm{Sn}$ e outros metais utilizados como estabilizantes em tubos de PVC não plastificados usados na canalização de água. Foram estudadas as diversas variáveis que afetam a migração com relação aos 
parâmetros de qualidade da água, a saber: $\mathrm{pH}$, temperatura, sólidos totais dissolvidos, tempo de circulação de água no tubo e, também, a exposição direta à radiação ultravioleta. Os resultados mostraram que esses parâmetros da qualidade da água influenciam na migração de $\mathrm{Pb}, \mathrm{Sn}$ e outros metais estabilizantes presentes no PVC e, além disso, foram criados modelos empíricos para predizer a concentração de $\mathrm{Pb}$ que migra para a água em função do tempo de exposição à migração, $\mathrm{pH}$ da água e as concentrações de sólidos dissolvidos na água.

Bernardo et al. (2005), do IAL, no período de 2000 a 2004, avaliaram os resultados obtidos nas análises de 1952 amostras de embalagens e equipamentos poliméricos destinados a entrar em contato com alimentos. Seus resultados indicaram que $20,35 \%$ das amostras (392 amostras) foram consideradas insatisfatórias e, desse total, 11,99\% (47 amostras) foram reprovadas devido aos contaminantes inorgânicos. Os pesquisadores chegaram à conclusão de que os dados obtidos no monitoramento evidenciam a necessidade de controle contínuo da qualidade do material para uso em contato com alimentos.

Shotyk et al. (2006), utilizando a técnica de análise instrumental por ativação com nêutrons (INAA) analisaram amostras de PET e verificaram a presença de $\mathrm{Sb}$ em concentrações que variaram de 351 a $397 \mathrm{mg} \mathrm{kg}^{-1}$. Esta alta concentração de $\mathrm{Sb}$ foi atribuída ao uso do catalisador $\mathrm{Sb}_{2} \mathrm{O}_{3}$ na fabricação do PET. Utilizando a ICP-MS estes pesquisadores analisaram amostras de águas naturais e estocadas em recipientes de PP e PET, provenientes do Canadá, e detectaram $\mathrm{Sb}$ em todas as amostras, sendo que os seus teores mais altos foram encontrados nas amostras engarrafadas em PET. Foi verificado também que a concentração de $\mathrm{Sb}$ aumenta com o tempo de estocagem da amostra na embalagem. Nas amostras de água engarrafada em PET proveniente de vários países da Europa, esses pesquisadores verificaram a presença de $\mathrm{Sb}$ em todas as amostras, porém, todos com resultados abaixo dos limites estabelecidos para águas potáveis pelos diversos órgãos regulamentadores do Canadá e da Europa.

Shotyk e Krachler (2007) utilizando a técnica analítica de ICP-MS estudaram a variação das concentrações de Sb em 132 amostras de água engarrafadas adquiridas em 28 países e estocadas por 6 meses em embalagens 
PET. No caso, um aumento da concentração desse elemento foi verificado nas amostras de água após o período de ensaio. Todas as amostras analisadas apresentaram Sb em concentrações abaixo das recomendadas pela Organização Mundial de Saúde (WHO) de $20 \mu \mathrm{g} \mathrm{L}^{-1}$, Agência de Proteção Ambiental dos Estados Unidos (USEPA), Ministério do Meio Ambiente de Ontário de $6 \mu \mathrm{g} \mathrm{L}^{-1} \mathrm{e}$ Ministério Federal do Meio Ambiente da Alemanha de $5 \mu \mathrm{g} \mathrm{L}^{-1}$, porém, duas amostras apresentaram valores maiores que o permitido pela legislação do Japão para águas potáveis, $2 \mu \mathrm{g} \mathrm{L}^{-1}$.

Westerhoff et al. (2008), nos Estados Unidos, utilizando ICP-MS determinaram $\mathrm{Sb}$ em águas comercializadas em embalagens de PET provenientes dos Estados Unidos. As garrafas com água estocadas por um período de três meses em diferentes temperaturas apresentaram baixa taxa de extração em temperaturas abaixo de $60^{\circ} \mathrm{C}$ e, para temperaturas acima, foi verificado que a extração do Sb pode ocorrer rapidamente e, à temperatura de $80^{\circ} \mathrm{C}$ após sete dias de exposição, a quantidade de Sb lixiviado excedeu o limite estabelecido pela Agência de Proteção do Meio Aambiente dos Estados Unidos (USEPA) de 6ppb.

Com relação à migração de compostos orgânicos do plástico, esse tema tem sido investigado para diversas substâncias, como pode ser visto no trabalho de Lawson et al. (1996). Nesse trabalho, foram utilizadas as técnicas de cromatografia gasosa acoplada à espectroscopia de massa (GC-MS), cromatografia líquida de alta eficiência (HPLC), espectroscopia no ultravioleta e testes colorimétricos para estudar a migração de compostos orgânicos das embalagens plásticas laminadas de alimentos que, para consumo, são cozidos na própria embalagem. Os resultados obtidos indicaram que o material dentro desta embalagem está exposto a níveis de migrantes menores que o limite total de migração estabelecido pela legislação.

Sarbach et al. (1996), aplicando a técnica de HPLC, avaliaram a migração de impurezas dos frascos plásticos de produtos farmacêuticos, especialmente as de solução parenteral. Esses pesquisadores, estudando a migração de um filme tri-laminado constituído de polipropileno na parte externa, poliamida-6 (PA6) no meio e o polietileno em contato direto com a solução 
parenteral, verificaram que o produto principal encontrado na solução foi a $\varepsilon$-caprolactama proveniente da PA6.

Yamamoto e Yasuhara (1999) utilizaram a técnica de GC-MS para quantificar bisfenol A lixiviado de amostras de plástico pela água. Os resultados da concentração de bisfenol $A$ obtido variaram de valores não detectáveis a $139 \mu \mathrm{g} \mathrm{g}^{-1}$ e os maiores valores de lixiviação foram para amostras de PVC, uma vez que o bisfenol A é utilizado como estabilizante na fabricação deste polímero.

Como os alimentos são muitas vezes processados na própria embalagem, por alta pressão, irradiação entre outros, Ozen e Floros (2001) fizeram uma revisão de trabalhos sobre os efeitos dos diferentes métodos de processamento de alimentos nas embalagens com relação à sua estrutura mecânica, propriedades de barreira e migração de aditivos nelas presentes. Esses pesquisadores chamaram a atenção sobre a importância em compreender os efeitos causados na embalagem durante o processamento do alimento para escolher o filme com características adequadas de modo a conservar as propriedades originais do alimento.

Nerín et al. (2002), na Espanha, aplicando a técnica de GC-MS verificaram a possibilidade de migração de produtos voláteis de recipientes plásticos quando utilizados para aquecimento de alimentos em forno de microondas. Seus resultados permitiram concluir que esses recipientes de plástico não são inertes e podem liberar vários compostos orgânicos, alguns tóxicos, como, por exemplo, metilbenzeno, xileno, estireno entre outros. Entretanto, os resultados de migração de compostos orgânicos tóxicos liberados dos recipientes, quando aquecidos a $100^{\circ} \mathrm{C}$, foram consideravelmente menores que o limite de migração específica da legislação adotada pela União Européia $(E U)$.

Marcato et al. (2003) estudando a migração de aditivos antioxidantes, Irganox 1010 e Irgafos 168 de embalagens poliolefínicas para um simulante oleoso, utilizando a técnica de HPLC, verificaram que a liberação dos dois antioxidantes variava com o grau de cristalização e estrutura da poliolefina. A liberação de aditivos foi maior em poliolefinas com alto conteúdo de 
fração amorfa e, desta forma, esses materiais não são apropriados para a produção de embalagens que ficam em contato direto com óleos.

Mutsuga et al. (2006) utilizando a técnica de HPLC analisaram a migração de formaldeído e acetaldeído de garrafas PET para água mineral e verificaram que os níveis de migração destes dois compostos dependiam dos seus teores nas embalagens e do tempo de estocagem.

Conforme mostra a revisão bibliográfica realizada neste trabalho, vários contaminantes orgânicos e inorgânicos estão presentes nos materiais poliméricos e podem ser transferidos para os alimentos quando estocados nas embalagens confeccionadas com este tipo de material.

\subsection{Legislação aplicada a embalagens plásticas para alimentos}

Como conseqüência do interesse cada vez maior pela saúde pública, especialistas desta área, órgãos reguladores e a própria população vêm exigindo um maior controle da qualidade dos alimentos, o que inclui, também a sua embalagem. Vários livros, artigos e regulamentos tratam desse assunto.

Um desses livros é o de Crosby (1981) que aborda os diferentes aspectos que devem ser considerados na seleção de materiais para embalagens de alimentos, dentre eles, a análise da contaminação do alimento originária da embalagem e, também, da toxicidade e legislações específicas para fabricação e controle de embalagens desenvolvidas no Reino Unido, na Comunidade Européia, nos Estados Unido, entre outros.

Na Europa, em 1990, a Comissão da Comunidade Européia propôs a diretriz 90/128/EEC referente a materiais poliméricos e artigos que entram em contato com alimentos. Nesta norma, foram estabelecidos os limites de migração total e específica do material polimérico da embalagem para o seu interior (CEC, 1990). Devido às inúmeras emendas a essa diretriz 90/128/EEC, a mesma foi substituída pela Diretriz 2002/72/EC publicada em agosto de 2002 (CEC, 2002). Esta nova diretriz inclui, em seus anexos, a quantidade máxima de 
substâncias permitidas nos materiais poliméricos e nos seus alimentos, bem como, os valores limites de migração os quais já haviam sido estabelecidos nas diretrizes anteriores.

O Mercado Comum do Sul, MERCOSUL, constituído pelo Brasil, Argentina, Paraguai e Uruguai por meio do Grupo Mercado Comum (GMC), aprovou resoluções para uso na área de embalagem em contato com alimentos. Dentre essas resoluções aprovadas se destacam as que tratam dos materiais destinados às embalagens plásticas para contato direto com alimentos. Essas resoluções contêm a lista de polímeros, resinas e aditivos autorizados para a confecção desse tipo de embalagem com suas especificações quanto às restrições dos materiais, como a quantidade máxima permitida de um determinado componente no material polimérico, ou seja, o limite de composição (LC) e, a quantidade máxima admissível de transferência de um componente específico para um simulante de alimento sob condições de ensaio, isto é, o limite de migração específica (LME) entre outras especificações. As resoluções estabelecem também o limite de migração total ou global da massa total do migrante por superfície da embalagem em $8 \mathrm{mg} \mathrm{dm}^{-2}$ ou da massa total do migrante por massa de simulante em $50 \mathrm{mg} \mathrm{kg}^{-1}$. Essas resoluções estabelecidas pelo GMC estão sendo incorporadas nas legislações nacionais dos países integrantes do MERCOSUL (Padula e Cuervo, 2004; IAL, 2005; Murata et al., 2002).

No Brasil, a ANVISA é o órgão responsável pela elaboração de portarias e resoluções referentes a alimentos e é, também, responsável pela revisão e ampliação das metodologias analíticas, bem como pela incorporação dos regulamentos técnicos aprovados pelo GMC à legislação nacional (Murata et al., 2002; Padula e Cuervo, 2004). Esse órgão, por meio da resolução $n^{\circ} 105$ de 19 de maio de 1999 - RE-105/99, estabeleceu regulamentos técnicos para o uso de embalagens e equipamentos plásticos que entram em contato com alimentos, bem como os limites de migração permitidos, incorporando as especificações estabelecidas pelo GCM, quanto ao limite de migração total. Nessa resolução, também, foram estabelecidos os tipos de simulante, a temperatura e o tempo de contato adequados para a avaliação da migração em função do tipo de alimento contido na embalagem (ANVISA, 1999). 
A Norma Técnica ABNT MB-3092, da Associação Brasileira de Normas Técnicas (1989), assim como a resolução RE-105/99 da ANVISA (1999) estabelecem critérios para determinação de migração de substâncias presentes em materiais poliméricos em contato com alimentos. Ambas as publicações estabelecem que, para avaliar a migração, a relação da área superficial da amostra exposta à migração $\left(\mathrm{em}^{\mathrm{cm}}{ }^{2}\right.$ ) por volume do solvente simulante (em $\left.\mathrm{mL}\right)$ deve estar compreendida entre 0,5 e 2,0.

Heckman (2005) aborda os regulamentos existentes nos Estados Unidos e nos países da Comunidade Européia para uso de materiais como embalagens de alimentos. Nos Estados Unidos, os regulamentos estabelecem a necessidade da determinação da migração, isto é, da quantificação e identificação dos componentes transferidos da embalagem para o alimento e, se nenhuma substância ou se somente substâncias de baixa toxicidade forem transferidas, então a embalagem é considerada segura. Já na Comunidade Européia, há uma preocupação, também, com relação à quantidade extraída, mesmo que essas substâncias sejam pouco significativas do ponto de vista toxicológico. Foram estabelecidos os valores limites de migração global de $60 \mathrm{mg} \mathrm{L}^{-1}$ (massa de migrante por volume de simulante), na Bélgica, França e Holanda, e de $50 \mathrm{mg} \mathrm{L}^{-1}$, na Itália, cujo valor limite é também adotado no Brasil, sendo que a migração de componentes específicos não poderá ser superior aos limites estabelecidos na lei.

O controle de material reciclado a ser utilizado na confecção de embalagens de alimentos também é uma preocupação de vários pesquisadores. Santos et al. (2004) destacaram a necessidade de regulamento específico para a utilização de plástico reciclado na produção de embalagens para contato direto com alimentos. O controle do material a ser reciclado para reuso em embalagens de alimentos é relevante, uma vez que, no caso do material polimérico, a reutilização da embalagem alimentícia para outros fins, como, por exemplo, para o armazenamento de produtos químicos tóxicos, solventes, agentes desinfetantes ou outros produtos pode contaminar o plástico devido às suas características de sorção e difusão. Quando esse material é reutilizado na confecção de novas embalagens alimentícias, o contaminante pode ser transferido para o alimento. Segundo Santos et al. (2004) a fim de preservar a saúde do consumidor, a 
legislação deve estabelecer o nível máximo aceitável de um contaminante químico no plástico reciclado para evitar a possível migração para alimentos.

Também segundo Nunes et al. (2003), do IAL, a reciclagem de embalagens para alimentos deve ser amplamente discutida. Para a reutilização do material na confecção de embalagens, deve-se levar em conta medidas como conscientização do consumidor em relação ao reuso e descarte da embalagem plástica de alimentos, a elaboração de um programa de coleta seletiva específico para este fim e demonstrar por meio de estudos analíticos que os níveis de contaminantes químicos estejam dentro dos limites permitidos.

O uso de material reciclado em garrafas de PET multicamadas descartáveis utilizadas para acondicionamento de bebidas não alcoólicas carbonatadas está autorizado pela Secretaria de Vigilância Sanitária (Brasil, 1999), por meio da Portaria 987. Entretanto essa autorização não permite o uso do material reciclado em contato direto com o alimento, isto é, a camada interna da embalagem deve ser obrigatoriamente constituída de PET virgem, a única a ter contato direto com o produto e por uma ou mais camadas externas sucessivas que podem ser de PET reciclado. O controle do material reciclado é efetuado, também, de acordo os regulamentos técnicos existentes para a utilização em embalagens de alimentos.

A reciclagem de determinados tipos de plásticos para uso em contato direto com alimentos é permitida nos Estados Unidos e Alemanha (Santos et al., 2004). A ANVISA (2007), considerando os regulamentos estabelecidos pelo MERCOSUL, expôs à consulta pública, desde agosto de 2007, um regulamento técnico com a finalidade de regulamentar a utilização de PET reciclado em embalagens para contato direto com alimentos. Esse regulamento visa a proteção à saúde da população permitindo um maior controle sanitário e, também, facilitar a comercialização de alimentos no MERCOSUL. 


\subsection{Efeitos da irradiação dos materiais poliméricos com nêutrons do reator nuclear}

Uma vez que no presente trabalho o estudo da migração envolve a irradiação de materiais poliméricos com nêutrons antes da exposição à migração, julgou-se importante fazer um exame dos trabalhos existentes sobre as modificações que possam ocorrer no plástico com a irradiação.

Entre os trabalhos referentes ao efeito da irradiação de materiais poliméricos, destaca-se o de Tabata e Katsumura (1985), que estudaram os efeitos da irradiação com nêutrons rápidos e com raios gama de um irradiador de ${ }^{60} \mathrm{Co}$ em amostras de PE, de borracha de etileno-propileno e do copolímero tetrafluoroetileno-propileno pela medição do conteúdo de gel do polímero e pelo ensaio de inchamento. Os resultados obtidos indicaram que a ocorrência da reticulação desses polímeros pela irradiação com nêutrons rápidos é a mesma daquela com raios gama de uma fonte de ${ }^{60} \mathrm{Co}$.

Yagoubi et al. (1999) verificaram, por meio das técnicas de calorimetria exploratória diferencial (DSC), HPLC e análise termogravimétrica associada à espectroscopia no infravermelho com transformada de Fourier (TGA/FTIR), as modificações estruturais produzidas em amostras de PP quando estas são irradiadas com diferentes doses de radiação gama e de feixes de elétrons. Estes pesquisadores verificaram que os dois tipos de radiação provocaram a degradação no polímero e em seus aditivos. E, no caso de aplicação de doses maiores que 100 e 150kGy, a perda de cristalinidade foi maior para o PP irradiado com radiação gama do que aquela obtida por radiação de feixe de elétrons.

Terence e Guedes (2002) estudaram o efeito da radiação gama na estrutura molecular do poli (álcool vinílico) (PVAL) utilizando doses de zero a 200kGy e concluíram que não há ocorrência de variações significativas na estrutura do PVAL, mas somente um pequeno amarelecimento do material foi observado devido à formação de radicais poliméricos.

Evora et al. (2002) avaliaram as alterações que ocorrem no interior e na superfície da PA6 reciclada quando irradiada na presença de oxigênio e feixe 
de elétrons de $1,5 \mathrm{MeV}$, na dose de $500 \mathrm{kGy}$. O estudo comparativo dos resultados obtidos na análise por espectroscopia na região do infravermelho com transformada de Fourier (FTIR) de transmissão, de reflexão e fotoacústica mostrou a possibilidade da irradiação ocasionar a formação de grupos $\mathrm{OH}$ e $\mathrm{COOH}$ e/ou $\mathrm{C}=\mathrm{O}$ bem como mudanças de estruturas nos grupos $\mathrm{NH}$ e $-\mathrm{CN}-\mathrm{C}=\mathrm{O}$ e esse tratamento com radiação atingiu a PA6 tanto na superfície quanto no interior do material.

Welle et al. (2002) em seu trabalho, discutem os efeitos causados aos materiais poliméricos de embalagens pelas radiações ionizantes. Esses pesquisadores afirmaram que, em geral, a irradiação dos plásticos favorece a formação de radicais livres e íons, com efeitos secundários como a reticulação e degradação oxidativa do polímero. Esses efeitos resultam na formação de compostos voláteis que podem afetar a qualidade do produto contido na embalagem, ocasionando danos à saúde do consumidor. Também, os aditivos dos polímeros podem ser afetados pela irradiação com a mudança de seu comportamento na migração específica ou por sua decomposição.

Moura et al. (2003) utilizando a técnica de FTIR analisaram o efeito da radiação gama na irradiação de amostras de filme monocamada de polietileno com doses de radiação que variaram de zero a 100kGy. Esses pesquisadores observaram variações mais significativas para as doses superiores a $30 \mathrm{kGy}$, devido à formação de produto de oxidação durante a irradiação em presença de oxigênio.

Lambri et al. (2005) irradiaram amostras de monômeros de etilenopropeno-dieno com fluxo de nêutrons da ordem de $1,04 \times 10^{8} \mathrm{n} \mathrm{cm}^{-2} \mathrm{~s}^{-1}$, $3,6 \times 10^{8} \mathrm{n} \mathrm{cm}^{-2} \mathrm{~s}^{-1}$ e $7,2 \times 10^{8} \mathrm{n} \mathrm{cm}^{-2} \mathrm{~s}^{-1}$ e empregaram as técnicas de análise dinâmico-mecânica (DMA), de análise térmica diferencial (DTA), de difração de raios $X$, de DSC e análises na região do infravermelho para avaliar o comportamento das amostras com a irradiação. Seus resultados mostraram que a concentração e o tamanho dos cristais desenvolvidos na cristalização química (chemi-crystalisation) dependem da dose de nêutrons e o grau de dano causado ao polímero pela irradiação depende tanto da dose como do fluxo de nêutrons. 


\section{CAPÍTULO 4}

\section{CONSIDERAÇÕES SOBRE O ENSAIO DE MIGRAÇÃO}

\subsection{Conceitos de migração}

A migração é o termo utilizado para designar a passagem de substâncias de um material, no caso da embalagem, para uma solução que pode ser um alimento ou um simulante do alimento. A transferência de elementos químicos ou moléculas orgânicas de embalagens para alimentos ou simulantes é um fenômeno complexo e muitos tratamentos matemáticos relacionados à difusão, têm sido considerados.

Na avaliação da migração, pode-se determinar a migração total ou a específica.

A migração total se refere à quantidade total de substâncias que é transferida do material para um simulante do alimento. Esse ensaio é efetuado em condições de tempo e temperatura de acordo com as características do emprego e armazenamento do produto. O resultado desse ensaio indica o potencial de interação alimento/material da embalagem (Saron, 2007; Padula e Ito, 2006; IAL, 2005).

A migração específica é a quantidade de um componente nãopolimérico de interesse toxicológico transferido do material para o alimento ou soluções que o simulem (Padula e Ito, 2006; IAL, 2005; ANVISA, 1999). 


\subsubsection{Difusão}

Diversos estudos têm evidenciado que a migração dos constituintes orgânicos e inorgânicos dos materiais poliméricos para líquidos (alimentos ou simulantes de alimentos) ocorre por um processo de difusão.

A difusão é a transferência de massa resultante de movimentos moleculares espontâneos que ocorrem sem o auxílio de forças externas como agitação ou correntes de convecção do líquido. Há uma tendência natural nos materiais da difusão ocorrer de áreas de alta concentração para áreas de baixa concentração até que o equilíbrio se estabeleça. É mais correto e mais usual que a difusão ocorra de área de alto potencial químico para áreas de baixo potencial até que se estabeleça uma constante de equilíbrio (Crosby, 1981).

A velocidade de migração de uma propriedade pode ser medida pelo seu fluxo (J). No processo de difusão, este fluxo está relacionado ao movimento de matéria que se difunde paralelamente à direção do eixo $x$ e que é proporcional à derivada primeira da concentração, conforme equação 4.1 (Atkins, 1999).

$$
J \propto \frac{d N}{d X}
$$

em que $\mathrm{N}$ é a densidade numérica de partículas.

A proporcionalidade entre o fluxo de matéria e o gradiente de concentração é a primeira lei de Fick que pode ser expressa matematicamente de acordo com a equação 4.2 (Moore, 1972; Crosby, 1981; Paine e Paine, 1983).

$$
\frac{1}{\mathrm{~A}} \frac{\partial \mathrm{N}}{\partial \mathrm{X}}=-\mathrm{D} \frac{\partial \mathrm{C}}{\partial \mathrm{X}}
$$

em que D é o coeficiente de difusão, A é a área da superfície de contato e $\partial \mathrm{C} / \partial \mathrm{X}$ é a derivada da concentração. 
A segunda lei de Fick da equação da difusão relaciona as variações da concentração com o tempo $(\mathrm{t})$ e a distância $(X)$, conforme equação 4.3 (Moore, 1972; Crosby, 1981; Paine e Paine, 1983).

$$
\frac{\partial \mathrm{C}}{\partial \mathrm{t}}=-\mathrm{D} \frac{\partial^{2} \mathrm{C}}{\partial \mathrm{X}^{2}}
$$

Essa equação mostra que a taxa de variação da concentração é proporcional à derivada segunda da concentração em relação a uma coordenada de distância.

Pesquisadores têm se dedicado à obtenção de equações baseadas nos coeficientes de difusão do sistema plástico/alimento a fim de prever a quantidade de substâncias que migram da embalagem plástica para o seu conteúdo, sem a necessidade do ensaio analítico. Vários pesquisadores baseados na primeira e segunda leis de Fick elaboraram modelos de migração a serem utilizados para prever, matematicamente, a quantidade de migrantes de sistemas plástico/alimento (Dole et al., 2006; O’Brien e Cooper, 2002; Reynier et al., 2002; Piringer et al., 1998; Lickly et al., 1995). A avaliação desses modelos de migração foi também foco de estudo, principalmente, com a finalidade de apoiar as regulamentações para plásticos em contato com alimentos (Begley et al., 2005; Franz, 2005).

Lickly et al. (1995) utilizaram as técnicas de GC-MS e HPLC para determinar a migração de estireno de artigos de espuma de poliestireno, como copos e pratos, para simulantes de alimento. Esses pesquisadores verificaram que a quantidade de estireno que migrou das várias amostras analisadas para o simulante óleo foi proporcional à raiz quadrada do tempo de exposição. A partir dos dados obtidos em diferentes temperaturas e tempos de exposição e assumindo que a migração do estireno obedece à Lei de Fick, definiram os valores dos coeficientes de difusão aparente utilizando resultados obtidos da análise da migração dos compostos. 
Segundo Philo et al. (1997), a ocorrência da migração pode ser prevista por meio de modelos de difusão. Esses pesquisadores estimaram a migração de óxido de estireno para alimentos por meio de dados pré-existentes e supondo que a tendência de migração do óxido de estireno é a mesma do monômero de estireno.

O'Brien e Cooper (2002), na Inglaterra, avaliaram o uso de modelo matemático, utilizando o programa "Migratest Lite" software desenvolvido pela Fabes Research Company em Munique - Alemanha, para previsão da migração de aditivos de plásticos em contato com alimentos. Para este estudo, esses pesquisadores obtiveram um grande número de dados experimentais de migração específica de aditivos em óleo de oliva sob várias condições de tempo e temperatura e esses dados foram utilizados para avaliar um modelo de migração baseado nos princípios da Lei de Fick. No caso, foi estudada a migração de aditivos com diferentes massas molares, composições e funções químicas. Nessa pesquisa, foi concluído que o modelo matemático utilizado pôde prever migrações em óleo de oliva fornecendo resultados que foram próximos ou maiores que os dados obtidos experimentalmente.

Reynier et al. (2002), na França, apresentaram um modelo matemático para avaliar a migração de aditivos de polímeros para simulantes de alimentos baseado no efeito da sorção do simulante e no aumento do coeficiente de difusão durante o tempo de contato. Para esse estudo foram utilizadas amostras de PP e o modelo matemático desenvolvido para análise numérica da migração pôde ser modificado para situações mais complexas como difusão em sistemas multicamadas com diferentes tipos de polímeros.

Tehrany e Desobry (2004), na França, fazendo uma revisão sobre estudos dos coeficientes de partição em sistemas alimento/embalagem chegaram à conclusão que, nos processos de migração, inúmeros fatores tais como estrutura física e química dos alimentos, das embalagens e dos migrantes, assim como concentração e mistura de migrante, $\mathrm{pH}$, o conteúdo de água e gordura dos alimentos pode afetar a partição do migrante entre 0 sistema alimento/embalagem. 
Begley et al. (2005) investigaram os modelos de migração a serem utilizados como um apoio à regulamentação para o uso de plásticos que entram em contato com alimentos. O trabalho descreve os passos principais a serem seguidos para desenvolver e validar um modelo de migração que possa ser utilizado para uma série de materiais poliméricos em contato com alimentos.

Nos Estados Unidos, os modelos de migração já são utilizados pela Food and Drug Administration (FDA) como uma ferramenta adicional para auxiliar na tomada de decisões em regulamentos relacionados à migração do material polimérico para o alimento. A União Européia recentemente incorporou, por meio da Diretriz 200/72/EC a opção de utilizar modelos reconhecidos de migração como uma ferramenta para verificação da conformidade ou garantia de qualidade de materiais poliméricos em contato com alimentos. No caso de nãoconformidade, é ainda obrigatória a confirmação dos valores de migração por meio de testes experimentais (Begley et al., 2005).

Rosa et al. (2007) do Centro de Tecnologia das Radiações do IPEN propuseram uma técnica numérica para simular os resultados de migração de elementos $\mathrm{Cd}$ e $\mathrm{Sb}$ de embalagens plásticas de derivados de leite para uma solução de ácido acético a $3 \%$. Foi concluído, nesse estudo, que essa técnica se ajusta muito bem aos pontos obtidos experimentalmente e pode ser utilizada como ferramenta complementar nas medições experimentais. Além disso, essa técnica permite um melhor entendimento do processo de difusão, bem como para estimar a migração de elementos em situações em que medições experimentais não podem ser obtidas.

\subsection{Seleção dos simulantes de alimentos para avaliação da migração}

Os alimentos são uma mistura de carboidratos, proteínas, gordura, água e outros constituintes em menor quantidade como vitaminas, sais, antioxidantes, corantes entre outros. Essa mistura complexa implica na dificuldade da escolha de um simulante que represente cada tipo de alimento. Para simplificar essa situação, os alimentos foram divididos em determinados 
grupos, como sólidos secos, líquidos neutros, ácidos, alcoólicos e substâncias gordurosas (Crosby, 1981). Dessa forma, os simulantes de alimentos foram classificados em quatro classes: água destilada $(A)$, solução diluída de ácido $(B)$, mistura etanol/água (C) e simulantes de alimentos gordurosos (D).

No Brasil, de acordo com a Resolução no 105/99 da ANVISA (1999), os simulantes de alimentos estabelecidos para o ensaio de migração são os apresentados na Tabela 4.1.

Tabela 4.1. Simulantes utilizados em ensaios de migração.

\begin{tabular}{lc}
\hline Simulante & Líquido simulante \\
\hline A & Água destilada \\
B & Solução de ácido acético em água destilada a $3 \%(\mathrm{~m} / \mathrm{v})$ \\
C & $\begin{array}{r}\text { Solução de etanol em água destilada a } 15 \% \text { ou na } \\
\text { concentração mais próxima da real de uso }\end{array}$ \\
D & Azeite de oliva refinado ou n-heptano \\
\hline
\end{tabular}

Os alimentos são classificados por tipos, segundo sua natureza e, para cada tipo de alimento, tem-se o simulante adequado para o teste de migração. Os tipos de alimentos e os correspondentes simulantes estão relacionados na Tabela 4.2 (ANVISA, 1999).

De acordo com a RE 105/99 (ANVISA, 1999), no caso de alimentos que necessitem do simulante $D$, óleo de oliva, os resultados de ensaio da migração devem ser divididos por um fator $\mathrm{n}$, o qual está mencionado no Anexo 1 da RE-105/99 (ANVISA, 1999). Quando é utilizado n-heptano como simulante D, os resultados de migração obtidos devem ser divididos por cinco (5). Essa redução é feita para levar em conta a alta capacidade extrativa do simulante n-heptano com relação ao alimento em questão. 
Tabela 4.2. Tipos de alimentos e simulantes utilizados no ensaio de migração.

\begin{tabular}{|c|c|c|}
\hline Tipo & Alimento & Simulante \\
\hline I & $\begin{array}{l}\text { Alimentos aquosos não ácidos } \\
\qquad(\mathrm{pH}>5)\end{array}$ & A \\
\hline II & Alimentos aquosos ácidos $(\mathrm{pH}<5)$ & $\mathrm{B}$ \\
\hline III a & $\begin{array}{l}\text { Alimentos aquosos não ácidos } \\
\text { contendo óleo ou gordura }\end{array}$ & A ou $D$ \\
\hline III b & $\begin{array}{c}\text { Alimentos aquosos ácidos contendo } \\
\text { óleo ou gordura }\end{array}$ & B ou $D$ \\
\hline IV & Alimentos oleosos ou gordurosos & $\mathrm{D}$ \\
\hline V & $\begin{array}{l}\text { Alimentos alcoólicos (conteúdo em } \\
\text { álcool superior a } 5 \%, v / v)\end{array}$ & $\mathrm{C}$ \\
\hline VI & $\begin{array}{c}\text { Alimentos sólidos secos ou de ação } \\
\text { extrativa pouco significativa }\end{array}$ & $\begin{array}{l}\text { Nenhum, ou ocasionalmente um } \\
\text { dos simulantes (A,B,C ou } D) \\
\text { dependendo do tipo de alimento }\end{array}$ \\
\hline
\end{tabular}

\subsection{Temperatura e tempo de migração}

Os alimentos, em suas embalagens, podem ser estocados em refrigeradores e geladeiras e também podem ser aquecidos nas próprias embalagens. Assim, o intervalo de temperaturas a que as embalagens são submetidas é muito grande.

Figge e Koch (1973) fizeram um estudo sobre a migração de aditivos de PVC, poliestireno (PS) e HDPE para óleos comestíveis e para o simulante HB307, uma mistura sintética de triglicerídeos. Os resultados obtidos para o estudo da migração de estearato n-butila de poliestireno como simulante, num intervalo de temperatura de 30 a $80^{\circ} \mathrm{C}$, mostraram que a $40^{\circ} \mathrm{C}$ não há migração depois de três dias de exposição. Dessa maneira, esses pesquisadores concluíram que um teste efetuado com dez dias de exposição é adequado para medir o valor final de migração. Esses mesmos pesquisadores verificaram, 
também, o efeito da variação da temperatura fixando o tempo de migração em dez dias e observaram que, a $40^{\circ} \mathrm{C}$, o equilíbrio é obtido em poucos dias e que em temperaturas acima de $50^{\circ} \mathrm{C}$ ocorre um aumento na migração não ocorrendo o equilíbrio. Concluíram que o teste de migração em altas temperaturas deve ser criteriosamente analisado, quanto ao tempo de exposição e a temperatura de ensaio, pois podem ser obtidos altos valores de transferência de aditivos que não condizem com a realidade na estocagem.

A ANVISA (1999) definiu o tempo e temperatura de ensaio de migração baseando-se nas condições reais de contato e o simulante utilizado. Essas recomendações são apresentadas na Tabela 4.3.

\subsection{Volume de amostra e massa de simulante}

No ensaio convencional de determinação da migração, é recomendada pela ANVISA a utilização de uma amostra cuja área superficial total de contato com o simulante de alimento seja em torno de $600 \mathrm{~cm}^{2}$. Também para a relação entre área da amostra a ser exposta à migração e o volume do simulante é recomendado pela legislação o valor entre 0,5 a $2,0 \mathrm{~cm}^{2} \mathrm{~mL}^{-1}$ (ANVISA, 1999).

No presente trabalho, procurou-se adaptar o procedimento do método radiométrico às condições recomendadas na legislação. No método radiométrico, a amostra de embalagem para migração é irradiada com nêutrons em um dispositivo de alumínio ("coelho"), o qual limita o tamanho da amostra. Desta forma, foram utilizados três corpos-de-prova de $1,5 \mathrm{~cm} \times 4,5 \mathrm{~cm}$. A área total exposta foi de $40,5 \mathrm{~cm}^{2}$, considerando que as duas faces da amostra são expostas a migração.

Com relação ao volume do simulante de alimento, foi decidido utilizar um volume de $30 \mathrm{~mL}$, volume esse adequado para efetuar as medições na espectrometria de raios gama e, além disso, os corpos-de-prova ficaram totalmente imersos no líquido. A relação entre área exposta à migração e o volume de simulante utilizado no presente estudo foi de $1,35 \mathrm{~cm}^{2} \mathrm{~mL}^{-1}$, o que está dentro da faixa de valores da relação recomendada pela legislação. 
Tabela 4.3. Condições para os ensaios de migração estabelecidas pela ANVISA (1999).

\begin{tabular}{|c|c|c|c|c|c|}
\hline \multirow{3}{*}{ Condições reais de contato } & \multicolumn{5}{|c|}{ Condições de ensaio } \\
\hline & \multirow{2}{*}{$\begin{array}{c}\text { Simulante A } \\
\text { Água destilada }\end{array}$} & \multirow{2}{*}{$\begin{array}{c}\text { Simulante B } \\
\text { ácido acético a } 3 \%\end{array}$} & \multirow{2}{*}{$\begin{array}{l}\text { Simulante C } \\
\text { etanol a } 15 \%\end{array}$} & \multicolumn{2}{|c|}{ Simulante D } \\
\hline & & & & n-heptano ${ }^{c}$ & azeite de oliva $^{d}$ \\
\hline \multicolumn{6}{|c|}{ a.Conservação (contato prolongado, $\mathrm{t}^{\mathrm{a}}>24 \mathrm{~h}$ ) } \\
\hline $\mathrm{T}^{\mathrm{b}}<5^{\circ} \mathrm{C}$ & $5^{\circ} \mathrm{C} / 10$ dias & $5^{\circ} \mathrm{C} / 10$ dias & $5^{\circ} \mathrm{C} / 10$ dias & $5^{\circ} \mathrm{C} / 30 \mathrm{~min}$ & $5^{\circ} \mathrm{C} / 10$ dias \\
\hline $5^{\circ} \mathrm{C}<\mathrm{T}<40^{\circ} \mathrm{C}$ & $40^{\circ} \mathrm{C} / 10$ dias & $40^{\circ} \mathrm{C} / 10$ dias & $40^{\circ} \mathrm{C} / 10$ dias & $20^{\circ} \mathrm{C} / 30 \mathrm{~min}$ & $40^{\circ} \mathrm{C} / 10$ dias \\
\hline$(2 \mathrm{~h}<\mathrm{t}<24 \mathrm{~h})$ à temperatura ambiente & $40^{\circ} \mathrm{C} / 24 \mathrm{~h}$ & $40^{\circ} \mathrm{C} / 24 \mathrm{~h}$ & $40^{\circ} \mathrm{C} / 24 \mathrm{~h}$ & $20^{\circ} \mathrm{C} / 15 \mathrm{~min}$ & $40^{\circ} \mathrm{C} / 24 \mathrm{~h}$ \\
\hline \multicolumn{6}{|l|}{ c. Contato momentâneo } \\
\hline$(\mathrm{t}<2 \mathrm{~h})$ à temperatura ambiente & $40^{\circ} \mathrm{C} / 2 \mathrm{~h}$ & $40^{\circ} \mathrm{C} / 2 \mathrm{~h}$ & $40^{\circ} \mathrm{C} / 2 \mathrm{~h}$ & $20^{\circ} \mathrm{C} / 15 \mathrm{~min}$ & $40^{\circ} \mathrm{C} / 2 \mathrm{~h}$ \\
\hline $80^{\circ} \mathrm{C}<\mathrm{T}=100^{\circ} \mathrm{C}$ & $100^{\circ} \mathrm{C} / 30 \mathrm{~min}$ & $100^{\circ} \mathrm{C} / 30 \mathrm{~min}$ & & $50^{\circ} \mathrm{C} / 15 \mathrm{~min}$ & $100^{\circ} \mathrm{C} / 30 \mathrm{~min}$ \\
\hline $\mathrm{T}>100^{\circ} \mathrm{C}$ & $120^{\circ} \mathrm{C} / 30 \mathrm{~min}$ & $120^{\circ} \mathrm{C} / 30 \mathrm{~min}$ & & $60^{\circ} \mathrm{C} / 15 \mathrm{~min}$ & $120^{\circ} \mathrm{C} / 30 \mathrm{~min}$ \\
\hline
\end{tabular}

${ }^{a} \mathrm{t}=$ tempo; ${ }^{\mathrm{b}} \mathrm{T}=$ Temperatura; ${ }^{\mathrm{c}}$ Os resultados obtidos com $\mathrm{n}$-heptano devem ser divididos por 5 . ${ }^{\mathrm{d}}$ Os resultados obtidos com azeite de oliva devem ser divididos pelos fatores de redução especificados no Anexo 1 da RE-105/99 (ANVISA, 1999). 


\subsection{Cálculos de migração de elementos e limites máximos permitidos pela legislação}

No método radiométrico, a medição das taxas de contagens do simulante de alimento exposto à migração permite, pelo método comparativo, obter a massa do elemento que migrou da amostra de plástico para o simulante. Tendo a massa total do elemento que migrou e conhecendo a massa do simulante e a área do material polimérico exposta à migração pode-se calcular em termos de massa do elemento que sofreu a migração por unidade de área exposta e por unidade de massa do simulante, ou seja, em unidades de $\mathrm{ng} \mathrm{kg} \mathrm{dm}^{-2}$.

Essa massa de elemento corresponde à migração que ocorreu para $1 \mathrm{~kg}$ de simulante em $1 \mathrm{dm}^{2}$ de área superficial da embalagem.

Para verificar se uma determinada embalagem pode ser utilizada para estocar um determinado alimento é necessário conhecer os valores máximos das concentrações permitidas. Esses valores máximos das concentrações dos elementos que podem migrar para os alimentos são valores dos limites máximos de tolerância (LMT) para contaminantes inorgânicos em alimentos estabelecidos pela ANVISA $(1965,1998)$ dados em $\mathrm{mg}$ do elemento por $\mathrm{kg}$ de alimento.

Uma vez obtidos os valores de migração em massa do elemento por massa do simulante e por área do material exposta à migração, para se obter a concentração, foi adotada a convenção, apresentada por Botrel (1982), em que $1 \mathrm{~kg}$ de alimento ocupa uma área de $600 \mathrm{~cm}^{2}\left(6 \mathrm{dm}^{2}\right)$.

Para os resultados do método convencional seguido de AAS ou INAA, a migração é calculada observando-se que para melhorar a capacidade de detecção, o volume do simulante foi reduzido por meio de concentração após a extração. 


\section{CAPÍTULO 5}

\section{MÉTODOS DE ANÁLISE}

Tendo em vista que no presente trabalho serão utilizados os métodos analíticos de ativação com nêutrons e de espectroscopia de absorção atômica, serão apresentados, a seguir, de maneira bastante resumida, os fundamentos teóricos destas duas técnicas.

\subsection{Análise por ativação neutrônica}

A análise por ativação neutrônica (NAA) se baseia na medição de radioatividade induzida aos elementos da amostra pela sua irradiação com fluxo de nêutrons de um reator nuclear. Neste processo de irradiação, os isótopos estáveis são transformados em isótopos radioativos ou radionuclídeos artificiais.

$\mathrm{Na}$ irradiação, quando um nêutron interage com um núcleo alvo por meio de uma colisão não-elástica, forma-se um núcleo composto num estado excitado. A energia de excitação do núcleo composto é devida à energia de ligação do nêutron com $\mathrm{o}$ núcleo e à energia cinética do nêutron. $O$ núcleo composto, quase que instantaneamente, sofre des-excitação para uma configuração mais estável, por meio da emissão de raios gama "pronto" característicos. Os raios gama pronto servem para identificar e quantificar o elemento e, neste caso, tem-se a análise por ativação por gama pronto (PGA). $O$ tempo de vida do núcleo composto é da ordem de $10^{-16}$ a $10^{-14} \mathrm{~s}$. Em muitos casos, esta nova configuração produz um núcleo radioativo, que também sofre des-excitação por meio da emissão de um ou mais raios gama de decaimento 
característicos, mas a uma razão mais lenta, de acordo com o tempo de meiavida do nuclídeo radioativo.

Esse processo de interação para formação de um nuclídeo radioativo pode ser representado pelo esquema da reação nuclear mostrado na Figura 5.1.

A medição da radiação emitida por ${ }_{Z}^{A+1} X$ permite a análise qualitativa $e$ quantitativa do elemento que deu origem a este radioisótopo. Como cada radionuclídeo decai com uma determinada meia-vida e como a maioria deles emite um ou mais raios gama, a identificação do radioisótopo é feita pela meia-vida e energia dos raios gama.

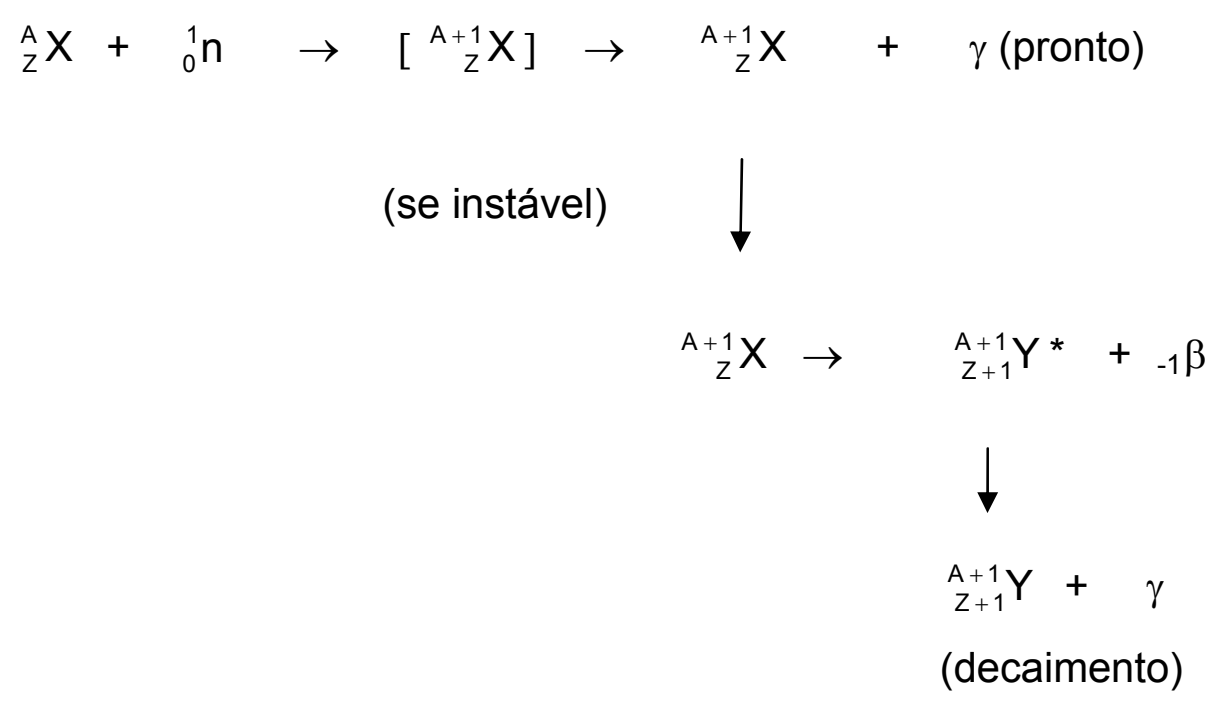

Figura 5.1. Esquema da captura radioativa. 
A atividade em taxas de contagens (A) induzida a um elemento após certo tempo de irradiação é dada por (De Soete et al., 1972):

$$
\mathrm{A}=\frac{\mathrm{z} \phi \sigma \mathrm{Nmf}\left[1-\mathrm{e}^{-0,693 \mathrm{t}_{\mathrm{i}} / \mathrm{t}_{1 / 2}}\right]}{\mathrm{M}}
$$

em que, $\quad A=$ atividade em taxas de contagens; $z=$ coeficiente de detecção ou eficiência do detector; $\phi=$ fluxo de nêutrons, em $\mathrm{n} \mathrm{cm}^{-2} \mathrm{~s}^{-1}$; $\sigma=$ secção de choque, em barns; $N=$ constante de Avogadro; $m=$ massa do

elemento; $f=$ abundância isotópica do nuclídeo alvo; $M=$ massa atômica do elemento; $t_{i}=$ tempo de irradiação; $t_{1 / 2}=$ tempo de meia-vida do radionuclídeo considerado.

\subsubsection{Método comparativo}

A determinação das concentrações dos elementos pode ser feita pelo método comparativo, em que um padrão do elemento de massa conhecida, é irradiado e medido nas mesmas condições da amostra.

Escrevendo a equação (5.1) para amostra e padrão, que foram irradiados e medidos na mesma geometria, e dividindo uma pela outra, tem-se:

$$
\frac{\mathrm{A}_{\mathrm{a}}^{0}}{\mathrm{~A}_{\mathrm{p}}^{0}}=\frac{\mathrm{m}_{\mathrm{a}}}{\mathrm{m}_{\mathrm{p}}}
$$

em que, $\mathrm{A}_{\mathrm{a}}^{0}$ e $\mathrm{A}_{\mathrm{p}}^{0}$ são as taxas de contagens para o tempo de decaimento $\mathrm{t}=0$ e os índices a e $\mathrm{p}$ se referem a amostra e padrão, respectivamente. 
Na prática, a amostra e padrão são medidos para diferentes tempos de decaimento, $t_{d a}$ e $t_{d p}$, respectivamente. Para a correção do tempo de decaimento, aplica-se a relação da lei de decaimento radioativo (Friedlander et al.,1964).

Pela lei do decaimento tem-se $\mathrm{A}=\mathrm{A}_{0} \mathrm{e}^{-0,693 \mathrm{t}_{\mathrm{d}} / \mathrm{t}_{1 / 2}}$, o qual pode ser escrito para o caso da amostra e padrão e substituído na equação (5.2), obtendose a seguinte equação:

$$
\mathrm{m}_{\mathrm{a}}=\frac{\mathrm{m}_{\mathrm{p}} \cdot \mathrm{A}_{\mathrm{a}} \cdot \mathrm{e}^{0,693 \frac{\left(\mathrm{t}_{\mathrm{da}}-\mathrm{t}_{\mathrm{dp}}\right)}{\mathrm{t}_{1 / 2}}}}{\mathrm{~A}_{\mathrm{p}}}
$$

em que, $A_{a}$ e $A_{p}$ são os valores das taxas de contagens da amostra e padrão medidos para diferentes tempos de decaimento, $t_{d a}$ e $t_{d p}$, respectivamente; $m_{a}$ e $m_{p}$ são as massas dos elementos na amostra e no padrão, respectivamente.

Sendo $C_{a}$ a concentração do elemento na amostra $\left(C_{a}=m_{a} / M_{a}\right)$ e substituindo-se na equação (5.3), tem-se a equação (5.4):

$$
C_{a}=\frac{m_{p} \cdot A_{a} \cdot e^{0,693 \frac{\left(t_{d a}-t_{d p}\right)}{t_{1 / 2}}}}{M_{a} A_{p}}
$$

em que, $M_{a}=$ massa total da amostra.

A equação (5.4) é utilizada no cálculo da concentração do elemento numa amostra.

Na prática, o método instrumental consiste de três estágios: irradiação da amostra com nêutrons no reator nuclear, seguida de um período de decaimento e, finalmente, a medição da radioatividade da amostra e do padrão. 
A análise por ativação com nêutrons permite a determinação de cerca de 40 elementos em uma única amostra, dependendo do tipo de matriz. Para uma análise multielementar, os elementos são divididos em grupos, dependendo da meia-vida dos radioisótopos.

Para uma análise completa dos elementos componentes da matriz, em geral, são realizadas duas séries de irradiações:

- de 1 a 5 min sob fluxo de nêutrons térmicos da ordem de $5 \times 10^{11} \mathrm{n} \mathrm{cm}^{-2} \mathrm{~s}^{-1}$ para determinação de elementos: $\mathrm{Al}, \mathrm{Br}, \mathrm{Ca}, \mathrm{Cl}, \mathrm{Cu}, \mathrm{K}, \mathrm{I}, \mathrm{Mn}, \mathrm{Mg}, \mathrm{Na}$, Ti e V e,

- de 8 a $16 \mathrm{~h}$ sob fluxo de nêutrons de $5 \times 10^{12} \mathrm{n} \mathrm{cm}^{-2} \mathrm{~s}^{-1}$ para determinação dos elementos $\mathrm{Ag}, \mathrm{As}, \mathrm{Au}, \mathrm{Ba}, \mathrm{Br}, \mathrm{Ca}, \mathrm{Ce}, \mathrm{Cd}, \mathrm{Co}, \mathrm{Cr}, \mathrm{Cs}, \mathrm{Eu}, \mathrm{Fe}$, $\mathrm{Hf}, \mathrm{Hg}, \mathrm{K}, \mathrm{La}, \mathrm{Lu}, \mathrm{Mo}, \mathrm{Na}, \mathrm{Nd}, \mathrm{Rb}, \mathrm{Sc}, \mathrm{Sb}, \mathrm{Se}, \mathrm{Sm}, \mathrm{Sr}, \mathrm{Tb}, \mathrm{Th}, \mathrm{U}, \mathrm{Yb}, \mathrm{Zn}$ e Zr.

A instrumentação para medir a radiação gama consiste de um detector de Ge hiperpuro conectado a um sistema multianalisador (Multichannel analyserMCA/computador) e sistema eletrônico associado. O tipo de detector, geralmente, utilizado é coaxial que permite medição de raios gama com energias de cerca de $60 \mathrm{keV}$ a 3,0MeV,refrigerado com $\mathrm{N}_{2}$ líquido.

\subsection{Espectroscopia de absorção atômica}

A espectroscopia de absorção atômica (AAS) trata do estudo da absorção da energia radiante nas regiões do visível e ultravioleta. Nessa técnica, a maioria dos átomos está na forma de vapor atômico no estado fundamental e a absorção da radiação provocará uma transição que, geralmente, se considera correspondente à passagem do estado fundamental ao estado excitado de mais baixa energia do átomo neutro (Skoog, 1985; Skoog et al., 2002).

A extensão da absorção que ocorre a essas transições é uma medida da quantidade de átomos do elemento responsável presente na chama, portanto da concentração do elemento na amostra. 


\subsubsection{Aparelhagem}

O equipamento utilizado para a AAS é constituído, basicamente, de uma fonte de radiação, um queimador, um monocromador e de um detetor. Um diagrama básico dessa configuração pode ser observado na Figura 5.2.

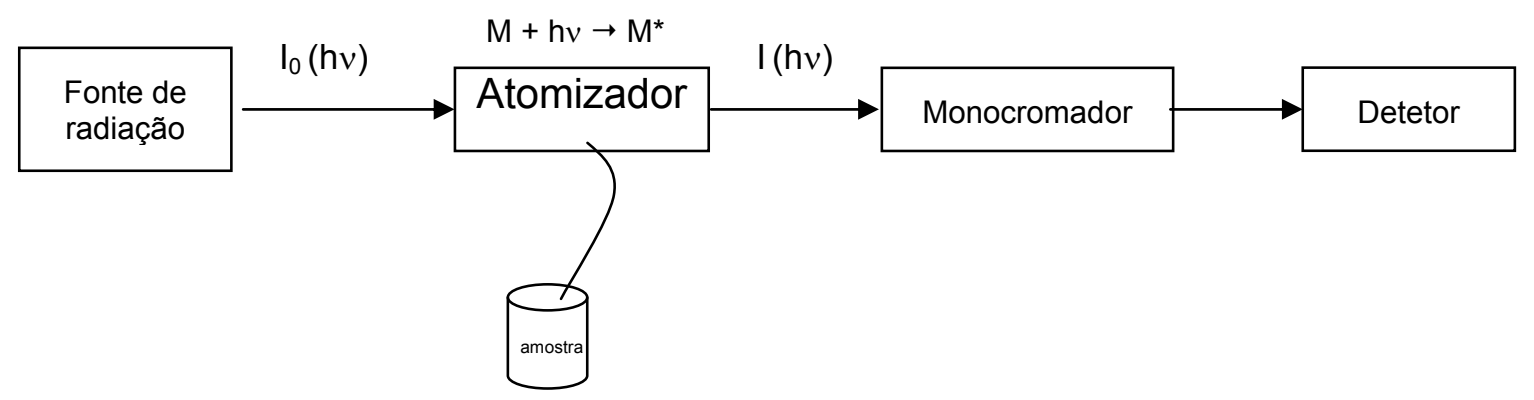

Figura 5.2. Esquema básico de um equipamento de AAS.

\section{Fonte de radiação}

Como as raias em absorção atômica são muito estreitas e as transições são únicas para cada elemento, a fonte deve emitir radiação com intensidade e estabilidade suficientes para permitir medições exatas de absorção. Isso se consegue com lâmpadas de catodo-oco, de descarga de vapor, de multielementos e as de descarga sem eletrodos.

\section{Atomizadores}

Nesta técnica, podem ser utilizados dois tipos de atomizadores: os de chama e os eletrotérmicos. No primeiro, a chama tem as funções de transformar a substância em análise no estado de vapor (vaporização); de converter as espécies em vapor atômico (atomização); excitar o vapor atômico até a emissão das raias espectrais, de forma que a mistura gás combustível/comburente é 
bastante importante para o processo, pois dela depende a temperatura máxima que pode ser fornecida pela chama. Os combustíveis, normalmente utilizados são acetileno, gás natural e hidrogênio e, como comburente, ar, óxido nitroso e oxigênio. Nos atomizadores eletrotérmicos, toda a amostra é atomizada num período de tempo muito curto, resultando numa melhora da sensibilidade. Inicialmente, poucos mililitros da amostra são evaporados e, depois, incinerados numa temperatura mais alta. Após a incineração, há um aumento da temperatura para cerca de 2000 a $3000^{\circ} \mathrm{C}$, ocorrendo a atomização da amostra. Esse processo ocorre dentro de um tubo de grafita.

\section{Etapas de atomização}

A amostra é introduzida no aparelho na forma líquida e para que ocorra a absorção (quantização de energia) é necessário nebulizar e atomizar a amostra.

Quando a solução do elemento em estudo é aspirada para a chama ou para o atomizador eletrotérmico, verifica-se uma série de acontecimentos sucessivos, num curtíssimo intervalo de tempo: a água (ou outro solvente) é vaporizada deixando partículas diminutas do sal que são fundidas e, depois, vaporizadas; uma parte das moléculas gasosas é progressivamente dissociada de modo a originarem átomos neutros; os vapores dos átomos metálicos neutros encontram-se quase na totalidade no estado fundamental e podem, portanto, absorver radiação incidente específica proveniente da fonte de emissão-lâmpada de vapor do metal em análise.

Quando o vapor é iluminado por um feixe de energia radiante apropriado, o átomo no estado fundamental absorve um fóton que é a energia suficiente para saltar para o nível mais próximo de energia $\left(M+h v \rightarrow M^{*}\right)$. Se não houver absorção (ou se for mínima), como é o caso da pulverização do branco, o aparelho deverá ser levado ao zero e toda luz atingirá o detector. 


\section{Interferências}

Como os métodos de espectroscopia de absorção atômica são relativos, as determinações quantitativas só podem ser feitas por comparação com padrões, e, portanto, qualquer comportamento da amostra que seja diferente das soluções padrão pode levar a uma interferência. As interferências podem ser subdivididas em químicas, físicas e espectrais.

Em princípio, as interferências químicas são causadas por conversão não quantitativa da amostra em átomos, devido à dificuldade em fundir e vaporizar o sal ou as espécies químicas são dissociadas de forma incompleta ou, ainda, átomos livres reagem espontaneamente com outros átomos ou radicais próximos e, então, ficam indisponíveis para a absorção, dependendo, portanto, da estequiometria da chama e da afinidade dos átomos para outros existentes na chama. As interferências químicas na chama são, principalmente, provocadas pela formação de óxidos e hidróxidos do metal em análise.

As propriedades físicas da solução que afetam o valor da absorbância lida são devidas, principalmente, à pressão de vapor e à tensão superficial porque esses parâmetros definem o tamanho das gotas. A viscosidade também influencia a velocidade com que o aerossol atinge a chama por aspiração. Portanto, é fundamental que a viscosidade de padrões e das amostras sejam próximas o máximo possível. Em princípio, as interferências físicas podem ser eliminadas diluindo a amostra ou transferindo a matriz para os padrões, o que nem sempre é possível, mesmo usando diferentes métodos de análise.

As interferências espectrais ocorrem quando a absorção ou emissão de uma espécie interferente se sobrepõe ou se aproxima da absorção ou emissão do analito, impossibilitando a resolução pelo monocromador. Algumas das causas de interferências espectrais são os produtos de combustão formados como, por exemplo, dos óxidos refratários formados a partir de elementos contidos na matriz, das espécies orgânicas contidas nas amostras ou dos solventes orgânicos utilizados na diluição. Os métodos mais comumente utilizados em determinações por AAS são os da curva analítica e da adição de padrão, sendo que este último apresenta a vantagem de neutralizar total ou parcialmente as interferências químicas produzidas por efeito de matriz. 


\section{CAPÍTULO 6}

\section{PARTE EXPERIMENTAL}

\subsection{Aquisição de amostras de embalagens para estudo}

No período de agosto a dezembro de 2003, foram comprados 29 produtos alimentícios nacionais, como refrigerantes, águas, condimentos (ketchup, mostarda, maionese), iogurtes, leite, manteiga, margarina e sucos, todos acondicionados em embalagens plásticas de homopolímeros. Essas embalagens adquiridas com seus respectivos alimentos, após o seu consumo, foram utilizadas como corpos-de-prova para o presente trabalho. Na sua maioria, as embalagens eram constituídas dos polímeros poli (tereftalato de etileno), polipropileno e polietileno e foram codificadas de acordo com seu conteúdo.

Na Figura 6.1, está a foto de algumas embalagens analisadas no presente trabalho. As quantidades, códigos e o tipo de polímero das embalagens analisadas são apresentados na Tabela 6.1.

Em 2006, foram também adquiridas cinco amostras de embalagens plásticas de refrigerantes e de água consumidas na Argentina, Portugal e Espanha. Essas embalagens foram também codificadas de acordo com o conteúdo, origem e tipo de polímero, conforme apresentado na Tabela 6.2. 


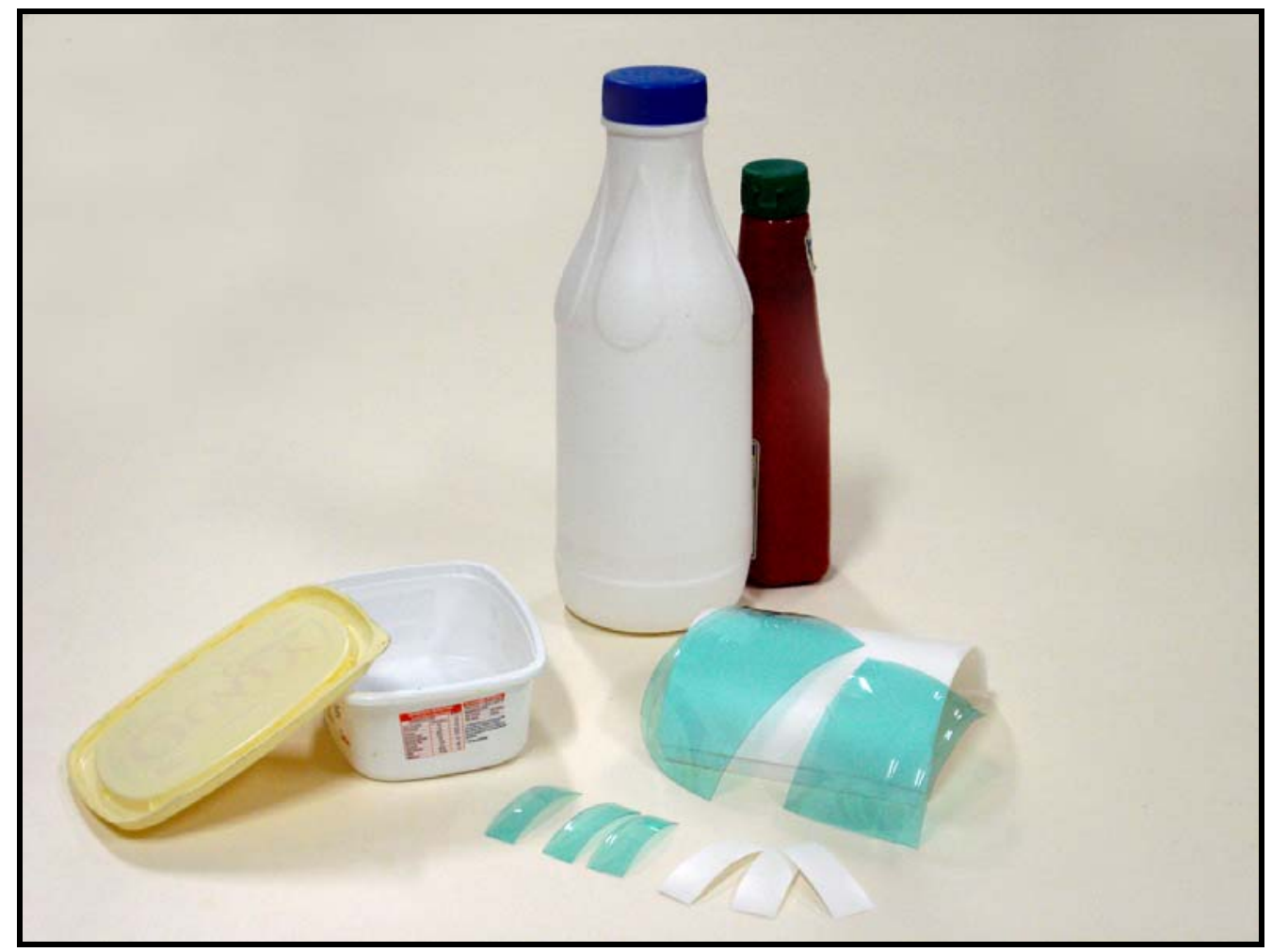

Figura 6.1. Amostras de embalagens de alimentos analisadas.

\subsection{Limpeza e preparação das amostras de embalagens plásticas}

Uma vez adquiridas as amostras de embalagens para estudo, o seu conteúdo foi consumido e os rótulos foram removidos. Essas embalagens foram, primeiramente, lavadas com detergente doméstico e água. Em seguida, as amostras foram cortadas em dimensões de aproximadamente $15 \mathrm{~cm} \times 10 \mathrm{~cm}$, lavadas com água deionizada e, após secagem, foram limpas com hexano p.a., utilizando-se, para isto, chumaços de algodão embebidos com este reagente. 
Tabela 6.1. Dados das embalagens nacionais adquiridas para o presente trabalho e seus respectivos códigos, conteúdo, quantidade de embalagens e tipo de polímero.

\begin{tabular}{|c|c|c|c|}
\hline Código da embalagem & Conteúdo da embalagem & Quantidade de embalagens & Polímero \\
\hline R1, R2, R3, R4, R5, R6, R7, R8 & Refrigerante & 8 & $\mathrm{PET}^{\mathrm{a}}$ \\
\hline S1 & \multirow{2}{*}{ Suco } & 1 & HDPE $^{\mathrm{b}}$ \\
\hline S2 & & 1 & PET \\
\hline AG1, AG2, AG3, AG5, AG6 & \multirow{2}{*}{ Água } & 5 & PET \\
\hline AG4 & & 1 & $\mathrm{PP}^{\mathrm{c}}$ \\
\hline L1, L2, L3, L5, L6 & \multirow{2}{*}{ Leite e derivados } & 5 & HDPE \\
\hline L4 & & 1 & PP \\
\hline G1T, G1P, G2, G3 & Produtos gordurosos & 4 & PP \\
\hline G4 & \multirow{3}{*}{$\begin{array}{l}\text { Produtos aquosos contendo óleo ou } \\
\text { gordura e pH ácido; }\end{array}$} & 1 & PP \\
\hline G5 & & 1 & PET \\
\hline G6, G7 & & 2 & HDPE \\
\hline
\end{tabular}

${ }^{a}$ PET - Poli (tereftalato de etileno); ${ }^{b} \mathrm{HDPE}$ - Polietileno de alta densidade; ${ }^{\mathrm{C} P P}$ - Polipropileno 
Tabela 6.2. Amostras de embalagens de alimentos adquiridas do exterior e seus respectivos códigos, conteúdo, quantidade de embalagens, país de origem e tipo de polímero.

\begin{tabular}{lcccc}
\hline $\begin{array}{l}\text { Código da } \\
\text { embalagem }\end{array}$ & $\begin{array}{c}\text { Conteúdo da } \\
\text { embalagem }\end{array}$ & $\begin{array}{c}\text { Quantidade de } \\
\text { embalagens }\end{array}$ & País de origem & Polímero \\
\hline RA & Refrigerante & 1 & Argentina & PET \\
RP & 1 & Portugal & PET \\
\hline AA & Água & 1 & Argentina & PET \\
AE1 e AE2 & & 2 & Espanha & PET \\
\hline
\end{tabular}

\subsection{Procedimento experimental para determinação de elementos presentes nas embalagens pelo método de análise por ativação com nêutrons}

\subsubsection{Preparação de padrões sintéticos a serem utilizados na análise por ativação com nêutrons}

A partir de soluções padrão estoque de As, Cd, Co, Cr e Sb adquiridas da Spex Certiprep, cujas concentrações certificadas são apresentadas na Tabela 6.3, foram preparadas solução padrão simples de As e outra mista contendo Cd, Co, Cr e Sb. Para preparação destas soluções, foram utilizados balões volumétricos e pipetadores automáticos previamente verificados quanto à sua calibração. As concentrações das soluções preparadas são apresentadas na Tabela 6.4.

A partir das soluções padrão apresentadas na Tabela 6.4, foram preparados padrões sintéticos de As, Cd, Cr, Co e Sb, pipetando-se 50 $\mu \mathrm{L}$ de cada solução padrão sobre tiras de papel filtro Whatman $n^{\circ} 40$ que após a sua secagem, à temperatura ambiente, foram dobradas e colocadas em invólucros de polietileno. 
Tabela 6.3. Soluções padrão de elementos da Spex Certiprep utilizadas no trabalho.

\begin{tabular}{lccc}
\hline Elemento & $\begin{array}{c}\text { Valor certificado } \\
\mathrm{mg} \mathrm{L}^{-1}\end{array}$ & $\begin{array}{c}\text { Incerteza associada } \\
\mathrm{mg} \mathrm{L}^{-1}\end{array}$ & Lote $\mathrm{n}^{\circ}$ \\
\hline As & 1000 & 3,0 & $10-06 \mathrm{AS}$ \\
$\mathrm{Cd}$ & 998,5 & 3,0 & $10-03 \mathrm{CD}$ \\
$\mathrm{Co}$ & 1000 & 3 & $9-156 \mathrm{CO}$ \\
$\mathrm{Cr}$ & 1002,5 & 3 & $9-157 \mathrm{CR}$ \\
$\mathrm{Sb}$ & 1004 & 3,0 & $10-43 \mathrm{SB}$ \\
\hline
\end{tabular}

Tabela 6.4. Soluções padrão preparadas a partir das soluções padrão certificadas da Spex Certiprep

\begin{tabular}{lccc}
\hline $\begin{array}{l}\text { Tipos de } \\
\text { solução padrão }\end{array}$ & $\begin{array}{c}\text { Elementos presentes } \\
\text { na solução padrão }\end{array}$ & $\begin{array}{c}\text { Concentração } \\
\mathrm{mg} \mathrm{L}^{-1}\end{array}$ & $\begin{array}{c}\text { Massas dos } \\
\text { elementos }(\mu \mathrm{g})\end{array}$ \\
\hline Simples & As & 60,0 & 3,000 \\
\hline \multirow{2}{*}{ Mista } & Cd & 199,7 & 9,985 \\
& Co & 5,0 & 0,250 \\
& Cr & 40,1 & 2,005 \\
& Sb & 20,1 & 1,004 \\
\hline
\end{tabular}

\subsubsection{Procedimento da análise por ativação com nêutrons}

As amostras de embalagens para NAA foram submetidas a uma nova limpeza usando solução de hexano p.a., solução de ácido nítrico p.a. diluído e em água purificada no sistema de purificação da Millipore. Essas amostras de plástico foram cortadas em dimensões inferiores a $1,0 \mathrm{~cm} \times 1,0 \mathrm{~cm}$, pesadas em uma balança analítica da marca Mettler com a precisão de $\pm 0,00005 \mathrm{~g}$ e colocadas em invólucros de polietileno. A massa da amostra utilizada foi de cerca de $200 \mathrm{mg}$. Esses invólucros de polietileno foram confeccionados usando uma seladora 
elétrica para plásticos e folhas de polietileno previamente lavadas com solução de ácido nítrico p.a. diluído e água purificada.

Foram utilizados dispositivos de alumínio chamados "coelhos" para irradiação de amostras e padrões no reator nuclear. Em cada dispositivo, foram colocados padrões de elementos e a amostra, todos envoltos separadamente em folhas de alumínio. As irradiações foram realizadas no reator nuclear IEA-R1 por um período de 16 horas e sob um fluxo de nêutrons térmicos de $5 \times 10^{12} \mathrm{n} \mathrm{cm}^{-2} \mathrm{~s}^{-1}$.

Três dias após a irradiação, as amostras e os padrões foram montados em pranchetas (panelinhas) de aço inoxidável para a medição de atividades gama (Figura 6.2). A primeira medição foi efetuada após cerca de cinco dias de decaimento e a segunda após, aproximadamente, dez dias de decaimento sendo que as amostras e os padrões foram medidos na mesma geometria.

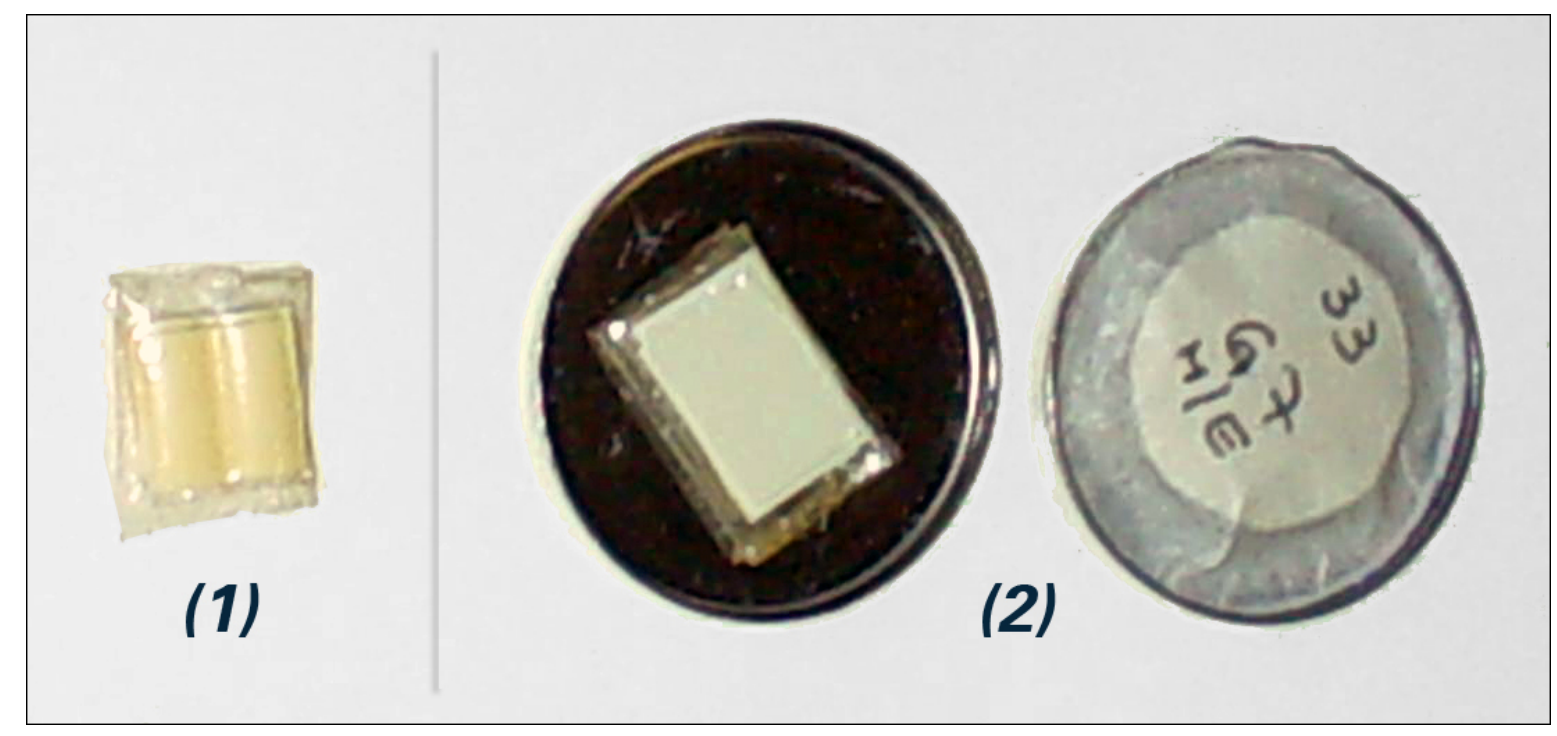

Figura 6.2. Amostra embalada em invólucro de polietileno (1) e montada na prancheta (2). (Diâmetro das pranchetas $=3 \mathrm{~cm}$ ). 
As medições foram realizadas no sistema Canberra, o qual utiliza detector de Ge hiperpuro (modelo GX2020) acoplado a um Processador integrado de sinais modelo 1510 e a placa $\$ 100$, ambos da marca Canberra. A resolução do sistema (FWHM) utilizado foi de $0,80 \mathrm{keV}$ para pico de $121,97 \mathrm{keV}$ de ${ }^{57} \mathrm{Co}$ e $1,80 \mathrm{keV}$ para pico de $1331,57 \mathrm{keV}$ da fonte de ${ }^{60} \mathrm{Co}$. O sistema foi diariamente verificado quanto ao seu funcionamento por meio da medição de uma fonte de ${ }^{57} \mathrm{Co}+{ }^{60} \mathrm{Co}$. Os padrões sintéticos foram medidos por um período de 5400 a 6000 segundos e as amostras de 25000 a 50000 segundos dependendo da meia-vida e da atividade do radioisótopo a ser medido.

Para a aquisição dos espectros, utilizou-se o programa de computação S100 da Canberra e, para processamento dos dados de espectros, o programa VERSAO2, uma nova versão do programa VISPECT2 (Piccot, 1989). Esse programa VERSAO2 nos fornece as energias dos raios gama e as taxas de contagens com seus desvios padrão relativos. A identificação do radioisótopo foi feita pela energia dos raios gama e meia-vida e o cálculo das concentrações foi feito pelo método comparativo de análise por ativação com o programa "Espectro", o qual utiliza a equação (5.4) no seu cálculo. Na Tabela 6.5, encontram-se os radioisótopos utilizados neste trabalho. O esquema geral do procedimento da NAA pode ser observado na Figura 6.3.

Tabela 6.5. Radioisótopos medidos com suas respectivas energias de raios gama e meias-vidas (IAEA, 1990).

\begin{tabular}{lccc}
\hline Elemento & Radioisótopo medido & $\mathrm{E} \gamma(\mathrm{keV})$ & Tempo de meia-vida \\
\hline As & ${ }^{76} \mathrm{As}$ & 559,10 & 26,32 horas \\
$\mathrm{Cd}$ & ${ }^{115} \mathrm{Cd}$ & $336,26 / 527,91$ & 53,46 horas \\
$\mathrm{Co}$ & ${ }^{60} \mathrm{Co}$ & $1173,24 / 1332,50$ & 5,27 anos \\
$\mathrm{Cr}$ & ${ }^{51} \mathrm{Cr}$ & 320,08 & 27,70 dias \\
$\mathrm{Sb}$ & ${ }^{122} \mathrm{Sb}$ & 564,24 & 2,70 dias \\
$\mathrm{Sb}$ & ${ }^{124} \mathrm{Sb}$ & 1690,98 & 60,20 dias \\
\hline
\end{tabular}




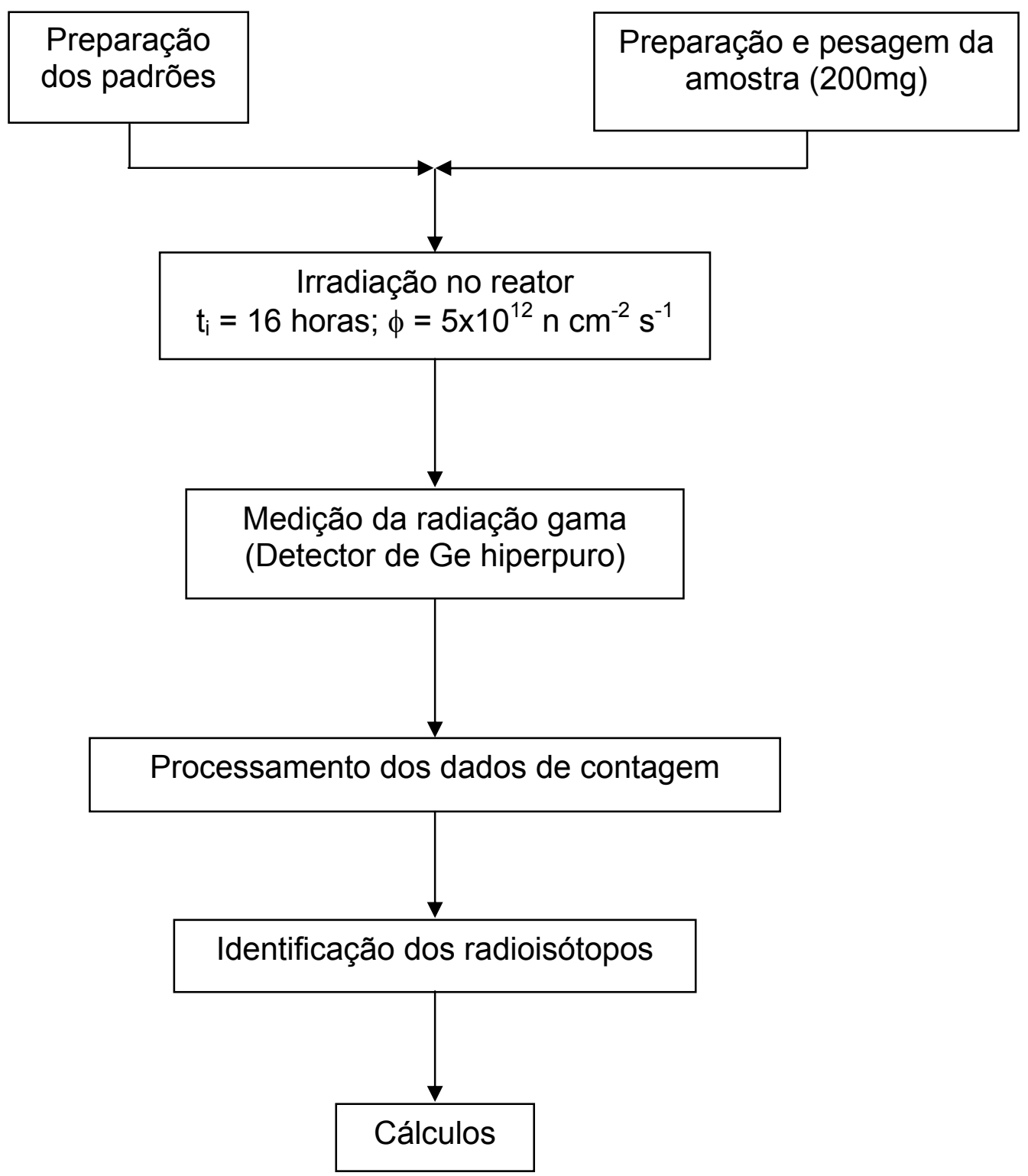

Figura 6.3. Esquema geral do procedimento da NAA. 


\subsubsection{Análise de materiais de referência certificados}

Para avaliar a exatidão e a precisão dos resultados da NAA, foram analisados os materiais de referência certificados IMEP-10 trace elements in Polyethylene e BCR-681 trace elements in Polyethylene (low level) ambos do Institute for Reference Materials and Measurements (IRMM, 1993 e 2000) da Bélgica, MPH-2 Mixed Polish Herbs do Institute of Nuclear Chemistry and Technology (INCT, 2002) da Polônia e MESS-2 Marine Sediment for trace metals and other constituents do National Research Council Canadá (NRCC, 1997). Para as análises destes materiais, foram pesados em invólucros de polietileno cerca de $200 \mathrm{mg}$ de cada material de referência e irradiados junto com as amostras.

\subsection{Procedimento radiométrico para avaliação da migração dos elementos do plástico para o seu conteúdo ou para os simulantes de alimentos}

$\mathrm{Na}$ determinação da migração dos elementos, foram selecionadas amostras de embalagens plásticas apresentando superfícies regulares ou sem riscos. A área de cada corpo-de-prova de plástico ou embalagem submetido ao teste de migração foi de $1,5 \mathrm{~cm} \times 4,5 \mathrm{~cm}$. Utilizaram-se três corpos-de-prova de cada amostra, em cada determinação, sendo que a área total a ser exposta à migração foi de $40,5 \mathrm{~cm}^{2}$. Essa área foi escolhida de modo a satisfazer as normas da ANVISA, isto é, conforme descrito no Capítulo 4 deste trabalho. Esses corposde-prova colocados em invólucros de polietileno foram irradiados no reator nuclear em um dispositivo de alumínio junto com os padrões sintéticos de elementos. Esses padrões sintéticos foram preparados conforme descrito no item 6.3.1. No caso, essas tiras de padrões de elementos foram dobradas nas mesmas dimensões dos corpos-de-prova, conforme apresentado na Figura 6.4 para se proceder, na mesma geometria, à irradiação da amostra e padrão. Os padrões e as amostras envoltos em alumínio foram colocados em um dispositivo 
de alumínio ("coelho") para irradiação no reator nuclear por 16 horas e sob fluxo de nêutrons térmicos de $5 \times 10^{12} \mathrm{n} \mathrm{cm}^{-2} \mathrm{~s}^{-1}$. Verificou-se que os plásticos resistiram a essa condição de irradiação, não ocorrendo nenhuma deformação. Houve apenas uma leve mudança de coloração com a irradiação.

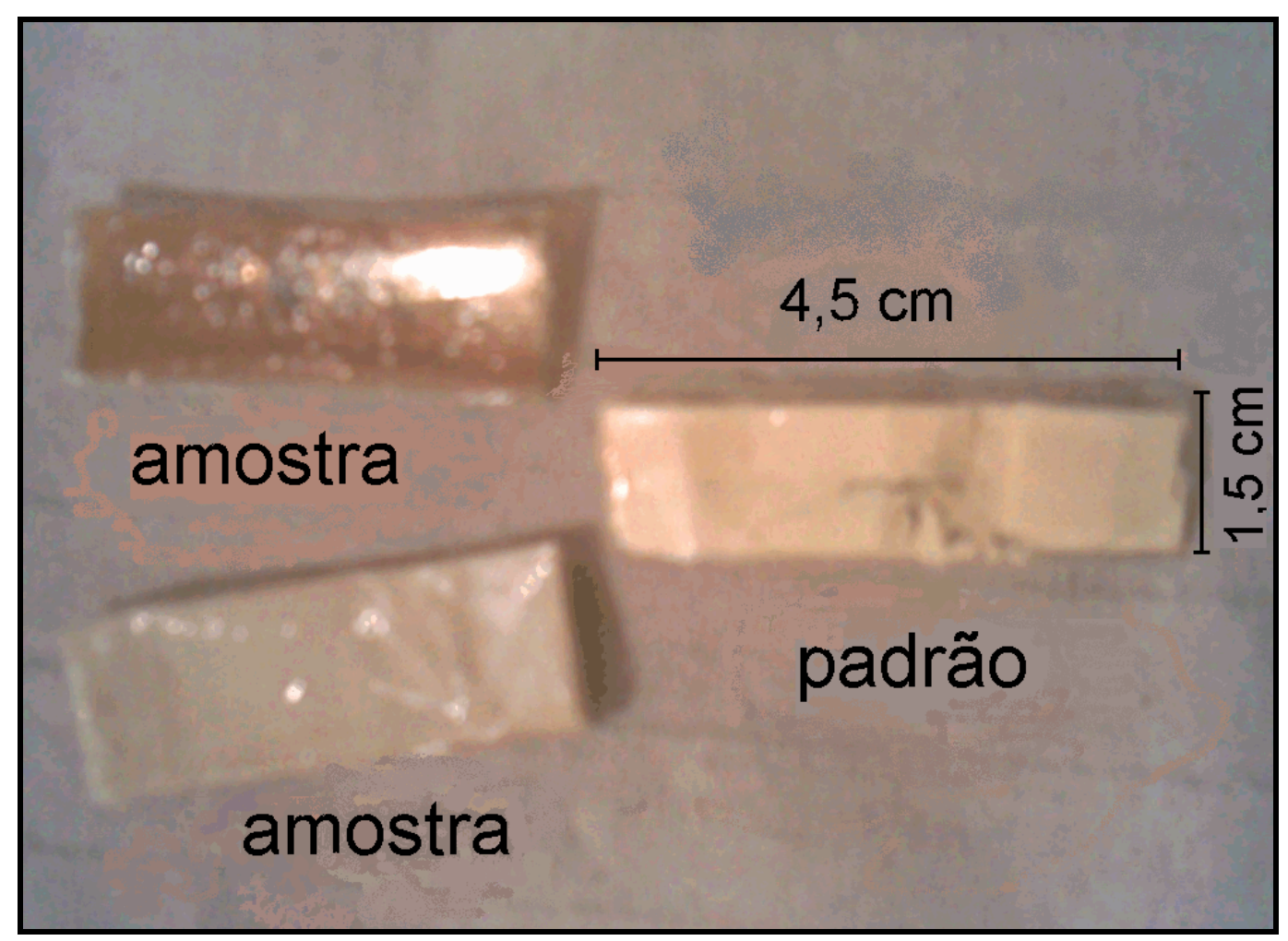

Figura 6.4. Foto do padrão e corpo-de-prova (amostra).

Após cinco dias de decaimento, as amostras de plástico irradiadas foram removidas do invólucro de polietileno e imersas em $30 \mathrm{~mL}$ de simulante de alimento colocados em um frasco de vidro (Figura 6.5). A escolha do simulante $e$ das condições da migração foram baseadas nas recomendações da ANVISA (1999), de acordo com o tipo de alimento contido na embalagem. O tempo de migração para alimentos analisados com os simulantes do tipo $A$ ou $B$ foi de 10 dias a uma temperatura de $40^{\circ} \mathrm{C}$. No caso de simulante do tipo $\mathrm{D}$ (n-heptano), o tempo de migração foi de 30 minutos e a temperatura foi de $20^{\circ} \mathrm{C}$. A massa da solução simulante foi obtida por meio da pesagem na balança Modelo BG2000 da Gehaka. 
Decorrido o tempo de exposição estabelecido, os corpos-de-prova foram retirados do simulante e descartados. O simulante foi transferido para um frasco de polipropileno e, a seguir, no caso do simulante $B$ (solução de ácido acético a 3\%), ele foi neutralizado com solução de $\mathrm{NaOH} 1 \mathrm{M}$ para evitar a realização da medição de uma solução ácida. Também os frascos de polipropileno foram limpos externamente e a tampa vedada com parafilme para evitar a eventual contaminação do detector de Ge.

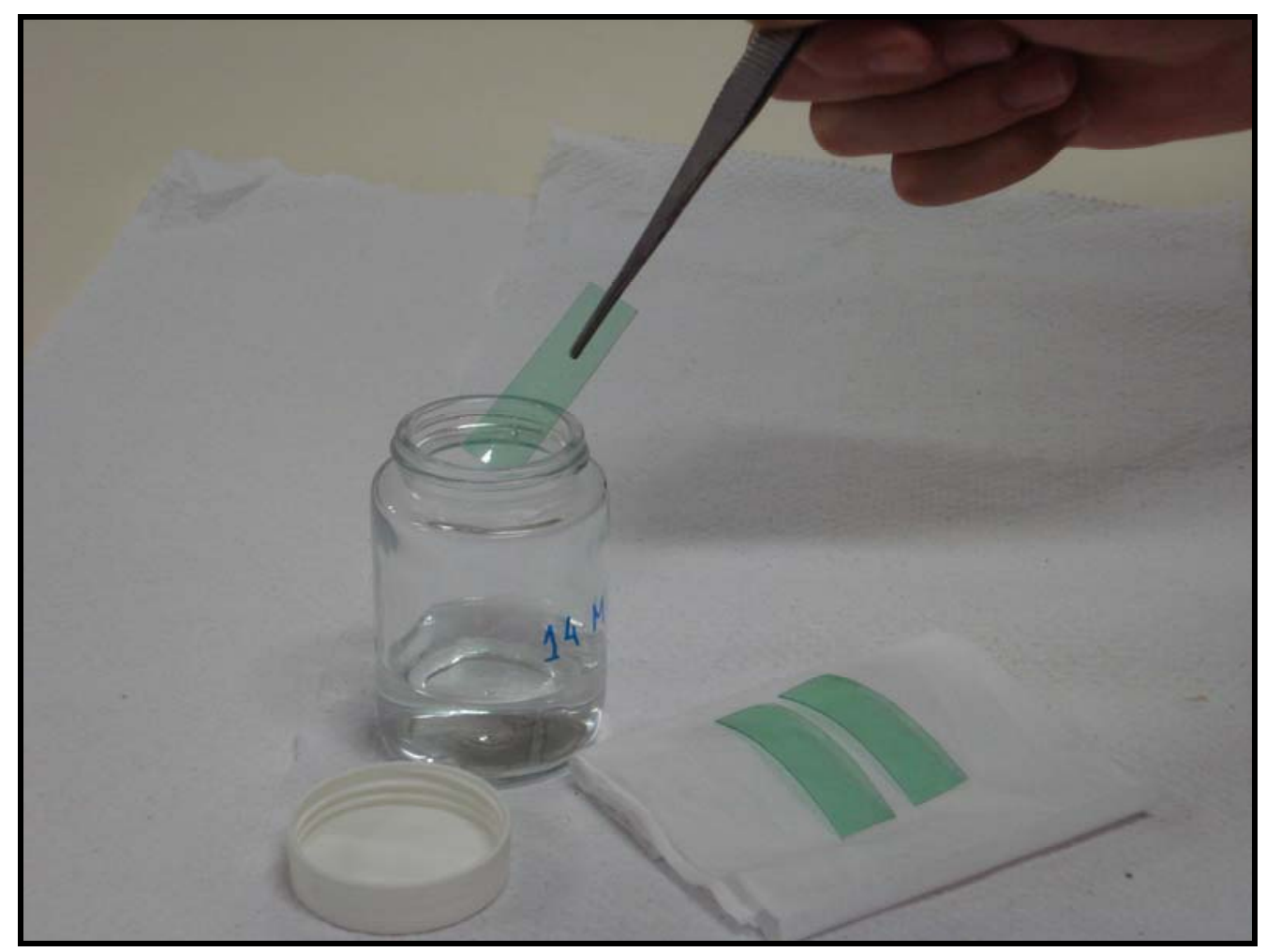

Figura 6.5. Foto da amostra de embalagem irradiada a ser imersa no simulante de alimento.

Os padrões dos elementos irradiados em tiras de papel de filtro foram transferidos para um béquer de capacidade $100 \mathrm{~mL}$, com $100 \mu \mathrm{L}$ de uma solução de carregador contendo $200 \mu \mathrm{g} \mathrm{mL}^{-1}$ de cada um dos elementos As, Cd, Cr, Co e Sb e dissolvidos com algumas gotas de $\mathrm{HNO}_{3}$ diluído. Essa solução de carregador foi utilizada para evitar perda pela adsorção dos elementos químicos dos padrões 
nas superfícies das paredes dos béqueres durante a dissolução da tira de papel de filtro.

As soluções resultantes da dissolução da tira de papel foram transferidas para frascos de polipropileno e os seus volumes foram completados para $30 \mathrm{~mL}$. Dessa maneira, os padrões foram obtidos na mesma geometria das amostras de simulante de alimento. Os tempos de contagem da amostra e do padrão foram de 50000 e 15000s, respectivamente. Na Figura 6.6, pode ser observado o esquema geral do procedimento da análise radiométrica para a determinação da migração.

O cálculo da migração em unidades da massa do elemento que migrou do plástico para o simulante por área do corpo-de-prova exposto a migração foi efetuado por meio da equação 6.1 , derivada da equação 5.4 :

Erro! Indicador não definido.

$$
\mathrm{m}_{\mathrm{i}}=\frac{\mathrm{m}_{\mathrm{p}} \cdot \mathrm{A}_{\mathrm{a}} \cdot \mathrm{e}^{0,693 \frac{\left(\mathrm{t}_{\mathrm{dd}}-\mathrm{t}_{\mathrm{dp}}\right)}{\mathrm{t}_{1 / 2}}}}{\mathrm{~A}_{\mathrm{p}} \cdot \mathrm{A} \cdot \mathrm{M}_{\mathrm{s}}}
$$

em que, $m_{i}$ é a massa do elemento que migrou por área do corpo-de-prova da embalagem exposta a migração (A) e por massa do simulante $\left(\mathrm{M}_{\mathrm{s}}\right)$.

Desta forma, os resultados de migração serão expressos em massa do elemento que migrou por massa do simulante e por área da embalagem exposta à migração, isto é, em $\mu \mathrm{g} \mathrm{dm} \mathrm{mg}^{-2}$. Para o cálculo da migração do elemento Co, foi levada em consideração a contribuição devida à atividade de ${ }^{60} \mathrm{Co}$ da radiação de fundo (background). As contagens da radiação de fundo do equipamento indicaram uma baixa taxa de contagens de ${ }^{60} \mathrm{Co}$, além das atividades dos radioisótopos naturais da série do urânio. 


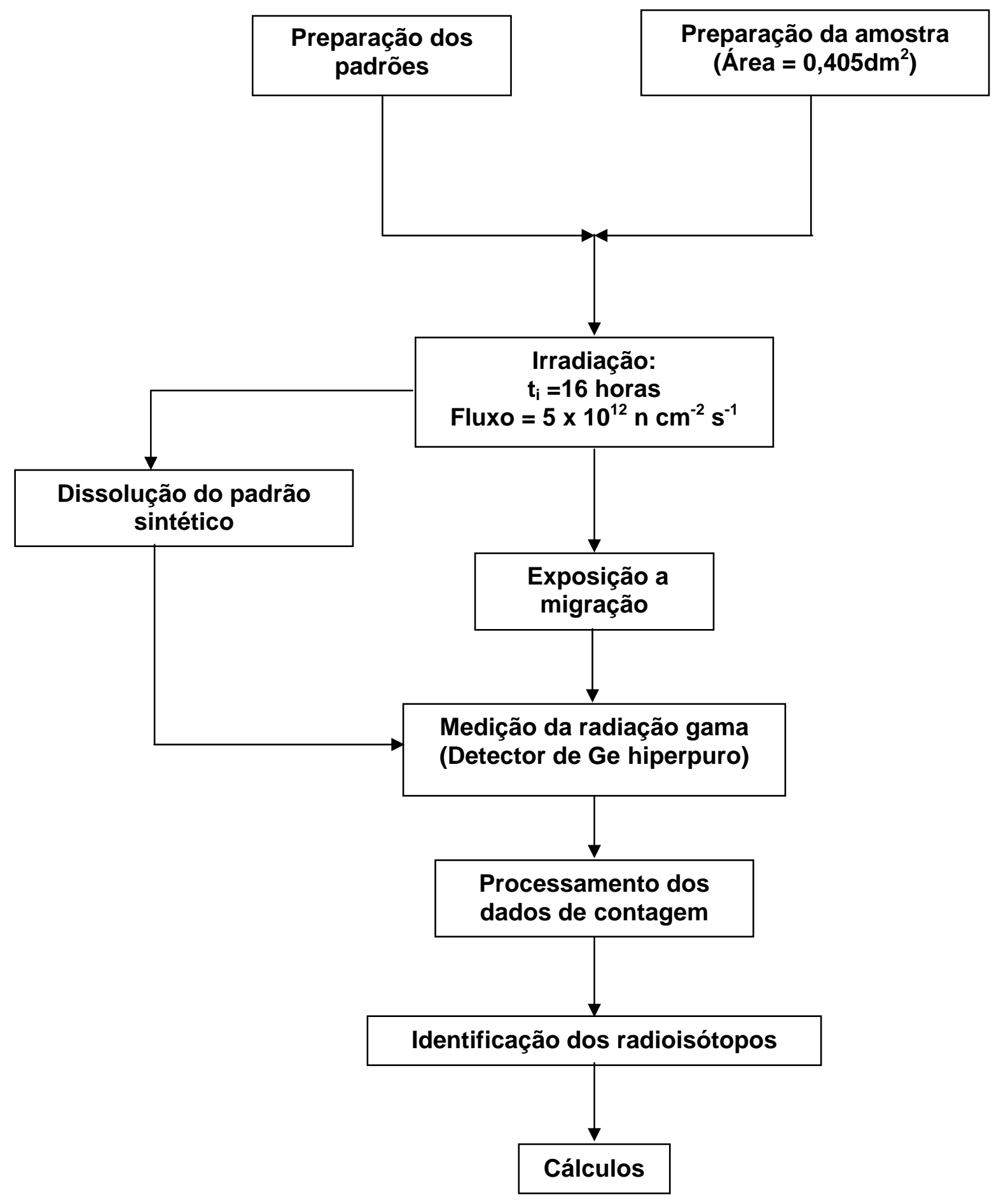

Figura 6.6. Esquema do procedimento para determinação da migração pelo método radiométrico. 


\subsection{Determinação de limite de detecção da migração pelo método radiométrico}

O limite de deteç̧ão (LD) para a determinação da migração pelo método radiométrico foi obtido de acordo com o critério de Currie (1968) para se ter uma idéia da capacidade de detecção desta técnica.

Para avaliar esse limite segundo esse critério, primeiramente, foi necessário calcular o valor do branco analítico ou da radiação de fundo, "background" (BG), o qual foi obtido diretamente de dados de saída emitidos pelo programa VERSAO2, para o fotopico do radioisótopo de interesse. Quando o fotopico não foi detectado pelo programa, repetiu-se a medição da amostra, sobrepondo a esta o padrão de elemento de interesse de baixa atividade, para verificar o menor sinal detectável.

Dessa forma, identificou-se o pico e calculou-se o BG. Com o valor de BG, utilizando-se a equação 6.2 (Currie, 1968), calculou-se o LD.

$$
\mathrm{LD}=2,71+4,65 \sqrt{\mathrm{BG}}
$$

Tendo o valor de LD e o tempo vivo de medição (LT), calculou-se a taxa de contagens (TC) correspondente à massa mínima detectável, em contagens por segundo, conforme a equação (6.3).

$$
\mathrm{TC}=\frac{\mathrm{LD}}{\mathrm{LT}}
$$

Dispondo do valor de TC, utilizando-se a equação (6.1), foi calculada a migração correspondente à massa mínima detectável (limite de detecção). 


\subsection{Procedimento para a determinação da migração pelo método convencional}

Os procedimentos de limpeza das amostras ou corpos-de-prova, preparação das soluções, exposição à migração e da evaporação das soluções para pré-concentração foram efetuados no Laboratório de Análises Químicas da Escola SENAI Fundação Zerrenner, São Paulo, Capital.

As análises por AAS foram realizadas no Laboratório de Meio Ambiente da Escola SENAI Mario Amato, em São Bernardo do Campo, São Paulo e as análises por NAA no Laboratório de Análises por Ativação Neutrônica do IPENCNEN-SP.

As amostras de embalagens limpas e secas foram cortadas em formas de quadrados ou retângulos, em número suficiente para que a soma das áreas para exposição à migração totalizasse $600 \mathrm{~cm}^{2}$. Todos os reagentes utilizados para o preparo dos simulantes de alimento foram de grau p.a e a água utilizada foi aquela denominada MilliQ purificada no aparelho da Millipore.

De acordo com a resolução $n^{\circ}$ 105/99 da ANVISA (1999), utilizou-se um volume de $1000 \mathrm{~mL}$ de simulante para que a relação área de contato/volume ficasse compreendida entre 0,5 a $2 \mathrm{~cm}^{2} \mathrm{~mL}^{-1}$. Essa solução foi colocada em béquer de $2000 \mathrm{~mL}$.

Os corpos-de-prova foram imersos no simulante contido no béquer, o qual foi coberto com vidro de relógio e colocado numa estufa com temperatura controlada a $40^{\circ} \mathrm{C}$ por um período de 10 dias. Foi efetuada uma análise em branco, nas mesmas condições utilizadas para o caso da amostra. 
Decorrido o tempo de exposição, as amostras foram retiradas do béquer. As soluções que continham as amostras e a solução do branco foram evaporadas em banho-maria e, em seguida, levadas à estufa por 1 hora a $105^{\circ} \mathrm{C}$. Os resíduos obtidos dessa evaporação das soluções foram dissolvidos com ácido nítrico concentrado e transferidos para balões de $10 \mathrm{~mL}$, cujos volumes foram completados com água MilliQ. As soluções resultantes foram analisadas por espectroscopia de absorção atômica de chama, de forno de grafita e análise por ativação com nêutrons (NAA).

Para NAA, 400 $\mu \mathrm{L}$ de cada uma das soluções foram pipetados em tiras de papel Whatman $n^{\circ} 40$. Após a secagem, estas tiras foram acondicionadas em invólucros de polietileno e irradiadas no reator nuclear IEA-R1, juntamente com padrões sintéticos dos elementos, por um período de 16 horas e sob um fluxo de nêutrons térmicos de $5 \times 10^{12} \mathrm{n} \mathrm{cm}^{-2} \mathrm{~s}^{-1}$.

Tendo o volume do simulante inicial utilizado na migração e o volume resultante na pré-concentração para análise por AAS e NAA, determinou-se a massa de elemento extraído por $1000 \mathrm{~mL}$, ou seja, $1 \mathrm{~kg}$ de simulante, considerando a densidade do simulante como sendo $1 \mathrm{~kg} \mathrm{~L}^{-1}$. Para calcular a migração do elemento por área da embalagem exposta à migração, foi considerado que $1 \mathrm{~kg}$ de alimento ocupa uma área de $600 \mathrm{~cm}^{2}$ no acondicionamento numa embalagem, adotando a convenção de Botrel (1982). O esquema do procedimento para determinação da migração pelo método convencional é mostrado na Figura 6.7. 


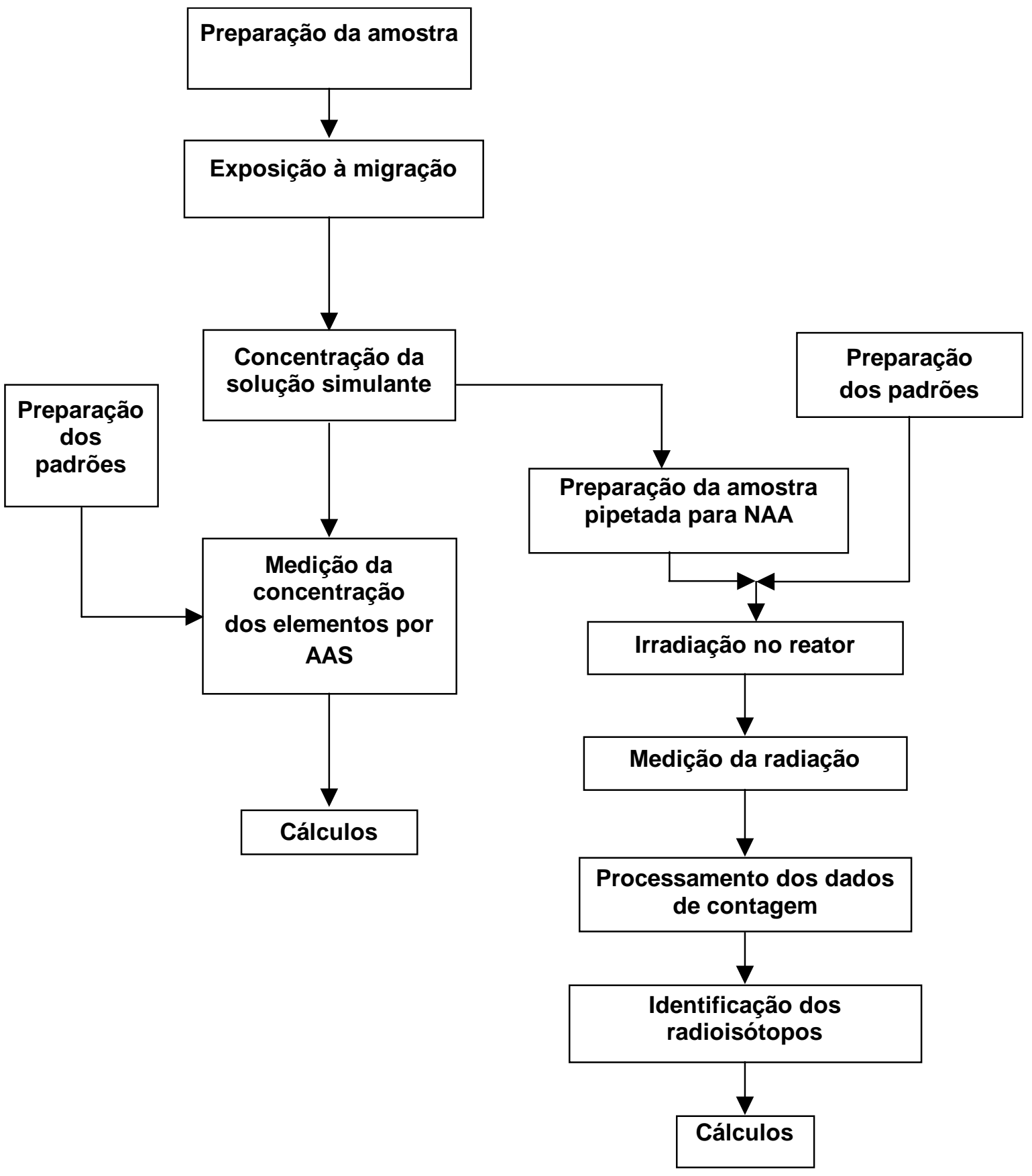

Figura 6.7. Esquema do procedimento para determinação da migração pelo método convencional seguido de AAS e NAA. 


\subsubsection{Procedimento utilizado para determinação da migração de elementos em material de referência certificado de polietileno}

Devido a não disponibilidade de uma embalagem contendo os elementos tóxicos de interesse para o estudo da migração, resolveu-se determinar a migração de um material de referência certificado de polietileno adquirido para uso na validação dos resultados das concentrações de elementos.

Esse material de referência certificado utilizado para avaliação da migração, foi o material BCR-681 trace elements in Polyethylene (low level) do Institute for Reference Materials and Measurements (IRMM, 2000), cuja amostra está na forma de grânulos. A composição dos elementos tóxicos $\mathrm{As}$, $\mathrm{Cd}$ e $\mathrm{Cr}$, desse material, segundo o seu certificado (IRMM, 2000), é a seguinte, Tabela 6.6:

Tabela 6.6. Valores certificados de concentração de elementos no material de referência BCR-681 (IRMM, 2000).

\begin{tabular}{lc}
\hline Elemento & $\begin{array}{c}\text { Fração mássica } \\
\left(\mathrm{mg} \mathrm{kg}^{-1}\right)\end{array}$ \\
\hline As & $3,93 \pm 0,15$ \\
Cd & $21,7 \pm 0,7$ \\
Cr & $17,7 \pm 0,6$ \\
\hline
\end{tabular}

Como esse material de referência certificado de polietileno se apresentava na forma de grânulos e não sendo possível obter a área superficial a ser exposta, a migração dos elementos foi determinada usando uma massa de $1,67815 \mathrm{~g}$ de material de referência e $25 \mathrm{~mL}$ da solução simulante de ácido acético a $3 \%$. O tempo de exposição à migração foi de 10 dias a $40^{\circ} \mathrm{C}$.

Na primeira etapa, foi feita a determinação da migração pelo método convencional, conforme descrito no item 6.6 deste Capítulo, e a análise dos migrantes na solução simulante foi feita pela técnica de AAS. 
A seguir, essa amostra de material de referência certificado utilizada na obtenção da migração pelo método convencional, foi irradiada no reator nuclear para determinação da migração pelo método radiométrico.

\subsection{Procedimento utilizado na avaliação dos efeitos da irradiação com nêutrons nas embalagens plásticas}

Esse estudo foi realizado aplicando a espectroscopia na região do infravermelho por transformada de Fourier (FTIR) e a calorimetria exploratória diferencial (DSC) em amostras de embalagens irradiadas e não irradiadas. As análises por FTIR foram realizadas no Laboratório de Análise Instrumental e as de DSC no Laboratório de Ensaios em Plástico, ambos da Escola SENAI Mario Amato e as irradiações das embalagens com nêutrons foram realizadas no reator nuclear de pesquisa IEA-R1, do IPEN, sob fluxo de nêutrons térmicos de $5 \times 10^{12} \mathrm{n} \mathrm{cm}^{-2} \mathrm{~s}^{-1}$ para os diferentes tempos de irradiação de 3 minutos e de 16 horas (960 minutos).

A análise dos polímeros irradiados por FTIR e DSC foi efetuada após 10 meses de decaimento para evitar o manuseio do material radioativo. As análises por FTIR e DSC puderam ser realizadas somente nas embalagens que apresentaram baixa atividade gama dos radioisótopos. Na análise por FTIR, foram preparadas pastilhas de $\mathrm{KBr}$ com as amostras irradiadas e não irradiadas. Foi utilizado um espectrômetro de FTIR da marca Nicolet modelo Magna IR 550 series II. As análises de DSC foram efetuadas em calorímetro da marca Seiko EXC STAR 6200. 


\section{CAPÍTULO 7}

\section{RESULTADOS E DISCUSSÃO}

Os resultados e a discussão serão apresentados neste Capítulo na seguinte seqüência:

- análise elementar das embalagens plásticas aplicando o método de NAA;

- determinação da migração pelo método radiométrico;

- determinação da migração pelo método convencional;

- identificação dos polímeros em amostras de embalagens irradiadas.

7.1 Análise elementar de embalagens plásticas pelo método de análise por ativação com nêutrons

\subsubsection{Análise dos materiais de referência certificados}

Como foi descrito na parte experimental, para o controle de qualidade dos resultados das análises de embalagens plásticas com relação à exatidão e precisão, foram analisados os materiais de referência certificados: IMEP-10 Polyethylene e BCR-681 Polyethylene ambos do Institute for Reference Materials and Measurements (IRMM, 1993 e 2000) da Bélgica, Mixed Polish Herbs MPH-2 do Institute of Nuclear Chemistry and Technology (INCT,2002) da Polônia e Marine Sediment MESS-2 do National Research Council (NRCC, 1997) do Canadá. 
$\mathrm{Na}$ Tabela 7.1, são apresentados os resultados de As, Cd, Co, Cr e Sb obtidos nos materiais de referência, juntamente com os valores do certificado para comparação. Esses resultados indicam, para a maioria dos elementos, uma boa concordância com os valores certificados com porcentagens de erros relativos inferiores a $13,5 \%$. O Co no material Mixed Polish Herbs MPH-2 apresentou $16,7 \%$ de erro relativo devido, provavelmente, ao seu baixo teor na amostra. Os resultados apresentaram boa precisão com desvios padrão relativos variando de 0,5 a 5,9\%. Segundo Brito et al. (2003) a precisão do processo analítico depende do nível de concentração do elemento e como os elementos determinados apresentaram concentrações da ordem de $\mu \mathrm{g} \mathrm{g}^{-1}$ é aceitável um desvio padrão relativo até $16 \%$.

Para analisar os resultados dos materiais de referência com relação à exatidão, calculou-se também, a diferença padronizada ou valor de $z_{i}$ score (Bode, 1996), usando a seguinte equação:

$$
z_{i}=\frac{C_{i}-C_{r e f, i}}{\sqrt{\sigma_{i}^{2}+\sigma_{r e f, i}^{2}}}
$$

em que, $\mathrm{C}_{\mathrm{i}}=$ concentração do elemento $\mathrm{i}$ obtida no trabalho; $\mathrm{C}_{\text {ref }, \mathrm{i}}=$ concentração no certificado ou de consenso para o elemento $\mathrm{i}$; $\sigma_{\mathrm{i}}=$ incerteza da concentração obtida para o elemento $\mathrm{i} ; \sigma_{\mathrm{ref}, \mathrm{i}}=$ incerteza da concentração do valor certificado para o elemento i.

Os resultados dos valores de $z_{i}$ score obtidos, apresentados na Tabela 7.1, variaram entre $-2,85 \mathrm{e}+1,40$, isto é, $-3<z_{i}<+3$, indicando que os dados obtidos são satisfatórios e estão dentro das faixas dos valores certificados a um nível de confiança de 99\%. 
Tabela 7.1. Concentrações de elementos obtidos nos materiais de referência Polyethylene IMEP-10 e BCR-681, Marine Sediment MESS-2 e Mixed Polish Herbs MPH-2 (IRMM, 1993 e 2000; NRCC, 1997; INCT, 2002).

\begin{tabular}{|c|c|c|c|c|c|c|c|c|}
\hline \multirow{2}{*}{ Elemento } & \multirow{2}{*}{ Material de referência } & \multirow{2}{*}{ unidade } & \multirow{2}{*}{$\mathrm{n}^{\mathrm{a}}$} & \multicolumn{4}{|c|}{ Este Trabalho } & \multirow{2}{*}{$\begin{array}{l}\text { Valores dos } \\
\text { certificados }\end{array}$} \\
\hline & & & & $x \pm D P$ & $E_{r}{ }^{b}, \%$ & $\mathrm{DPR}^{\mathrm{c}}, \%$ & Valor $z_{i}$ score & \\
\hline \multirow{4}{*}{ As } & IMEP 10 & $\mu g^{-1}$ & 2 & $7,97 \pm 0,09$ & - & 1,1 & - & $(9,61 \pm 0,57)^{d}$ \\
\hline & BCR-681 & $\mu g^{-1}$ & 7 & $3,4 \pm 0,2$ & 13,5 & 5,9 & $-2,12$ & $3,93 \pm 0,15$ \\
\hline & MESS-2 & $\mu g g^{-1}$ & 5 & $21,0 \pm 0,5$ & 1,4 & 2,4 & 0,32 & $20,7 \pm 0,8$ \\
\hline & MPH-2 & $\mathrm{ng} \mathrm{g}^{-1}$ & 5 & $196 \pm 7$ & 2,6 & 3,6 & 0,21 & $191 \pm 23$ \\
\hline \multirow{2}{*}{$\mathrm{Cd}$} & IMEP 10 & $\mu g^{-1}$ & 2 & $113 \pm 2$ & 5,6 & 1,8 & $-1,01$ & $119,7 \pm 6,3$ \\
\hline & BCR-681 & $\mu g^{-1}$ & 7 & $21,6 \pm 0,1$ & 0,5 & 0,5 & $-0,14$ & $21,7 \pm 0,7$ \\
\hline \multirow{2}{*}{ Co } & MPH-2 & $\mathrm{ng} \mathrm{g}^{-1}$ & 5 & $245 \pm 2$ & 16,7 & 0,8 & 1,40 & $210 \pm 25$ \\
\hline & MESS-2 & $\mu g^{-1}$ & 5 & $13,5 \pm 0,2$ & 2,2 & 1,5 & $-0,21$ & $13,8 \pm 1,4$ \\
\hline \multirow{4}{*}{$\mathrm{Cr}$} & IMEP 10 & $\mu g^{-1}$ & 2 & $95 \pm 3$ & 5,8 & 3,2 & $-0,92$ & $100,9 \pm 5,7$ \\
\hline & BCR-681 & $\mu g g^{-1}$ & 7 & $15,9 \pm 0,2$ & 10,2 & 1,2 & $-2,85$ & $17,7 \pm 0,6$ \\
\hline & MPH-2 & $\mu g^{-1}$ & 5 & $1,81 \pm 0,04$ & 7,1 & 2,2 & 0,88 & $1,69 \pm 0,13$ \\
\hline & MESS-2 & $\mu g g^{-1}$ & 5 & $104 \pm 2$ & 1,9 & 1,9 & $-0,24$ & $106 \pm 8$ \\
\hline $\mathrm{Sb}$ & MPH-2 & $\mathrm{ng} \mathrm{g}^{-1}$ & 5 & $64 \pm 1$ & 2,3 & 1,6 & $-0,16$ & $65,5 \pm 9,1$ \\
\hline
\end{tabular}

$\overline{\mathrm{a}} \mathrm{n}=$ número de determinações; ${ }^{\mathrm{b}} \mathrm{E}_{\mathrm{r}}=$ erro relativo percentual; ${ }^{\mathrm{c}} \mathrm{DPR}=$ Desvio padrão relativo; ${ }^{\mathrm{d}}(\mathrm{l})=$ Valor informativo. 


\subsubsection{Análise das amostras de embalagem}

$\mathrm{Na}$ Tabela 7.2, são apresentados os resultados das análises de embalagens de refrigerantes e de águas e, na Tabela 7.3, os resultados obtidos para as embalagens de sucos, leite, derivados de leite, alimentos aquosos contendo óleo ou gordura e de produtos gordurosos. Nas embalagens cujos elementos não foram detectados são apresentados, nessas Tabelas, os valores dos limites de detecção. Os resultados dessas Tabelas indicaram a presença de Co e Sb em todas as amostras, com exceção em uma embalagem de produto gorduroso, G7, na qual não foi detectado o $\mathrm{Sb}$. Os maiores valores desses elementos foram os das embalagens de refrigerante nacionais (PET).

A presença de Co e Sb, nas embalagens plásticas, se deve provavelmente ao uso de catalisadores no processo de obtenção dos polímeros (Dias, 1988; Thompson et al., 1997). Para o caso do Sb, este elemento pode ser originado do catalisador trióxido de antimônio $\left(\mathrm{Sb}_{2} \mathrm{O}_{3}\right)$ utilizado, principalmente, na síntese do PET (Shotyk et al., 2006; Shotyk e Krachler, 2007). Como o Sb é considerado um elemento tóxico, se torna de grande interesse avaliar a sua migração para o conteúdo de embalagens.

O elemento $\mathrm{Cd}$ foi detectado nas quatro embalagens nacionais de água (PET), em duas de alimentos aquosos contendo óleo ou gordura (PP e PET) e em uma de embalagem de suco (HDPE).

Com relação às amostras de embalagens de refrigerantes e águas provenientes do exterior, essas apresentaram $\mathrm{Cd}$ em concentrações que variaram de 7 a $34 \mu \mathrm{g}$ g-1. Somente em uma embalagem de água, $A A$, esse elemento não foi detectado. Na Holanda, Bode (1993) também determinou Cd em diversos tipos de plásticos. Os compostos de Cd são utilizados como pigmento e agente estabilizante em alguns tipos de plásticos e, em vários países da Europa, foi proibido o uso do elemento Cd na composição de materiais poliméricos. Todas essas embalagens eram em PET.

O elemento tóxico As foi detectado em um grande número de embalagens analisadas neste trabalho. A sua presença foi observada em todas as embalagens de leite e derivados de leite (HDPE e PP), assim como, em três embalagens de alimentos gordurosos (PP), duas de alimentos aquosos contendo óleo ou gordura (PP e HDPE) e também em uma embalagem de água (PP) e uma de suco (HDPE). Em nenhuma amostra de embalagem em PET foi verificada a presença de As. 
Tabela 7.2. Concentrações de elementos nas embalagens plásticas de refrigerantes e águas, em $\mu \mathrm{g} \mathrm{g}^{-1}$, obtidos por NAA.

\begin{tabular}{|c|c|c|c|c|c|c|}
\hline \multirow{2}{*}{$\begin{array}{l}\text { Código da } \\
\text { embalagem }\end{array}$} & \multicolumn{5}{|c|}{ Concentrações de elementos $^{f}$} & \multirow{2}{*}{ Tipo de polímero } \\
\hline & As & $\mathrm{Cd}$ & Co & $\mathrm{Cr}$ & $\mathrm{Sb}$ & \\
\hline $\mathrm{R} 1^{\mathrm{a}}$ & $\mathrm{Nd}^{\mathrm{e}}$ & $\mathrm{Nd}$ & $1,96 \pm 0,03$ & $\mathrm{Nd}$ & $223 \pm 2$ & \multirow{8}{*}{ PET } \\
\hline $\mathrm{R} 2$ & $\mathrm{Nd}$ & $\mathrm{Nd}$ & $28,4 \pm 0,5$ & $\mathrm{Nd}$ & $229 \pm 3$ & \\
\hline R3 & $<0,43$ & $<3,97$ & $62,3 \pm 0,5$ & $<1,17$ & $243 \pm 1$ & \\
\hline $\mathrm{R} 4$ & $\mathrm{Nd}$ & $\mathrm{Nd}$ & $55,9 \pm 0,5$ & $\mathrm{Nd}$ & $244 \pm 1$ & \\
\hline R5 & $<0,35$ & $<3,75$ & $50,8 \pm 0,4$ & $<1,28$ & $247 \pm 1$ & \\
\hline $\mathrm{R} 6$ & $<0,21$ & $<2,94$ & $33,4 \pm 0,3$ & $<1,15$ & $218 \pm 1$ & \\
\hline $\mathrm{R} 7$ & $\mathrm{Nd}$ & $\mathrm{Nd}$ & $66,4 \pm 0,7$ & $\mathrm{Nd}$ & $248 \pm 5$ & \\
\hline R8 & $\mathrm{Nd}$ & $\mathrm{Nd}$ & $23,7 \pm 0,3$ & $\mathrm{Nd}$ & $228 \pm 4$ & \\
\hline $\mathrm{RA}^{\mathrm{b}}$ & $\mathrm{Nd}$ & $34 \pm 2$ & $2,54 \pm 0,03$ & $<0,28$ & $239 \pm 3$ & \multirow{2}{*}{ PET } \\
\hline RP & $\mathrm{Nd}$ & $20 \pm 2$ & $6,86 \pm 0,07$ & $<0,27$ & $208 \pm 3$ & \\
\hline$A G 1^{c}$ & $\mathrm{Nd}$ & $\mathrm{Nd}$ & $52 \pm 2$ & $\mathrm{Nd}$ & $255 \pm 2$ & \multirow{3}{*}{ PET } \\
\hline AG2 & $\mathrm{Nd}$ & $4,9 \pm 0,7$ & $2,17 \pm 0,04$ & $\mathrm{Nd}$ & $231 \pm 1$ & \\
\hline AG3 & $\mathrm{Nd}$ & $3,1 \pm 0,7$ & $58 \pm 1$ & $\mathrm{Nd}$ & $191 \pm 1$ & \\
\hline AG4 & $0,010 \pm 0,001$ & $\mathrm{Nd}$ & $0,0161 \pm 0,0006$ & $<0,12$ & $0,00715 \pm 0,00002$ & PP \\
\hline AG5 & $\mathrm{Nd}$ & $10 \pm 1$ & $48 \pm 1$ & $\mathrm{Nd}$ & $246,9 \pm 0,9$ & \multirow{2}{*}{ PET } \\
\hline AG6 & $\mathrm{Nd}$ & $19 \pm 2$ & $43 \pm 1$ & $<0,40$ & $219,9 \pm 0,8$ & \\
\hline$A A^{d}$ & $<1,57$ & $<4,11$ & $0,123 \pm 0,007$ & $<0,41$ & $232 \pm 3$ & \multirow{3}{*}{ PET } \\
\hline $\mathrm{AE} 1$ & $\mathrm{Nd}$ & $6,9 \pm 0,7$ & $14,1 \pm 0,1$ & $\mathrm{Nd}$ & $185 \pm 2$ & \\
\hline AE2 & $<6,22$ & $20 \pm 2$ & $15,7 \pm 0,2$ & $\mathrm{Nd}$ & $233 \pm 3$ & \\
\hline
\end{tabular}


Tabela 7.3. Concentrações de elementos nas embalagens plásticas de sucos, leite e derivados de leite, produtos gordurosos e produtos aquosos contendo óleo ou gordura, em $\mu \mathrm{g} \mathrm{g}{ }^{-1}$, obtidos por NAA.

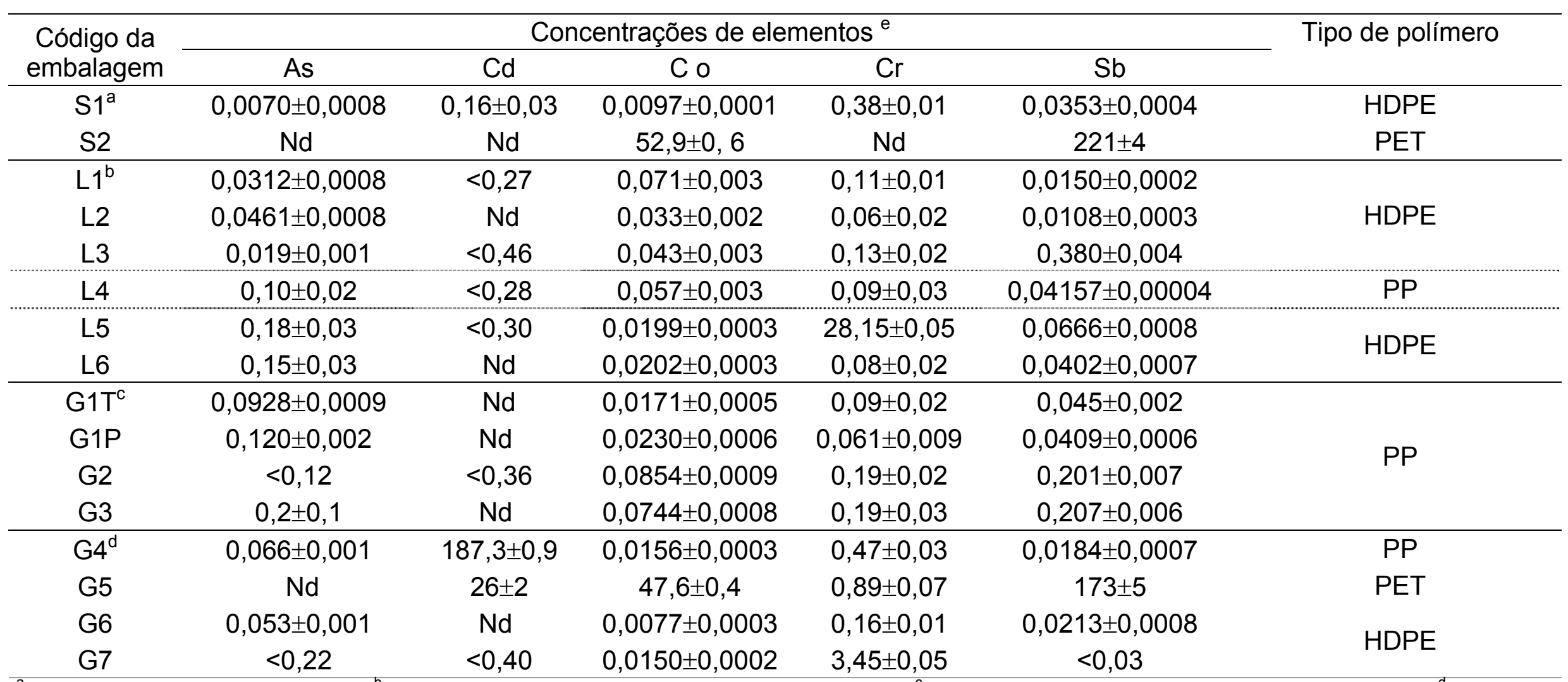

${ }^{a}$ S1 e S2 - embalagens de sucos; ${ }^{b} \mathrm{~L} 1$ a L6 - embalagens de leite e derivados de leite ${ }^{\mathrm{C}} \mathrm{G} 1 \mathrm{~T}$ a $\mathrm{G} 3$ - embalagens de produtos gordurosos; ${ }^{\mathrm{d}} \mathrm{G} 4$ a $\mathrm{G} 7$ embalagens de produtos aquosos contendo óleo ou gordura e pH ácido; ${ }^{e} A s$ concentrações são dadas com as incertezas calculadas usando os erros das medições de taxas de contagens do padrão e da amostra. 
O elemento $\mathrm{Cr}$ foi detectado em todas as embalagens de produtos derivados de leite (HDPE e PP), alimentos gordurosos (PP) e os aquosos que contêm óleo ou gordura e pH ácido (PP, PET, HDPE) e na embalagem de suco S1 (HDPE).

Fato digno de nota foi que uma embalagem de suco (S1), em HDPE e, uma de alimento aquoso, contendo óleo ou gordura (G4), em PP, apresentaram os cinco elementos As, Cd, Co, Cr e Sb.

7.2 Migração de elementos das embalagens plásticas para simulantes de alimentos ou para o próprio alimento, obtidas pelo método radiométrico

\subsubsection{Migração para simulantes de alimentos}

Os resultados da migração dos elementos das embalagens para soluções simulantes obtidos pelo método radiométrico são apresentados nas Tabelas 7.4 a 7.9 .

\section{Migração para simulante ácido acético 3\%}

Nas Tabelas 7.4 a 7.7, são apresentados os resultados da migração para o simulante ácido acético $3 \%$ obtidos para embalagens plásticas de alimentos do tipo II (alimentos aquosos ácidos: refrigerantes, sucos e derivados de leite) e embalagens de alimentos do tipo III b (alimentos aquosos que contêm óleo ou gordura e com $\mathrm{pH}$ ácido).

As embalagens de refrigerantes e suco, indicaram migração de Co e $\mathrm{Sb}$, com exceção de uma embalagem de suco (S1), que não foi detectada a migração do elemento Sb (Tabela 7.4 e 7.5). Todas as amostras de refrigerantes e a de suco $S 2$ eram em PET e a amostra S2 em HDPE. 
Tabela 7.4. Migração de elementos das embalagens de refrigerantes, obtida pelo método radiométrico, em $\mu \mathrm{g} \mathrm{dm}{ }^{-2} \mathrm{~kg}^{-1}$. Condições experimentais: Simulante $=$ ácido acético $3 \%$, Tempo de exposição $=10$ dias, Temperatura $=40^{\circ} \mathrm{C}$.

\begin{tabular}{|c|c|c|}
\hline \multirow{2}{*}{ Código da embalagem } & \multicolumn{2}{|c|}{ Migração de elementos $^{a}$} \\
\hline & Co & $\mathrm{Sb}$ \\
\hline \multirow{2}{*}{$\mathrm{R} 1^{\mathrm{b}}$} & $0,088 \pm 0,009^{c}$ & $1,58 \pm 0,05$ \\
\hline & $0,132 \pm 0,003$ & $0,93 \pm 0,01$ \\
\hline \multirow{2}{*}{$\mathrm{R} 2$} & $0,61 \pm 0,03$ & $0,16 \pm 0,01$ \\
\hline & $0,402 \pm 0,003$ & $0,203 \pm 0,009$ \\
\hline \multirow{2}{*}{ R3 } & $0,21 \pm 0,01$ & $0,92 \pm 0,05$ \\
\hline & $0,091 \pm 0,003$ & $0,675 \pm 0,009$ \\
\hline \multirow{2}{*}{$\mathrm{R} 4$} & $0,22 \pm 0,01$ & $1,19 \pm 0,06$ \\
\hline & $0,060 \pm 0,002$ & $1,05 \pm 0,01$ \\
\hline \multirow{2}{*}{ R5 } & $0,12 \pm 0,01$ & $1,19 \pm 0,09$ \\
\hline & $0,110 \pm 0,005$ & $1,24 \pm 0,02$ \\
\hline \multirow{10}{*}{ R6 } & $0,36 \pm 0,02$ & $0,8 \pm 0,1$ \\
\hline & $0,31 \pm 0,02$ & $0,59 \pm 0,03$ \\
\hline & $0,24 \pm 0,02$ & $1,05 \pm 0,06$ \\
\hline & $0,36 \pm 0,01$ & $1,18 \pm 0,02$ \\
\hline & $0,29 \pm 0,03$ & $0,78 \pm 0,07$ \\
\hline & $0,24 \pm 0,02$ & $0,57 \pm 0,05$ \\
\hline & $0,306 \pm 0,002$ & $1,05 \pm 0,01$ \\
\hline & $0,359 \pm 0,003$ & $1,13 \pm 0,02$ \\
\hline & $0,28 \pm 0,02$ & $0,95 \pm 0,04$ \\
\hline & $0,30 \pm 0,02$ & $1,19 \pm 0,05$ \\
\hline R7 & $0,29 \pm 0,02$ & $0,67 \pm 0,04$ \\
\hline R8 & $0,123 \pm 0,007$ & $1,27 \pm 0,07$ \\
\hline $\mathrm{RA}^{\mathrm{d}}$ & $0,037 \pm 0,001$ & $0,78 \pm 0,01$ \\
\hline $\mathrm{RP}$ & $0,072 \pm 0,001$ & $0,83 \pm 0,01$ \\
\hline
\end{tabular}

\footnotetext{
${ }^{a}$ A migração de elementos é dada com as incertezas calculadas considerando os erros das medições de taxas de contagens do padrão e da amostra; ${ }^{b} \mathrm{R} 1$ a R8 - embalagens de refrigerantes nacionais (PET); ${ }^{c}$ Amostras com dois ou mais resultados indicam que o processo total de migração foi aplicado para diferentes corpos-de-prova de uma mesma amostra; ${ }^{d}$ RA e RP- embalagens de refrigerantes do exterior (PET).
} 
Tabela 7.5. Migração de elementos das embalagens de suco, obtida pelo método

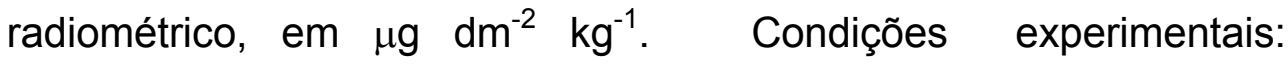
Simulante $=$ ácido acético $3 \%$, Tempo de exposição $=10$ dias, Temperatura $=40^{\circ} \mathrm{C}$.

\begin{tabular}{|c|c|c|c|}
\hline \multirow{2}{*}{$\begin{array}{l}\text { Código da } \\
\text { embalagem }\end{array}$} & \multicolumn{2}{|c|}{ Migração de elementos ${ }^{b}$} & \multirow[t]{2}{*}{ Tipo de polímero } \\
\hline & Co & $\mathrm{Sb}$ & \\
\hline \multirow[t]{2}{*}{$\mathrm{S} 1^{\mathrm{a}}$} & $0,101 \pm 0,008$ & $<0,28$ & HDPE \\
\hline & $0,102 \pm 0,008$ & $0,54 \pm 0,04$ & \\
\hline \multirow[t]{2}{*}{$\mathrm{S} 2$} & $0,15 \pm 0,01$ & $0,80 \pm 0,04$ & PET \\
\hline & $0,19 \pm 0,02$ & $0,68 \pm 0,04$ & \\
\hline
\end{tabular}

Analisando os resultados de migração obtidos para as embalagens de derivados de leite da Tabela 7.6 e de alimentos aquosos contendo óleo ou gordura da Tabela 7.7 verifica-se que a migração do $\mathrm{Co}, \mathrm{Cr}$ e Sb depende dos tipos de embalagem. De acordo com Tehrany e Desobry (2004), as estruturas físicas das embalagens e dos seus componentes podem afetar a partição dos migrantes do sistema alimento/embalagem. A embalagem de HDPE de derivado de leite, L5, que apresentou o mais alto valor de migração de $\mathrm{Cr}$ foi a que apresentou uma alta concentração desse elemento na sua análise.

\section{Migração para simulante água}

$\mathrm{Na}$ Tabela 7.8, estão os resultados da migração dos elementos de embalagens plásticas de alimentos do tipo I, água mineral e leite, para a solução simulante água. Quatro embalagens de água de origem nacional (PET) das seis avaliadas e as três embalagens de água do exterior (PET) apresentaram migração de Sb. Não foi detectada a transferência de nenhum dos elementos em estudo da embalagem de leite, L1, para a água utilizada como simulante. Neste grupo, as amostras AG4 (PP) e L1 (HDPE) foram as que apresentaram a menor concentração desse elemento (Tabela 7.2 e 7.3). 
Tabela 7.6. Migração de elementos das embalagens de derivados de leite, obtida pelo método radiométrico, em $\mu \mathrm{g} \mathrm{dm}^{-2} \mathrm{~kg}^{-1}$. Condições experimentais: Simulante $=$ ácido acético $3 \%$, Tempo de exposição = 10 dias, Temperatura $=40^{\circ} \mathrm{C}$.

\begin{tabular}{|c|c|c|c|}
\hline \multirow{2}{*}{$\begin{array}{l}\text { Código da } \\
\text { embalagem }\end{array}$} & \multicolumn{2}{|c|}{ Migração de elementos ${ }^{\text {b }}$} & \multirow[t]{2}{*}{ Tipo de polímero } \\
\hline & Co & $\mathrm{Cr}$ & \\
\hline $\mathrm{L}^{\mathrm{a}}$ & $0,134 \pm 0,009$ & $<0,89$ & \multirow{2}{*}{ HDPE } \\
\hline L3 & $<0,09$ & $<0,70$ & \\
\hline L4 & $<0,08$ & $<0,63$ & PP \\
\hline \multirow{3}{*}{ L5 } & $0,107 \pm 0,002$ & $3,100 \pm 0,2$ & \multirow{4}{*}{ HDPE } \\
\hline & $0,078 \pm 0,002$ & $2,19 \pm 0,08$ & \\
\hline & $\mathrm{Nd}$ & $2,60 \pm 0,09$ & \\
\hline L6 & $<0,08$ & $<0,73$ & \\
\hline
\end{tabular}

${ }^{\mathrm{a}}$ L2 a L6 - embalagens de derivados de leite; ${ }^{\mathrm{b}}$ A migração de elementos é dada com as incertezas calculadas considerando os erros das medições de taxas de contagens do padrão e da amostra.

Tabela 7.7. Migração de elementos das embalagens de alimentos aquosos contendo óleo ou gordura e $\mathrm{pH}$ ácido, em $\mu \mathrm{g} \mathrm{dm}^{-2} \mathrm{~kg}^{-1}$. Condições experimentais: Simulante $=$ ácido acético $3 \%$, Tempo de exposição $=10$ dias, Temperatura $=40^{\circ} \mathrm{C}$.

\begin{tabular}{|c|c|c|c|}
\hline \multirow{2}{*}{$\begin{array}{l}\text { Código da } \\
\text { embalagem }\end{array}$} & \multicolumn{2}{|c|}{ Migração de elementos ${ }^{b}$} & \multirow[t]{2}{*}{ Tipo de polímero } \\
\hline & Co & $\mathrm{Sb}$ & \\
\hline$G 4^{a}$ & $0,110 \pm 0,005$ & $<0,17$ & PP \\
\hline G5 & $0,160 \pm 0,004$ & $0,75 \pm 0,01$ & PET \\
\hline G6 & $<0,09$ & $<0,19$ & HDPE \\
\hline G7 & $<0,08$ & $<0,15$ & \\
\hline
\end{tabular}


Tabela 7.8. Migração de elementos das embalagens de água e leite, obtida pelo método radiométrico, em $\mu \mathrm{g} \mathrm{dm}{ }^{-2} \mathrm{~kg}^{-1}$. Condições experimentais: Simulante $=$ água, Tempo de exposição $=10$ dias, Temperatura $=$ $40^{\circ} \mathrm{C}$.

\begin{tabular}{|c|c|c|}
\hline $\begin{array}{c}\text { Código da } \\
\text { embalagem }\end{array}$ & Migração de Sb d & $\begin{array}{c}\text { Tipo de } \\
\text { polímero }\end{array}$ \\
\hline \multirow{2}{*}{$A G 1^{a}$} & $0,48 \pm 0,01$ & \\
\hline & $0,63 \pm 0,01$ & \\
\hline AG2 & $0,77 \pm 0,03$ & PET \\
\hline AG3 & $<1,69$ & \\
\hline AG4 & $\mathrm{Nd}$ & PP \\
\hline AG5 & $0,49 \pm 0,01$ & \\
\hline AG6 & $0,42 \pm 0,01$ & \\
\hline $\mathrm{AA}^{\mathrm{b}}$ & $0,311 \pm 0,004$ & PET \\
\hline $\mathrm{AE} 1$ & $0,413 \pm 0,006$ & \\
\hline $\mathrm{AE} 2$ & $0,85 \pm 0,01$ & \\
\hline$L 1^{c}$ & $\mathrm{Nd}$ & HDPE \\
\hline
\end{tabular}

${ }^{a}$ AG1 a AG6 - embalagens de água de origem nacional; ${ }^{b}$ AA, AE1 e AE2 são embalagens de água adquiridas no exterior; ${ }^{C} \mathrm{~L} 1$ - embalagem de leite; d A migração de elementos é dada com as incertezas calculadas considerando os erros das medições de taxas de contagens do padrão e da amostra.

\section{Migração para simulante n-heptano}

Os resultados da migração das embalagens plásticas de alimentos aquosos contendo óleo ou gordura e apresentando pH ácido (alimentos do tipo III b) e das embalagens de alimentos gordurosos (alimentos do tipo IV), para a solução simulante n-heptano da Tabela 7.9 mostram que para ambos os tipos de embalagens houve migração de Cd e Co. Todos os resultados da Tabela 7.9 são os já corrigidos, dividindo-se os dados obtidos experimentalmente por cinco, 
conforme a recomendação da RE-105/99 da ANVISA (1999). Segundo essa resolução, quando se utiliza o n-heptano com 0 simulante, os dados experimentais obtidos diretamente dos seus cálculos devem ser corrigidos.

Tabela 7.9. Migração de elementos das embalagens de produtos gordurosos e aquosos contendo óleo, obtida pelo método radiométrico, em $\mu \mathrm{g} \mathrm{dm}^{-2} \mathrm{~kg}^{-1}$. Condições experimentais Simulante $=\mathrm{n}$-heptano, Tempo de exposição $=30$ minutos, Temperatura $=20^{\circ} \mathrm{C}$.

\begin{tabular}{|c|c|c|c|c|c|}
\hline \multirow{3}{*}{$\begin{array}{c}\text { Código da } \\
\text { embalagem }\end{array}$} & \multicolumn{4}{|c|}{ Migração de elemento ${ }^{c}$} & \multirow{3}{*}{$\begin{array}{l}\text { Tipo de } \\
\text { polímero }\end{array}$} \\
\hline & \multicolumn{2}{|c|}{$\mathrm{Cd}$} & \multicolumn{2}{|c|}{ Co } & \\
\hline & Determinado & Corrigido $^{d}$ & Determinado & Corrigido & \\
\hline $\mathrm{G}_{1} \mathrm{~T}^{\mathrm{a}}$ & $\mathrm{Nd}$ & $\mathrm{Nd}$ & $<0,15$ & $<0,03$ & \\
\hline G1P & $\mathrm{Nd}$ & $\mathrm{Nd}$ & $<0,10$ & $<0,02$ & \\
\hline G2 & $\mathrm{Nd}$ & $\mathrm{Nd}$ & $<0,07$ & $<0,01$ & $r \Gamma$ \\
\hline G3 & $<0,03$ & $<0,006$ & $0,066 \pm 0,001$ & $0,0132 \pm 0,0002$ & \\
\hline $\mathrm{G} 4^{\mathrm{b}}$ & $3,2 \pm 0,5$ & $0,64 \pm 0,1$ & $<0,18$ & $<0,03$ & PP \\
\hline G5 & $4,0 \pm 0,3$ & $0,80 \pm 0,06$ & $0,076 \pm 0,004$ & $0,0152 \pm 0,0008$ & PET \\
\hline G6 & $\mathrm{Nd}$ & $\mathrm{Nd}$ & $\mathrm{Nd}$ & $\mathrm{Nd}$ & HDPE \\
\hline G7 & $\mathrm{Nd}$ & $\mathrm{Nd}$ & $<0,13$ & $<0,03$ & \\
\hline
\end{tabular}

${ }^{a}$ G1T a G3 embalagens de produtos gordurosos; ${ }^{b} \mathrm{G} 4$ a $\mathrm{G} 7$ embalagens de alimentos aquosos contendo óleo ou gordura e $\mathrm{pH}$ ácido; ${ }^{\mathrm{C}} \mathrm{A}$ migração de elementos é dada com as incertezas calculadas considerando os erros das medições de taxas de contagens do padrão e da amostra; ${ }^{d}$ Os resultados experimentais obtidos com $n$-heptano foram divididos por cinco conforme RE-105/99 (ANVISA, 1999).

\subsubsection{Migração dos elementos para alimentos}

$\mathrm{Na}$ Tabela 7.10, estão os resultados da migração dos elementos das embalagens plásticas de refrigerante, suco, água e derivado de leite para alimento. Para efetuar este ensaio foram adquiridos alimentos idênticos aos contidos originalmente nestas amostras de embalagens. Observa-se nessa 
Tabela que houve migração de Co das embalagens de refrigerante, suco e iogurte, do elemento $\mathrm{Sb}$ das embalagens de refrigerante, suco e água mineral $\mathrm{e}$ $\mathrm{Cr}$ da embalagem de iogurte.

Os resultados de migração obtidos com simulantes de alimentos para as embalagens R6, L5 e AG1 (Tabelas 7.4, 7.6, 7.8) foram bastante próximos daqueles obtidos usando o próprio alimento no lugar dos simulantes (Tabela 7.10) Já para a embalagem S2, os resultados da migração de Sb no próprio alimento (suco) foram ligeiramente superiores que aqueles obtidos com simulante ácido acético a 3\% (Tabela 7.5).

Tabela 7.10. Migração de elementos das embalagens, obtida pelo método radiométrico, em $\mu \mathrm{g} \mathrm{dm} \mathrm{kg}^{-1}$, para alimento. Condições experimentais: Tempo de exposição $=10$ dias, Temperatura $=40^{\circ} \mathrm{C}$.

\begin{tabular}{ccccc}
\hline $\begin{array}{c}\text { Código da } \\
\text { embalagem }\end{array}$ & $\begin{array}{c}\text { Conteúdo da } \\
\text { embalagem (tipo de } \\
\text { polímero) }\end{array}$ & Co & $\mathrm{Cr}$ & $\mathrm{Sb}$ \\
\hline & & $0,32 \pm 0,02$ & $<0,27$ & $0,60 \pm 0,02$ \\
R6 & Refrigerante (PET) & $0,35 \pm 0,02$ & $\mathrm{Nd}$ & $0,89 \pm 0,05$ \\
& & $0,35 \pm 0,02$ & $\mathrm{Nd}$ & $0,87 \pm 0,05$ \\
& & $0,321 \pm 0,007$ & $<0,29$ & $1,110 \pm 0,005$ \\
\hline \multirow{2}{*}{ S2 } & Suco (PET) & $0,21 \pm 0,01$ & $<0,28$ & $1,41 \pm 0,06$ \\
& & $0,209 \pm 0,003$ & & $2,15 \pm 0,03$ \\
\hline \multirow{2}{*}{ AG1 } & Água mineral com gás & $<0,04$ & $<0,36$ & $0,67 \pm 0,02$ \\
& (PET) & & & \\
\hline L5 & logurte (HDPE) & $0,107 \pm 0,002$ & $2,17 \pm 0,09$ & $<0,09$ \\
\hline
\end{tabular}
a A migração de elementos é dada com as incertezas calculadas considerando os erros das
medições de taxas de contagens do padrão e da amostra. 


\subsubsection{Avaliação da repetitividade na determinação da migração pelo método radiométrico}

Para avaliar a precisão na determinação da migração pelo método radiométrico bem como para verificar se há diferença entre os valores de migração obtidos para o simulante de alimento e para o próprio alimento, foram feitas as determinações em replicatas para uma embalagem de refrigerante (PET). Os resultados individuais obtidos usando simulante ácido acético $3 \%$ e o alimento refrigerante estão apresentados na Tabela 7.11, juntamente com as médias e os desvios padrão relativos.

A esses valores de migração foram aplicados os testes $Q$ de Dixon e o de Grubbs para verificar se o conjunto apresenta resultados discrepantes que devam ser desprezados (Barros Neto et al., 2007).

O teste $Q$ de Dixon é baseado na comparação do valor suspeito com os demais valores obtidos. Esse teste é efetuado calculando-se a menor e a maior diferença entre o valor suspeito e os demais valores do conjunto de resultados. Calcula-se então a razão entre essas diferenças (Q). O resultado obtido é então comparado com valores críticos tabelados $\left(Q_{c}\right)$ no nível de confiança desejado. Se o valor de $Q$ for maior que o de $Q_{c}$, o valor suspeito é considerado discrepante ("outlier") e deve ser rejeitado.

No teste de Grubbs, calcula-se a diferença entre o valor suspeito e a média do conjunto de resultados. Essa diferença é dividida pelo desvio padrão, resultando em um valor denominado $\mathrm{G}$. Esse valor $\mathrm{G}$ é comparado com valores críticos $\left(G_{c}\right)$ tabelados no nível de confiança desejado. Se o valor de $G$ for maior que o de $G_{c}$, o valor suspeito é considerado discrepante.

Os resultados dos parâmetros Q e G obtidos para os valores da Tabela 7.11 são apresentados na Tabela 7.12.

Aplicando os testes $Q$ de Dixon e de Grubbs, os valores de $Q$ e $G$ calculados foram menores que os seus valores tabelados ao nível de confiança de $95 \%$. Isso indica que não há resultados discrepantes (outliers) que devam ser desprezados. 
Os resultados da migração obtidos nas análises em replicata da Tabela 7.11 indicam que a precisão nestas determinações variou de 5,3 a 24,6\%. Os resultados menos precisos foram obtidos para $\mathrm{Sb}$ e isto se deve, provavelmente, às baixas taxas de contagens obtidas nas medições do radiosótopo ${ }^{122} \mathrm{Sb}$.

Tabela 7.11. Valores individuais da migração de Co e Sb de uma embalagem de refrigerante para o simulante ácido acético $3 \%$ e para o alimento.

\begin{tabular}{|c|c|c|}
\hline \multirow{2}{*}{$\begin{array}{l}\text { Simulante ou } \\
\text { alimento }\end{array}$} & \multicolumn{2}{|c|}{ Migração $\left(\mathrm{ng} \mathrm{dm}^{-2} \mathrm{~kg}^{-1}\right)$} \\
\hline & Co & $\mathrm{Sb}$ \\
\hline \multirow{10}{*}{ Ácido acético a 3\% } & 235 & 571 \\
\hline & 241 & 589 \\
\hline & 280 & 781 \\
\hline & 287 & 841 \\
\hline & 302 & 952 \\
\hline & 306 & 1045 \\
\hline & 309 & 1053 \\
\hline & 359 & 1132 \\
\hline & 362 & 1180 \\
\hline & 363 & 1188 \\
\hline Média $\pm \mathrm{DP}{ }^{\mathrm{a}}$ & $304 \pm 46$ & $933 \pm 230$ \\
\hline DPR, \% ${ }^{b}$ & 15,1 & 24,6 \\
\hline \multirow{5}{*}{ Refrigerante } & 319 & 599 \\
\hline & 320 & 869 \\
\hline & 321 & 891 \\
\hline & 353 & 993 \\
\hline & 354 & 1110 \\
\hline Média $\pm \mathrm{DP}$ & $333 \pm 18$ & $892 \pm 190$ \\
\hline DPR, \% & 5,3 & 21,3 \\
\hline
\end{tabular}

${ }^{a} \mathrm{DP}:$ Desvio padrão; ${ }^{\mathrm{b}}$ DPR: Desvio padrão relativo 
Tabela 7.12. Parâmetros obtidos na aplicação dos testes $Q$ de Dixon e Grubbs aos resultados da Tabela 7.11.

\begin{tabular}{|c|c|c|c|c|c|c|c|}
\hline \multirow[t]{2}{*}{ Elemento } & \multirow{2}{*}{$\begin{array}{c}\text { Solução de } \\
\text { ensaio }\end{array}$} & \multirow{2}{*}{$\begin{array}{l}\text { Graus de } \\
\text { liberdade }\end{array}$} & \multirow{2}{*}{$\begin{array}{c}\text { Valor } \\
\text { suspeito }\end{array}$} & \multicolumn{2}{|c|}{$\begin{array}{c}\text { Teste } Q \text { de } \\
\text { Dixon }\end{array}$} & \multicolumn{2}{|c|}{$\begin{array}{l}\text { Teste de } \\
\text { Grubbs }\end{array}$} \\
\hline & & & & $Q$ & $Q c^{*}$ & $G$ & $G c^{*}$ \\
\hline \multirow{4}{*}{ Co } & Solução ácido & \multirow{2}{*}{10} & Maior & 0,045 & \multirow{2}{*}{0,530} & 1,49 & \multirow{2}{*}{2,176} \\
\hline & acético a 3\% & & Menor & 0,013 & & 1,26 & \\
\hline & \multirow{2}{*}{ Refrigerante } & \multirow{2}{*}{5} & Maior & 0,044 & \multirow{2}{*}{0,710} & 1,58 & \multirow{2}{*}{1,749} \\
\hline & & & Menor & 0,045 & & 1,11 & \\
\hline \multirow{4}{*}{$\mathrm{Sb}$} & Solução ácido & \multirow{2}{*}{10} & Maior & 0,030 & \multirow{2}{*}{0,530} & 0,80 & \multirow[t]{2}{*}{2,176} \\
\hline & acético a 3\% & & Menor & 0,013 & & 1,14 & \\
\hline & \multirow{2}{*}{ Refrigerante } & \multirow{2}{*}{5} & Maior & 0,528 & \multirow{2}{*}{0,710} & 1,55 & \multirow[t]{2}{*}{1,749} \\
\hline & & & Menor & 0,228 & & 1,15 & \\
\hline
\end{tabular}

*Valores críticos para um nível de confiança de 95\%.

Aplicou-se o teste F (Barros Neto et al., 2007; Costa Neto, 2002), da razão entre as variâncias e foi verificado que as variâncias obtidas nos resultados da migração da Tabela 7.11 para simulantes e para o alimento são equivalentes a um nível de confiança de $97,5 \%$.

A comparação entre os resultados da migração obtidos para a solução simulante ácido acético $3 \%$ e os obtidos para refrigerante foi feita aplicando o teste estatístico $t$ de student (Barros Neto et al., 2007). Os resultados do teste $t$ indicam que os valores obtidos na migração com solução de ácido acético 3\% e com refrigerante foram estatisticamente iguais a um nível de confiança de $95 \%$.

\section{Comparação dos resultados de migração obtidos com os valores estabelecidos para limites máximos de tolerância (LMT)}

Esta comparação está apresentada somente para os resultados mais altos, de migração, obtidos neste trabalho, uma vez que todas embalagens analisadas apresentaram migração abaixo dos valores máximos de 
tolerância (LMT) estabelecidos na legislação (ANVISA, 1965). Conforme pode ser visto na Tabela 7.13, as embalagens analisadas apresentaram migração de Cd, Cr e Sb abaixo dos limites máximos de tolerância (LMT).

Algumas embalagens apresentaram a migração do elemento Co, entretanto não há valor de LMT estabelecido para este elemento.

Tabela 7.13. Comparação entre os resultados da migração de elementos Cd, Cr e $\mathrm{Sb}$ obtidos e os valores Limites Máximos de Tolerância (LMT) (ANVISA, 1965).

\begin{tabular}{|c|c|c|c|c|}
\hline \multirow{2}{*}{ Valores } & \multirow{2}{*}{ Unidade } & \multicolumn{3}{|c|}{ Elemento } \\
\hline & & $\mathrm{Cd}$ & $\mathrm{Cr}$ & $\mathrm{Sb}$ \\
\hline $\begin{array}{l}\text { Maior valor de } \\
\text { migração obtido }\end{array}$ & $\mu \mathrm{dm}^{-2} \mathrm{~kg}^{-1}$ & 0,8 & 3,1 & 2,15 \\
\hline Concentração ${ }^{a}$ & $\mu \mathrm{gg}^{-1}$ & 4,80 & 18,6 & 12,90 \\
\hline \multirow{4}{*}{ Valor do LMT } & \multirow{4}{*}{$\mu \mathrm{g} \mathrm{kg}{ }^{-1}$} & 200 (refrigerante) & \multirow{4}{*}{$\begin{array}{c}100 \\
\text { (qualquer } \\
\text { alimento) }\end{array}$} & 200 (refrigerante) \\
\hline & & 500 (suco) & & 1000 (suco) \\
\hline & & 200 (água) & & 200 (água) \\
\hline & & 1000 (iogurte) & & 2000 (iogurte) \\
\hline
\end{tabular}

\subsubsection{Valores limites de detecção da migração dos elementos}

Na Tabela 7.14, encontram-se os valores de limites de detecção da migração dos elementos $\mathrm{As}, \mathrm{Cd}, \mathrm{Co}, \mathrm{Cr}$ e $\mathrm{Sb}$ das embalagens para os simulantes e alimentos. Para As, Co, Cr e Sb estes limites foram inferiores a $3,84 \mu \mathrm{g} \mathrm{dm}^{-2} \mathrm{~kg}^{-1} \mathrm{e}$ para o elemento Cd, para a maioria das amostras, menores que $26,75 \mu \mathrm{g} \mathrm{dm}^{-2} \mathrm{~kg}^{-1}$, indicando a alta capacidade de detecção do método radiométrico, uma vez que esta técnica permite obter valores de migração menores que os valores de LMT. Verificase que, para duas amostras, os limites de detecção do elemento Cd foram superiores a $56 \mu \mathrm{g} \mathrm{dm}^{-2} \mathrm{~kg}^{-1} \mathrm{e}$, somente nesses casos, a capacidade de detecção do método radiométrico foi considerada baixa, com valores de migração superiores ao LMT. 
Tabela 7.14. Valores limites de detecção da migração de elementos em $\mu \mathrm{dm}^{-2} \mathrm{~kg}^{-1}$.

\begin{tabular}{|c|c|c|c|c|c|c|c|}
\hline \multirow{2}{*}{$\begin{array}{l}\text { Código da } \\
\text { embalagem }\end{array}$} & \multirow{2}{*}{$\begin{array}{l}\text { Simulante / } \\
\text { Alimento }\end{array}$} & \multirow{2}{*}{$\begin{array}{l}\text { Tempo de } \\
\text { exposição / } \\
\text { Temperatura }\end{array}$} & \multicolumn{5}{|c|}{$\begin{array}{c}\text { Limites de detecção da migração } \\
\text { Elemento }\end{array}$} \\
\hline & & & As & $\mathrm{Cd}$ & Co & $\mathrm{Cr}$ & $\mathrm{Sb}$ \\
\hline $\mathrm{R} 1^{\mathrm{a}}$ & & & -9 & 8,11 & 0,06 & 0,37 & 0,10 \\
\hline R2 & & & - & 8,72 & 0,05 & 0,35 & 0,11 \\
\hline R3 & & & - & 8,44 & 0,02 & 0,21 & 0,08 \\
\hline R4 & & & - & 16,44 & 0,02 & 0,20 & 0,10 \\
\hline R5 & & & - & 12,28 & 0,04 & 0,28 & 0,14 \\
\hline R6 & & & - & 14,86 & 0,04 & 0,28 & 0,14 \\
\hline R7 & & & - & 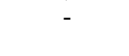 & 0,02 & 0,15 & 0,06 \\
\hline R8 & & & - & - & 0,04 & 0,21 & 0,09 \\
\hline RA & & & - & 10,45 & 0,02 & 0,30 & 0,08 \\
\hline $\mathrm{RP}$ & & & - & 9,58 & 0,02 & 0,22 & 0,09 \\
\hline$S 1^{b}$ & Acido acético & 10 dias $/ 40^{\circ} \mathrm{C}$ & - & & 0,08 & 0,39 & 0,28 \\
\hline S2 & & & - & 21,75 & 0,05 & 0,38 & 0,16 \\
\hline $\mathrm{L}^{\mathrm{c}}$ & & & - & 57,05 & 0,09 & 0,89 & 0,32 \\
\hline L3 & & & - & 16,30 & 0,09 & 0,70 & 0,16 \\
\hline L4 & & & - & 19,52 & 0,08 & 0,63 & 0,15 \\
\hline L5 & & & - & 26,75 & 0,06 & 0,44 & 0,13 \\
\hline L6 & & & - & 56,91 & 0,08 & 0,73 & 0,29 \\
\hline $\mathrm{G} 4^{\mathrm{d}}$ & & & - & 17,85 & 0,11 & 0,75 & 0,17 \\
\hline G5 & & & - & 17,70 & 0,10 & 0,84 & 0,19 \\
\hline G6 & & & - & - & 0,09 & 0,66 & 0,19 \\
\hline G7 & & & - & 3,43 & 0,08 & 0,53 & 0,15 \\
\hline R6 & Refrigerante & & - & 2,32 & 0,04 & 0,27 & 0,08 \\
\hline S2 & Suco & & - & 5,43 & 0,04 & 0,28 & 0,06 \\
\hline L5 & logurte & $10 \mathrm{dias} / 40^{\circ} \mathrm{C}$ & - & 6,56 & 0,02 & 0,22 & 0,09 \\
\hline AG1 & Água com gás & & - & 10,56 & 0,04 & 0,36 & 0,12 \\
\hline$A G 1^{e}$ & & & - & 13,05 & 0,09 & 0,61 & 0,16 \\
\hline AG3 & & & - & - & 0,25 & 3,84 & 1,69 \\
\hline AG6 & & & - & 12,10 & 0,06 & 0,57 & 0,14 \\
\hline AA & Agua & 10 dias $/ 40^{\circ} \mathrm{C}$ & - & 16,90 & 0,05 & 0,43 & 0,14 \\
\hline AE1 & & & - & 15,88 & 0,06 & 0,44 & 0,15 \\
\hline AE2 & & & - & 22,26 & 0,07 & 0,51 & 0,16 \\
\hline $\mathrm{G} 1 \mathrm{~T}^{\mathrm{f}}$ & & & - & - & 0,15 & 0,82 & 0,15 \\
\hline G1P & & & 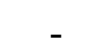 & - & 0,10 & 0,62 & 0,02 \\
\hline $\mathrm{G} 2$ & & & 0,01 & - & 0,07 & 0,29 & 0,06 \\
\hline G3 & n-heptano & $30 \mathrm{mIn} / 20^{\circ} \mathrm{C}$ & 0,02 & 0,03 & - & 0,22 & 0,06 \\
\hline G4 & & & 0,07 & 1,74 & 0,18 & 1,30 & 0,28 \\
\hline G7 & & & - & - & 0,13 & 0,83 & 0,23 \\
\hline
\end{tabular}

${ }^{a} \mathrm{R} 1$ a RP embalagens de refrigerantes; ${ }^{b} \mathrm{~S} 1$ a $\mathrm{S} 2$ embalagens de sucos; ${ }^{\circ} \mathrm{L} 2$ a $\mathrm{L} 6$ embalagens de derivados de leite; ${ }^{\mathrm{d}} \mathrm{G} 4$ a G7 embalagens de produtos aquosos contendo óleo ou gordura e pH ácido; ${ }^{e} A G 1 a$ AE2 embalagens de água; ${ }^{f}$ G1T a G3 embalagens de produtos gordurosos; g " - " = o limite de detecção não foi avaliado. 


\subsection{Migração de elementos das embalagens plásticas para simulantes de alimentos obtida pelo método convencional}

\subsubsection{Migração para simulante de alimento}

Foi determinada a migração de elementos de cinco embalagens plásticas de alimentos para simulantes de alimentos aplicando o método convencional seguido de espectroscopia de absorção atômica (AAS) com forno de grafita para os elementos As, Co e Sb, de AAS com chama para Cd e $\mathrm{Cr}$ e análise por ativação com nêutrons (NAA) para As, Cd, Co, Cr e Sb.

Os resultados obtidos em $\mathrm{mg} \mathrm{L}^{-1}$ (massa do elemento que migrou por volume de simulante) no método convencional foram convertidos em $\mu \mathrm{g} \mathrm{dm}^{-2} \mathrm{~kg}^{-1}$, conforme descrito no item 6.6. Na Tabela 7.15, estão os resultados obtidos pelo método convencional seguido de AAS e NAA juntamente com os valores de limite de detecção para elementos não detectados.

Com relação às análises das soluções branco convém salientar que foram detectados somente os elementos $\mathrm{Co}, \mathrm{Cr}$ e $\mathrm{Sb}$ pela NAA de modo que a sua contribuição foi considerada no cálculo da migração. Pela AAS, nenhum dos elementos em estudo foi detectado na análise do branco, bem como a presença As e Cd não foi verificada pela NAA.

Pelos resultados obtidos apresentados na Tabela 7.15, pode-se afirmar que, nas embalagens analisadas, não houve a migração de As e Cd ou a migração desses elementos é muito pequena, abaixo dos limites de detecção das técnicas utilizadas de AAS e NAA. Já a migração de Co foi verificada nas embalagens de refrigerante (R6), de alimento aquoso contendo óleo ou gordura (G5) e do derivado de leite (L5) e, na de suco, foi detectada apenas com a técnica de AAS. A migração do elemento Sb foi determinada nas embalagens de refrigerante e água pelas duas técnicas e nas embalagens de alimento gorduroso e suco apenas pela NAA. A ocorrência da migração de Co e Sb das embalagens analisadas foi também verificada pelo método radiométrico. 
Tabela 7.15. Migração dos elementos em $\mathrm{ng} \mathrm{dm} \mathrm{dg}^{-1}$, obtida pelo método convencional seguido de AAS e NAA. Condições experimentais: Tempo de exposição $=10$ dias, Temperatura $=40^{\circ} \mathrm{C}$.

\begin{tabular}{cccccccc}
\hline $\begin{array}{l}\text { Código da } \\
\text { embalagem }\end{array}$ & $\begin{array}{c}\text { Método de } \\
\text { análise }\end{array}$ & Simulante & As & Cd & Co & $\mathrm{Cr}$ & $\mathrm{Sb}$ \\
\hline \multirow{2}{*}{ R6 } & AAS $^{\mathrm{a}}$ & Ácido acético & $<17$ & $<83$ & 180 & 417 & 10 \\
& NAA $^{\mathrm{b}}$ & $3 \%$ & $\mathrm{Nd}$ & $<383$ & $16 \pm 2^{\mathrm{c}}$ & $353 \pm 28$ & $13,7 \pm 0,3$ \\
\hline \multirow{2}{*}{ G5 } & AAS & Ácido acético & $<166$ & $<830$ & 488 & $<1660$ & $<83$ \\
& NAA & $3 \%$ & $<15$ & $<710$ & $33 \pm 5$ & $<879$ & $20 \pm 1$ \\
\hline \multirow{2}{*}{ L5 } & AAS & Ácido acético & $<95$ & $<476$ & 472 & $<952$ & $<48$ \\
& NAA & $3 \%$ & Nd & Nd & $261 \pm 12$ & $306 \pm 170$ & $<43$ \\
\hline \multirow{2}{*}{ S2 } & AAS & Ácido acético & $<67$ & $<333$ & 329 & $<667$ & $<33$ \\
& NAA & $3 \%$ & $<9$ & $<978$ & $<36$ & $<173$ & $33,9 \pm 0,8$ \\
\hline \multirow{2}{*}{ AG1 } & AAS & Água & $<17$ & $<83$ & $<17$ & $<167$ & 65 \\
& NAA & $<4$ & $<275$ & $<24$ & $<103$ & $22 \pm 7$ \\
\hline
\end{tabular}

${ }^{a} \mathrm{AAS}=$ convencional com AAS; ${ }^{\mathrm{b}} \mathrm{NAA}=$ convencional com NA; ${ }^{\mathrm{c}} \mathrm{A}$ migração de elementos é dada com as incertezas calculadas considerando os erros das medições de taxas de contagens do padrão e da amostra. 
O elemento $\mathrm{Cr}$ foi determinado pelas duas técnicas nas embalagens de refrigerante e na de alimento aquoso contendo óleo apenas pela técnica de NAA. Sobre a ocorrência da migração de $\mathrm{Cr}$ da embalagem R6, não se encontrou uma justificativa, tendo em vista que na análise dessa embalagem não foi detectado esse elemento.

Uma das dificuldades encontradas na determinação da migração pelo método convencional foi trabalhar com grandes volumes do simulante $(1000 \mathrm{~mL})$, quantidade estabelecida de acordo com o procedimento, quando se utiliza amostra com área a ser exposta a migração de $600 \mathrm{~cm}^{2}$. Essa dificuldade foi verificada tanto na manipulação de grandes volumes do simulante para a migração e para o branco, como também, no uso da estufa para acondicionar o material durante os 10 dias de exposição, devido ao tamanho dos recipientes utilizados para conter o volume total da solução. Outra dificuldade da parte prática do método convencional resultou da necessidade de realizar a concentração do simulante por meio da evaporação antes da análise por AAS e NAA. A pré-concentração proporcionou aumento de capacidade de detecção do migrante, entretanto foi uma etapa bastante demorada. No método convencional seguido de NAA, devido à dificuldade de irradiar líquidos no reator, foi necessário pipetar $0,4 \mathrm{~mL}$ dessa solução concentrada para um suporte de papel de filtro a fim de obter uma concentração adequada do analito num suporte sólido. Isso foi feito pipetando-se alíquotas da solução com intervalos para secagem do líquido depositado sobre o papel, até obtenção do volume de $0,4 \mathrm{~mL}$, o que também ocasionou aumento do tempo de análise.

\subsubsection{Migração de elementos de um material de referência de polietileno para simulante de alimento}

Este estudo com material de referência certificado foi realizado para a comparação entre os resultados obtidos pelo método radiométrico e convencional.

Os resultados da determinação da migração do material de referência BCR-681 para o simulante obtidos pelo método convencional seguido de AAS e os obtidos no método radiométrico desta mesma amostra são apresentados na 
Tabela 7.16. Nessa Tabela, os resultados são dados em termos da massa total de cada um dos elementos lixiviados para $25 \mathrm{~mL}$ de simulante, em nanogramas. Pelo método convencional, não foi possível detectar nenhum dos elementos presentes na amostra, o que impossibilitou uma comparação dos dados do método convencional com os do método radiométrico.

Tabela 7.16. Migração dos elementos do material de referência BCR-681 obtida pelo método convencional seguido de AAS e pelo método radiométrico.

\begin{tabular}{lccccc}
\hline \multirow{2}{*}{ Método } & \multicolumn{5}{c}{ Massa do elemento, em nanograma ${ }^{\text {a }}$} \\
\cline { 2 - 6 } & As & $\mathrm{Cd}$ & $\mathrm{Co}$ & $\mathrm{Cr}$ & $\mathrm{Sb}$ \\
\hline Convencional + AAS & $<250$ & $<13$ & $<250$ & $<1250$ & $<125$ \\
Radiométrico & $<58$ & $<92$ & $1,6 \pm 0,1$ & $8 \pm 1$ & $6,6 \pm 0,7$ \\
\hline
\end{tabular}

${ }^{a}$ Massa total de cada elemento transferida para o simulante.

Comparando-se os resultados, observa-se que o método radiométrico apresenta melhor capacidade de deteç̧ão para os elementos analisados, com exceção do $\mathrm{Cd}$. Isto porque o elemento $\mathrm{Cd}$ não possui isótopos com características nucleares apropriadas para ativação com nêutrons. A não detecção da migração do As no método radiométrico se deve à meia-vida relativamente curta do ${ }^{76} \mathrm{As}, 26,32 \mathrm{~h}$. Como a medição do ${ }^{76} \mathrm{As}$ é efetuada após 10 dias de exposição à migração, fica impossibilitada a detecção da radiação.

\subsubsection{Comparação entre os métodos radiométrico e convencional para avaliação da migração.}

As principais vantagens do método radiométrico em relação ao convencional estão na não necessidade de reagentes de alta pureza, a quase inexistência de possibilidade de contaminação, pois a amostra é irradiada antes da migração, a utilização de pequenas quantidades de amostra e volumes de simulante, um menor tempo de trabalho do analista, além de permitir avaliação 
da migração no próprio alimento. Por outro lado, no método radiométrico há exposição do analista à radiação e este método apresenta um custo mais alto de análise devido à necessidade de um reator nuclear. A determinação de elementos cujos radioisótopos correspondentes apresentem meia-vida curta muitas vezes não pode ser feita devido ao tempo necessário para exposição à migração. $\mathrm{O}$ método radiométrico apresenta alta capacidade de detecção para a maioria dos elementos avaliados, exceto para alguns elementos, como o Cd, para o qual o método convencional seguido de AAS apresenta melhor capacidade de detecção. Na Tabela 1.17 está apresentada, de modo resumido, a comparação entre os dois métodos.

Tabela 7.17. Comparação entre os métodos de migração radiométrico e convencional.

\begin{tabular}{|c|c|c|}
\hline Parâmetros de comparação & Radiométrico & Convencional \\
\hline $\begin{array}{l}\text { Análise do branco e uso de } \\
\text { reagentes de alta pureza }\end{array}$ & Não & Sim \\
\hline $\begin{array}{l}\text { Avaliação da migração para o } \\
\text { simulante }\end{array}$ & $\operatorname{Sim}$ & Sim \\
\hline $\begin{array}{l}\text { Avaliação da migração para o } \\
\text { alimento }\end{array}$ & Sim & Não \\
\hline Contaminação durante o ensaio & Baixa & Alta \\
\hline $\begin{array}{l}\text { Análise da migração de } \\
\text { multielementos }\end{array}$ & Sim & Depende da técnica \\
\hline $\begin{array}{l}\text { Volume de simulante e área da } \\
\text { amostra }\end{array}$ & Pequeno & Grande \\
\hline $\begin{array}{l}\text { Tempo de trabalho do analista por } \\
\text { amostra }\end{array}$ & Baixo & Alto \\
\hline Custo da análise & Alto & Baixo \\
\hline $\begin{array}{l}\text { Exposição à radiação e } \\
\text { necessidade de reator nuclear }\end{array}$ & Sim & Não \\
\hline
\end{tabular}




\subsection{Análises por calorimetria exploratória diferencial e espectroscopia no infravermelho por transformada de Fourier}

Essas análises foram realizadas para verificar o efeito da irradiação com nêutrons nos materiais poliméricos das embalagens. Nas análises DSC e FTIR, das embalagens irradiadas e não irradiadas, foram identificados os polímeros polietileno de alta densidade (HDPE) e poli (tereftalato de etileno) (PET) para as embalagens de suco e de refrigerante, respectivamente.

A análise por DSC também mostrou que o HDPE da embalagem de suco apresentou um decréscimo na temperatura de fusão cristalina $\left(T_{m}\right)$ e da entalpia de fusão $\left(\Delta \mathrm{H}_{\mathrm{m}}\right)$ com o aumento do tempo de irradiação com nêutrons, conforme a Tabela 7.18. Isso demonstra que a exposição do HDPE à irradiação com nêutrons causa modificações nas regiões cristalinas do polímero, fenômeno comum em polímeros expostos à radiação (Clegg e Collier, 1991). No caso das amostras de PET das embalagens de refrigerante, nenhuma variação significativa foi observada entre as propriedades térmicas das amostras irradiadas e não irradiadas, indicando que o PET é resistente à irradiação com nêutrons para período curto de irradiação.

Tabela 7.18. Propriedades térmicas das amostras de embalagens, em função do tempo de irradiação com nêutrons, obtidas por DSC.

\begin{tabular}{|c|c|c|c|c|}
\hline $\begin{array}{l}\text { Código da } \\
\text { Embalagem }\end{array}$ & $\begin{array}{l}\text { Tempo de irradiação } \\
(\text { (min) }\end{array}$ & $\mathrm{T}_{\mathrm{m}}^{\mathrm{c}}\left({ }^{\circ} \mathrm{C}\right)$ & $\mathrm{T}_{\mathrm{g}}{ }^{\mathrm{d}}\left({ }^{\circ} \mathrm{C}\right)$ & $\Delta \mathrm{H}_{\mathrm{m}}^{\mathrm{e}}(\mathrm{J} / \mathrm{g})$ \\
\hline \multirow{3}{*}{$\mathrm{S}^{\mathrm{a}}$ (HDPE) } & 0 & 130,5 & - & 44,2 \\
\hline & 3 & 129,8 & - & 42,0 \\
\hline & 960 & 122,9 & - & 37,5 \\
\hline \multirow{2}{*}{$\mathrm{R}^{\mathrm{b}}(\mathrm{PET})$} & 0 & 243,4 & 71,8 & 8,5 \\
\hline & 3 & 243,0 & 70,8 & 8,9 \\
\hline
\end{tabular}


A comparação dos espectros de FTIR das amostras de HDPE (embalagens de suco) não irradiadas e irradiadas por 3 minutos mostrou o aparecimento de uma banda em $1718 \mathrm{~cm}^{-1}$. Esses espectros são apresentados na Figura 7.1. A presença desta banda pode ser atribuída aos grupos carbonila, indicando que a irradiação com nêutrons pode provocar degradação oxidativa no polietileno (Lacoste e Carlsson, 1992; Moura et al., 2003), confirmando os resultados da análise DSC. O espectro FTIR da amostra irradiada por 960 minutos, quando comparado com o da amostra irradiada por 3 minutos, mostrou o aparecimento das bandas adicionais em 1642, 992, 966 e $909 \mathrm{~cm}^{-1}$, indicando a presença de ligações duplas de trans-vinilideno formadas, provavelmente, na quebra das ligações C-H (Carlsson, 1993). A banda $1642 \mathrm{~cm}^{-1}$ pode ser atribuída à vibração de deformação axial do grupo vinil $\mathrm{C}=\mathrm{C}$, a banda dublete em $992 \mathrm{~cm}^{-1}$ e 966 se deve, provavelmente, às torções fora do plano $\mathrm{C}=\mathrm{CH}_{2}$ (vibração típica de ligações duplas trans) e a banda $909 \mathrm{~cm}^{-1}$ devido à deformação fora do plano $\mathrm{C}=\mathrm{CH}_{2}$.

Como observado na Figura 7.2, o PET contém grupos $\mathrm{C}=\mathrm{O}$ na sua estrutura e, portanto, na comparação das amostras de embalagens de refrigerante não irradiada e irradiada por 3 minutos, a evidência da degradação oxidativa usando FTIR não é indicada.

Há poucos estudos sobre a avaliação dos efeitos da irradiação dos plásticos na migração de elementos químicos neles presentes. Na irradiação de polímeros com radiações ionizantes, há a formação de radicais livres e a destruição de aditivos, o que provavelmente pode ocasionar efeitos na migração dos elementos presentes nos materiais poliméricos (Welle et al., 2002). Outro trabalho existente sobre o assunto é o de Thompson et al. (1997) que afirma que a migração dos elementos não é afetada pela irradiação com nêutrons quando ocorre baixa migração desses elementos para o simulante de alimento. 


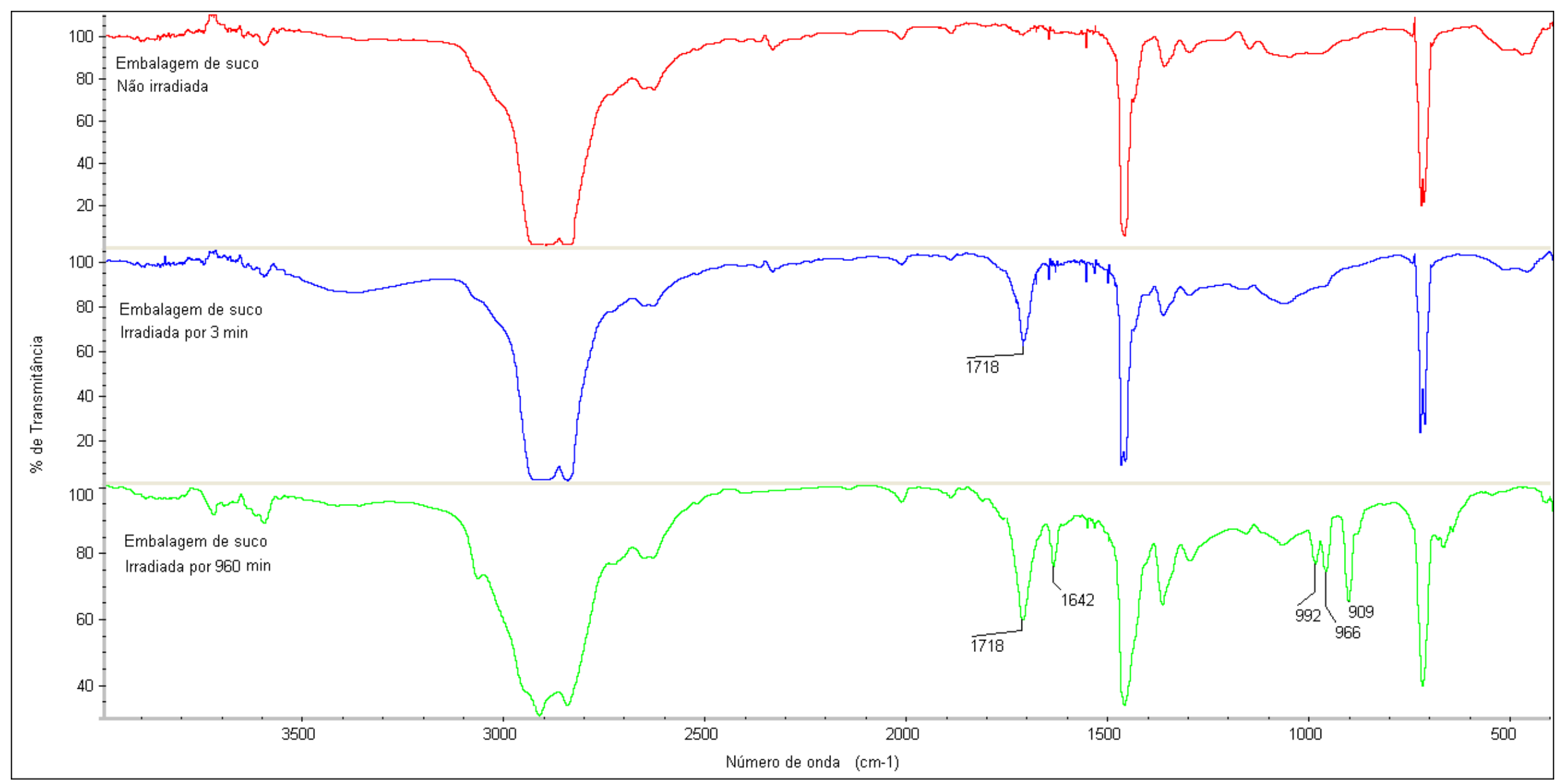

Figura 7.1. Espectros de FTIR de uma embalagem HDPE, de suco, não irradiada e irradiada com nêutrons por diferentes tempos. 


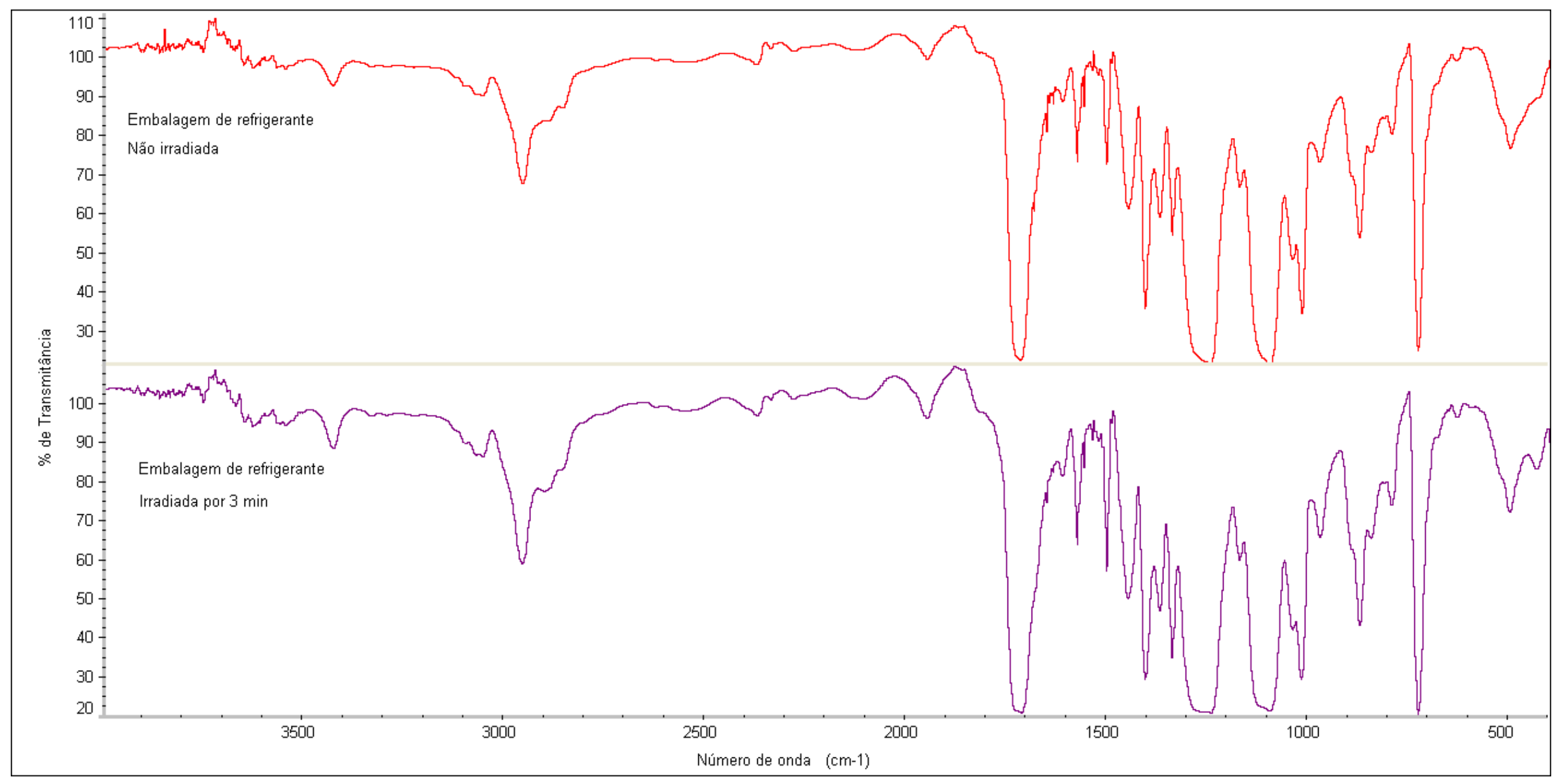

Figura 7.2. Espectros de FTIR de uma embalagem PET, de refrigerante, não irradiada e irradiada com nêutrons. 


\section{CAPÍTULO 8}

\section{CONCLUSÕES}

Os resultados obtidos na análise por ativação com nêutrons das embalagens plásticas mostraram que elas podem conter elementos tóxicos como As, $\mathrm{Cd}, \mathrm{Cr}$, Sb e também Co e estes podem constituir uma fonte de contaminação alimentar.

Os resultados de migração obtidos permitiram concluir que o método radiométrico apresenta requisitos favoráveis para sua aplicação na avaliação da migração de elementos das embalagens plásticas para alimentos. As análises de migração por esse método indicaram que os elementos $\mathrm{Cd}, \mathrm{Co}, \mathrm{Cr}$ e Sb passam para os simulantes de alimentos utilizados ou para o alimento, porém em quantidades menores que os limites máximos de tolerância (LMT) permitidos na legislação. Os resultados de limites de detecção da migração indicaram a alta capacidade de deteç̧ão do método radiométrico possibilitando obter dados que possam ser comparados aos valores de LMT. Para o $\mathrm{Cd}$, foi verificado que $\mathrm{o}$ método convencional seguido de AAS apresenta capacidade de detecção maior que o método radiométrico.

Os resultados obtidos na migração para simulantes foram estatisticamente iguais àqueles obtidos na migração para alimento, considerando-se embalagens de refrigerantes.

Os resultados da DSC permitiram concluir que a embalagem de suco constituída do polímero HDPE é afetada pela irradiação com nêutrons térmicos. Isso foi demonstrado pelo decréscimo nos valores de $T_{m}$ e $\Delta H_{m}$ com o aumento do tempo de irradiação com nêutrons, devido à degradação oxidativa do plástico o que foi confirmado, também, na análise por FTIR. A análise por FTIR mostrou 
que a irradiação com nêutrons pode causar cisão das ligações $\mathrm{C}-\mathrm{H}$. Por outro lado, a amostra de embalagem de refrigerante que contém o polímero PET mostrou ser resistente, não indicando nenhuma alteração na sua estrutura para tempo de irradiação no reator de até 3 minutos. Também na literatura não foram encontrados trabalhos que comprovem que a irradiação com nêutrons afeta a migração dos elementos químicos das embalagens para simulantes ou alimentos.

O método radiométrico mostrou ser bastante adequado em comparação ao método convencional devido à ausência do branco analítico e da não necessidade do uso de simulantes de alta pureza. Além disso, ele permite avaliar a migração no próprio conteúdo de alimento ou outro produto, no lugar do simulante de alimento. No método radiométrico, como o plástico a ser submetido ao teste de migração é irradiado previamente, não há o problema de contaminação, tornando o método bastante atrativo.

Além disso, esse método permite a avaliação simultânea da migração de diversos elementos em um único ensaio, bastando para isso irradiar os padrões dos elementos de interesse para o estudo, não necessitando da pré-concentração da solução, o que significa um tempo menor de análise.

Entretanto, o método radiométrico para determinação da migração não pode ser aplicado para elementos cujos radioisótopos apresentam meias-vidas curtas. Com a exposição da embalagem à migração por 10 dias, ocorre o decaimento da atividade do radioisótopo de meia-vida curta e este não pode ser detectado.

Os métodos convencionais apresentam a vantagem do baixo custo, não necessitando de um reator nuclear para a irradiação das amostras e não há exposição do analista à radiação.

Convém ainda salientar que este estudo gerou informações sobre a migração de elementos das embalagens plásticas no Brasil, cujos dados são praticamente inexistentes. Dessa forma, acredita-se que os resultados obtidos neste trabalho poderão trazer contribuições no uso do método radiométrico na avaliação da migração. 


\section{REFERÊNCIAS BIBLIOGRÁFICAS}

ABNT, Associação Brasileira de Normas Técnicas. Artigos poliméricos em contato com alimentos - Prova de cessão. Rio de Janeiro: ABNT, 1989. (NBR 11287- MB 3092)

ABRE, Associação Brasileira de Embalagem. Produção de embalagem deve crescer em 2007. São Paulo: ABRENEWS, v. 11, p. 4-5, 2007.

AL-MALACK, M. H. Migration of lead from unplasticized polyvinyl chloride pipes. J. Hazard. Mater., v. B82, p. 263-274, 2001.

ANVISA, Agência Nacional de Vigilância Sanitária. Consulta Pública $n^{\circ} 74$, de 10 de agosto de 2007. Diário Oficial da União, 13 ago. 2007.Disponível em:

$<$ http://www.anvisa.gov.br/scriptsweb/consulta_publica/consultas_paginado.asp?a no=2007>. Acesso em: 17 out. 2007.

ANVISA, Agência Nacional de Vigilância Sanitária. Resolução nº 105, de 19 de maio de 1999. Diário Oficial da União, 20 maio 1999. Brasil, 1999.

ANVISA, Agência Nacional de Vigilância Sanitária. Portaria $n^{\circ}$ 685, de 27 de agosto de 1998. Diário Oficial da União, 28 ago 1998. Brasil, 1998.

ANVISA, Agência Nacional de Vigilância Sanitária. Decreto n 55.871, de 26 de março de 1965. Diário Oficial da União, 09 abr. 1965. Brasil, 1965.

ARVANITOYANNIS, I. S.; BOSNEA, L. A. Recycling of polymeric materials used for food packaging: current status and perspectives. Food Rev. Int., v. 17, n. 3 , p. 291-346, 2001.

ATKINS, P. W. Físico-química. 6. ed. Rio de Janeiro: LTC, 1999. v. 3.

BARROS NETO, B.; SCARMINIO, I. S.; BRUNS, R. E. Como fazer experimentos. São Paulo: Unicamp, 2007.

BAYER, F. L. Polyethylene terephthalate recycling for food-contact applications: testing, safety and technologies: a global perspective. Food Addit. Contam., v. 19, p. 111-134, 2002. Supplement. 
BEGLEY, T.; CASTLE, L.; FEIGENBAUM, A.; FRANZ, R.; HINRICHS, K.; LICKLY, T.; MERCEA, P.; MILANA, M.; O'BRIEN, A.; REBRE, S.; RIJK, R.; PIRINGER, O. Evaluation of migration models that might be used in support of regulations for food-contact plastics. Food Addit. Contam., v. 22, n. 1, p. 73-90, 2005.

BERNARDO, P. E. M.; MURATA, L. T. F.; ALCÂNTARA, M. R. S.; NUNES, M. C. D.; PASCUET, N. Avaliação das embalagens e equipamentos poliméricos destinados a entrar em contato com alimentos, no período de 2000 a 2004. Bol. Inst. Adolfo Lutz, v. 15, n. 1, p. 31-32, 2005.

BICHINO, K. A.; PIRES, G. P.; STEDILE, F. C.; SANTOS, J. H. Z.; WOLF, C. R. Determination of catalyst metal residues in polymers by $\mathrm{X}$-ray fluorescence. Spectrochim. Acta [B], v. 60, p. 599-604, 2005.

BILLMEYER, F. W. Textbook of polymer science. 3rd ed. New York: Intersc. Publ, 1984.

BODE, P. The use of INAA for the determination of trace elements, in particular cadmium, in plastics in relation to the enforcement of pollution standards. J. Radioanal. Nucl. Chem., v. 167, n. 2, p. 361-367, 1993.

BODE, $P$. Instrumental and organizational aspects of a neutron activation analysis laboratory. 1996. Tese (Doutorado) - Interfaculty Reactor Institute, The Netherlands.

BOTREL, J. Problèmes posés par le controle de la migration des matériaux plastiques au contact des aliments, Ann. Fals. Exp. Chim., v. 75, n. 805, p. 75-80, févr. 1982.

BRASIL. Secretaria de Vigilância Sanitária. Ministério da Saúde. Portaria n 987. Embalagens descartáveis de polietilenotereftalato - PET - multicamada, destinadas ao acondicionamento de bebidas não alcoólicas carbonatadas. Brasília: DOU, 31 mar., seção 1, p. 30-31, 1999.

BRITO, N.M.; AMARANTE JUNIOR, O.P.; POLESE, L.; RIBEIRO, M.L. Validação de métodos analíticos: estratégia e discussão. Pesticidas: Rev. Ecotox. Meio Amb.,v.13, p.129-146, 2003.

CANEVAROLO JUNIOR, S. V. Ciência dos polímeros: um texto básico para tecnólogos e engenheiros. São Paulo: Artliber, 2002.

CARLSSON, D. J. Degradation and stabilization of polymers subjected to high energy radiation in SCOTT, J. Atmospheric oxidation and antioxidants. Amsterdam: Elsevier,. v. 2, p. 495-528, 1993.

CAVALCANTI, P.; CHAGAS, C. História da embalagem no Brasil. São Paulo: Grifos Projetos Históricos e Editoriais, 2006.

CEC, Commission of the European Communities, Directive 90/128/EEC relating to plastic materials and articles intend to come with foodstuff. Brussels, 23 Feb. 1990. 
CEC, Commission of the European Communities, Directive 2002/72/EC relating to plastic materials and articles intend to come with foodstuff. Brussels, 06 Aug. 2002.

CLEGG, D. W.; COLLYER, A. A. Irradiation effects on polymers. New York: Elsevier, 1991.

COSTA NETO, P.L.O. Estatística. São Paulo: Edgard Blücher, 2002.

CROMPTON, T. R. Additive migration from plastics into food. Oxford: Pergamon, 1979.

CROSBY, N. T. Food packaging materials: aspects of analysis and migration contaminants. London: Applied Science, 1981.

CURRIE, L. A. Limits for qualitative detection and quantitative determination. Application to radiochemistry. Anal. Chem., v. 40, n. 3, p. 586-593, 1968.

DATAMARK. Packaging data: materials by volume, 1997-2004a. Disponível em: <http://www.datamark.com.br/newdatamark/ASP/FS/FS_PK_E.ASP>. Acesso em: 10 jun. 06.

DATAMARK. Packaging data: materials consumption, 2004b. Disponível em: <http://www.datamark.com.br/newdatamark/ASP/FS/FS_PK_E.ASP>. Acesso em: 10 jun.06.

DATAMARK. Packaging data: packaging market by material, 2004c. Disponível em: <http://www.datamark.com.br/newdatamark/ASP/FS/FS_PK_E.ASP>. Acesso em: 10 jun. 06.

DE SOETE, D.; GILBELS, R.; HOSTE, J. Neutron activation analysis. New York: Wiley-Interscience, 1972.

DIAS, R. A. Catálise e Catalisadores. Rev. Cult. Cient., n. 3, p. 31-48,1998.

DIEMER, J; HEUMANN, K. G. Development of an ICP-IDMS method for accurate routine analyses of toxic heavy metals in polyolefins and comparison with results by TD-IDMS. Fresenius J. Anal. Chem., v. 368, p. 103-108, 2000.

DOLE, P.; FEIGENBAUM, A. E.; DE LA CRUZ, C.; PASTORELLI, S.; PASEIRO, P.; HANKEMEIER, T.; VOULZATIS, Y.; AUCEJO, S.; SAILLARD, P.; PAPASPYRIDES, C. Typical diffusion behaviour in packaging polymers - application to functional barriers. Food Addit. Contam., v. 23, n. 2, p. 202-211, 2006.

EVORA, M. C.; GONÇALEZ, O. L; DUTRA, R. C. L.; DINIZ, M. F.; WIEBECK, H.; ANDRADE E SILVA, L. G. Comparação de técnicas de FTIR de transmissão, reflexão e fotoacústica na análise de poliamida-6, reciclada e irradiada.

Polímeros, v. 12, n. 1, p. 60-68, 2002. 
FIGGE, K; KOCH, J. Effect of some variables on the migration of additives from plastics into edible fats. Food Cosmet. Toxicol., v. 11, p. 975-988, 1973.

FRANZ, R. Migration modelling from food-contact plastics into foodstuffs as a new tool for consumer exposure estimation. Food Addit. Contam., v. 22, n. 10, p. $920-$ 937, 2005.

FRIEDLANDER, G.; KENNEDY, J. W.; MILLER, J. M. Nuclear and radiochemistry. 2nd ed. New York: Wiley, 1964.

HAYASAKI, M. Por dentro do mundo plástico. Pack. v. 9, n. 11, p. 12-14, 2006.

HECKMAN, J. H. Food packaging regulation in United States and European Union. Regul. Toxicol. Pharmacol., v. 42, p. 96-122, 2005.

IAL, Instituto Adolfo Lutz, Métodos físico-químicos para análise de alimentos. 4. ed. São Paulo, 2005.

IAEA, International Atomic Energy Agency. Practical aspects of operating a neutron activation analysis laboratory. Vienna: IAEA, 1990. (IAEA - TECDOC564).

INCT, Institute of Nuclear Chemistry and Technology. Department of analytical chemistry. Polish certified reference material for multielement trace analysis: Mixed Polish Herbs. Certified reference material MPH-2. 2002.

IRMM, Institute for Reference Materials and Measurements. Commission of the European Communities, Joint research centre. Certified materials for determination of cadmium and trace elements in polyethylene: IMEP-10. 1993.

IRMM, Institute for Reference Materials and Measurements. European Commission, Joint Research Centre. Community Bureau of Reference - BCR. Certified reference material BCR-681. 2000.

IUPAC, International Union of Pure and Applied Chemistry. Macromolecular division. Commission on macromolecular nomenclature. Basic definitions of terms relating to polymers. Pure Appl. Chem., v. 40, n. 3, 1974.

IUPAC, União Internacional de Química Pura e Aplicada. Divisão macromolecular. Comissão de nomenclatura macromolecular. Compêndio de nomenclatura macromolecular. Rio de Janeiro: E-papers, 2002.

LACOSTE, J.; CARLSSON, D. J. Gamma-, photo-, and thermally-initiated oxidation of linear low density polyethylene: a quantitative comparison of oxidation products. J. Polym. Sci. [A1], v. 30, p. 493-500, 1992.

LAMBRI, O. A.; SALVATIERRA, L. M.; SÁNCHEZ, F. A.; MATTEO, C. L.; SORICHETTI, P. A.; CELAURO, C. A. Crystal growth in EPDM by chemicrystallisation as a function of the neutron irradiation dose and flux level. Nucl. Instr. Meth. Phys. Res. B, v. 237, p. 550-562, 2005. 
LAU, O. W.; WONG, S. K. Contamination in food from packaging material. J. Chromatogr. A, v. 882, p. 255-270, 2000.

LAWSON, G.; BARKBY, C. T.; LAWSON, C. Contaminant migration from food packaging laminates used for heat and eat meals. Fresenius J. Anal. Chem., v. 354, p. 483-489, 1996.

LICKLY, T. D.; LEHR, K. M.; WELSH, G. C. Migration of styrene from polystyrene foam food-contact articles. Food Chem. Toxicol., v. 33, n. 6, p. 475-481, 1995.

\section{LUCAS, E. T.; SOARES, B. G.; MONTEIRO, E. E. C. Caracterização de} polímeros: determinação de peso molecular e análise térmica. Rio de Janeiro: Epapers, 2001.

MANO, E. B. Polímeros como materiais de engenharia. São Paulo: Edgard Blücher, 1991.

MARCATO, B.; GUERRA, S.; VIANELLO, M. SCALIA, S. Migration of antioxidant additives from various polyolefinic plastics into oleaginous vehicles. Int. J. Pharm., v. 257, p. 217-225, 2003.

MESTRINER, F. Design de embalagem: curso básico. 2.ed. São Paulo: Pearson Makron Books, 2002.

MOORE, W. J. Physical Chemistry. 5th e. London: Longman, 1972.

MOURA, E. A. B; ORTIZ, A. V.; GOUVEAA, D.; CASTRO, R. H. R.; ROSSINI, E. L.; SILVA, A. L. A.; GOUVÊA, P. H. D.; WIEBECK, H.; KAWANO, Y.; ANDRADE E SILVA, L. G. Estudo por FTIR de filme de polietileno de baixa densidade submetido à radiação gama na presença de oxigênio. In: $7^{\circ}$ CONGRESSO BRASILEIRO DE POLÍMEROS. 2003. Belo Horizonte. Anais... ABPol, p. 660661, 2003, CD-ROM.

MURATA, L. T. F.; ALCÂNTARA, M. R. S.; NUNES, M. C. D; PASCUET, N. Atualização da legislação de embalagens e equipamentos destinados a entrar em contato com alimentos. Bol. Inst. Adolfo Lutz, v. 12, n. 1, p. 23-25, 2002.

MUTSUGA, M.; KAWAMURA, Y.; SUGITA-KONISHI, Y.; HARA-KUDO, Y.; TAKATORI, K.; TANAMOTO, K. Migration of formaldehyde and acetaldehyde into mineral water in polyethylene terephthalate (PET) bottles. Food Addit. Contam., v. 23 , n. 2, p. 212-218, 2006.

NERÍN, C.; ACOSTA, D.; RUBIO, C. Potential migration release of volatile compounds from plastic containers destined for use in microwave ovens. Food Addit. Contam., v. 19, n. 6, p. 594-601, 2002.

NOMURA, D. H.; MATEUS, S. F.; SAIKI, M.; BODE, P. Characterization of inorganic components in plastic materials. J. Radioanal. Nucl. Chem., v. 244, n. 1 , p. $61-65,2000$. 
NRCC, National Research Council Canada. Marine sediment reference materials for trace metals and other constituents. Certified reference material MESS-2. 1997.

NUNES, M. C. D; ALCÂNTARA, M. R. S.; MURATA, L. T. F.; PASCUET, N. S. Embalagens plásticas recicladas pós-consumo e o contato direto com alimentos. Bol. Inst. Adolfo Lutz, v. 13, n. 2, p. 10-11, 2003.

O'BRIEN, A.; COOPER, I. Practical experience in the use of mathematical models to predict migration of additives from food-contact polymers. Food Addit.

Contam., v. 19, p. 63-72, 2002. Supplement.

OZEN, B. F.; FLOROS, J. D. Effects of emerging food processing techniques on the packaging materials. Trends Food Sci. Tech., v. 12, p. 60-67, 2001.

PADULA, M.; ITO, D. Embalagem e segurança dos alimentos. Inf. CETEA, v. 18, n. 2 , p. $2-4,2006$.

PADULA, M.; CUERVO, M. Legislação de embalagem para contato com alimentos: MERCOSUL e outros países latinoamericanos. Polímeros, v. 14, n. 1, p. E8-E13, 2004.

PAINE, F. A.; PAINE, H. Y. A handbook of food packaging. Glasglow: Leonard Hill, 1983.

PRADO FILHO, H. R. As embalagens e a gestão ambiental de seus impactos. Banas Qualidade, v.15, n. 171, p. 94-96, 2006.

PHILO, M. R.; FORDHAM, P. J.; DAMANT, A. P.; CASTLE, L. Measurement of styrene oxide in polystyrenes, estimation of migration to foods, and reaction kinetics and products in food simulants. Food Chem. Toxicol., v. 35, p. 821-826, 1997.

PICCOT, D. Comunicação pessoal, 1989.

PIRINGER, O.; FRANZ, R.; HUBER, M.; BEGLEY, T. H.; MCNEAL, T. P. Migration from food packaging containing a functional barrier: mathematical and experimental evaluation. J. Agric. Food Chem., v. 46, p. 1532-1538, 1998.

RABELLO, M. S. Aditivação de Polímeros. São Paulo: Artliber, 2000.

REYNIER, A.; DOLE, P.; FEIGENBAUM, A. Migration of additives from polymers into food simulants: numerical solution of a mathematical model taking into account food and polymer interactions. Food Addit. Contam., v. 19, n. 1 , p. 89102, 2002. 
ROSA, F. M. L.; MANZOLI, J. E.; SOARES, E. P.; SAIKI, M. Simulation study of element plastic migration from radiometric measurements. In: INTERNATIONAL NUCLEAR ATLANTIC CONFERENCE, INAC 2007. Santos. Anais... INAC, 2007. CD-ROM.

SANTOS, A. S. F.; AGNELLI, J. A. M.; MANRICH, S. Tendências e desafios da reciclagem de embalagens plásticas. Polímeros, v. 14, n. 5, p. 307-312, 2004.

SARANTÓPOULOS, C. I. G. L.; OLIVEIRA, L. M.; PADULA, M.; COLTRO, L.; ALVES, R. M. V.; GARCIA, E. E. C. Embalagens plásticas flexíveis: principais polímeros e avaliação de propriedades. Campinas: CETEA/ITAL, 2002.

SARBACH, C.; YAGOUBI, N.; SAUZIERES, J.; RENAUX, C.; FERRIER, D.; POSTAIRE, E. Migration of impurities from a multilayer plastics container into a parenteral infusion fluid. Int. J. Pharm., v. 140, n. 2, p. 169-174, 1996.

SARON, E. S. Aprovação de embalagens para contato com alimentos no Brasil. Inf. CETEA, v. 19, n. 1, 2007.

SHOTYK, W., KRACHLER, M. Contamination of bottled waters with antimony leaching from polyethylene terephthalate (PET) increases upon storage.

Environ. Sci. Technol., v. 41, p. 1560-1563, 2007.

SHOTYK, W.; KRACHLER, M.; CHEN, B. Contamination of Canadian and European bottled waters with antimony from PET containers. J. Environ. Monit., v. 8, p. 288-292, 2006.

SHREVE, R. N.; BRINK JUNIOR, J. A. Indústrias de processos químicos. 4. ed., Rio de Janeiro: Guanabara Koogan, 1997.

SKOOG, D. A. Principles of instrumental analysis. 3rd ed. New York: Saunders College Publishing, 1985.

SKOOG, D. A.; HOLLER, F. J.; NIEMAN, T. A. Princípios de análise instrumental. 5. ed. Porto Alegre: Bookman, 2002.

SOARES, E. P.; NUNES, E. C. D.; SAIKI, M.; WIEBECK, H. Caracterização de polímeros e determinação de constituintes inorgânicos em embalagens plásticas metalizadas. Polímeros, v. 12, n. 3, p. 206-212, 2002.

SOARES, E. P.; SAIKI, M.; WIEBECK, H. Determination of inorganic constituents and polymers in metallized plastic materials. J. Radioanal. Nucl. Chem., v. 264, n. 1 , p. 9-13, 2005.

TABATA, Y.; KATSUMURA, Y. Fast neutron irradiation effects on polymers polyethylene, ethylene propylene rubber and tetrafluoroethylene propylene copolymer. J. Nucl. Mat., v. 133-134, p. 781-784, 1985. 
TERENCE, M. C.; GUEDES, S. M. L. Efeito da radiação gama na estrutura molecular do poli (álcool vinílico). In: INTERNATIONAL NUCLEAR ATLANTIC CONFERENCE - VI ENAN NATIONAL MEETING ON NUCLEAR APPLICATIONS, Rio de Janeiro. Anais... ENAN, 2002, CD-ROM.

TEHRANY, E. A.; DESOBRY, S. Partition coefficients in food/packaging systems: a review. Food Addit. Contam., v. 21, n. 12, p. 1186-1202, 2004.

THOMPSON, D.; PARRY, S. J.; BENZING, R. A novel method for the determination of migration of contaminants from food contact materials. J. Radioanal. Nucl. Chem. Lett., v. 213, n. 5, p. 349-359, 1996.

THOMPSON, D.; PARRY, S. J.; BENZING, R. The validation of a method for determining the migration of trace elements from food packaging materials into food. J. Radioanal. Nucl. Chem., v. 217, n. 1, p. 147-150, 1997.

WEISEL, C.; DEMAK, M.; MARCUS, S.; GOLDSTEIN, B. D. Soft plastic bread packaging: Lead content and reuse by families. Am. J. Public Health, v. 81, n. 6, p. 756-758, 1991.

WESTERHOFF, P.; PRAPAIPONG, P.; SHOCK, E.; HILLAIREAU, A. Antimony leaching from polyethylene terephthalate (PET) plastic used for bottled drinking water. Water Res., v. 42, p. 551-556, 2008.

WELLE, F.; MAUER, A.; FRANZ, R. Migration and sensory changes of packaging materials caused by ionising radiation. Radiat. Phys. Chem., v. 63, p. 841-844, 2002.

WIEBECK, H.; HARADA, J. Plásticos de engenharia. São Paulo: Artliber, 2005.

YAGOUBI, N.; PERON, R.; LEGENDRE, B.; GROSSIORD, J. L.; FERRIER, D. Gamma and electron beam radiation induced physico-chemical modifications of poly(propylene). Nucl. Instr. Meth. Phys. Res. B, v. 151, p. 247-254, 1999.

YAMAMOTO, T.; YASUHARA, A. Quantities of bisphenol A leached from plastic waste samples. Chemosphere, v. 38, n. 11, p. 2569-2576, 1999.

ZENEBON, O.; MURATA, L. T. F.; PASCUET, N.; ALCÂNTARA, M. R. S.; NUNES, M. C. D.; RIBEIRO, E. R.; TIGLEA, P.; Determinação de metais presentes em corantes e pigmentos utilizados em embalagens para alimentos.

Rev. Inst. Adolfo Lutz, v. 63, n. 1, p. 56-62, 2004. 